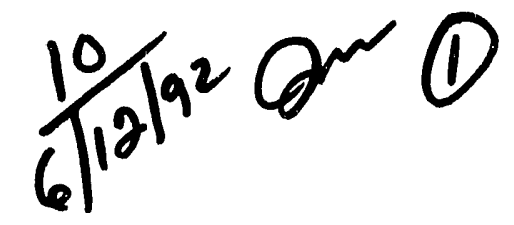

OAK RIDGE NATIONAL LABORATORY
ORNL/Sub/87-91345

\section{Experimental Investigation Of Steep-Front Short Duration (SFSD) Surge Effects on Power Systems Components}

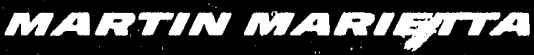

D. B. Miller

Mississippi State University

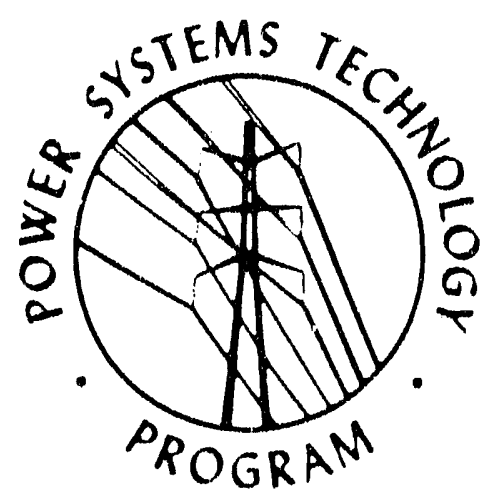


This report has been reproduced directly from the best available copy.

Available to DOE and DOE contractors from the Office of Scientific and Technical Information, P.O. Box 62, Oak Ridge, TN 37831; prices avallable from (615) 576.8401, FTS 626-8401.

Available to the public from the National Technical Information Service, U.S. Department of Commerce, 5285 Port Royal Rd., Springfield, VA 22161.

This report was prepared as an account of work sponsored by an agency of the United States Government. Neither the United States Government nor any agency thereof, nor any of their employees, makes any warranty, express or implied, or assumes any legal llability or responsibility for the accuracy, completeness, or usefulness of any information, apparatus, product, or process disclosed, or represents that its use would not infringe privately owned rights. Reference harein to any specific commercial product, process, or service by trade name, trademark, manufacturer, or otherwise, does not nocessarily constitute or imply its endorsement, recommendation, or favoring by the United States Government or any agency thereot. The views and opinions of authors expressed herein do not necessarily state or reflect those of the United States Government or any agency thereof. 
David B. Miller

May 1992

\author{
Prepared by \\ Mississippi State University \\ Department of Electrical and Computer Engineering \\ P. O. Drawer EE \\ Mississippi State, MS 39762 \\ under \\ Subcontract $19 \mathrm{X}-91345 \mathrm{C}$
}

for the

Power Systems Technology Program

Energy Division

OAK RIDGE NATIONAL LABORATORY

Oak Ridge, TN 37831

Managed by

MARTIN MARIETTA ENEF GY SYSTEMS, INC.

for the

U.S. DEPARTMENT OF ENERGY

under Contract No. DE-AC05-84OR21400 


\section{ACKNOWLEDGEMENTS}

The following organizations and individuals are recognized for their contributions of advice and equipment:

Oak Ridge National Laboratory: Steiner Dale, Randy Barnes, Ben McConnell, Frank Modine, Tom Hudson

Virginia Power: Olin Compton

Department of Energy: Ken Klein, Imre Gyuk

Manufacturers and utilities: Cooper, Kearney, RTE Corp., Raychem, Southwire Co., Conductor Products, Inc., Amerace, G\&W Electric, High Tech Cable Co., Joslyn Corp., Westinghouse Electric Corp., Mississippi Power Co., Mississippi Power and Light Co., Alabama Power Co., Louisiana Power and Light Co., Electric Power Research Institute.

MSU Electrical and Computer Engineering Department: Paul Jacob, Lynn Libby, Stan Grzybowski, Odie McHann, Andre Lux, David Kempkes, Hongbo Fan, Ann Dawson. 


\section{CONTENTS}

LIST OF FIGURES $\ldots \ldots \ldots \ldots \ldots \ldots \ldots \ldots \ldots \ldots \ldots \ldots \ldots \ldots \ldots \ldots \ldots \ldots \ldots$

LIST OF TABLES $\ldots \ldots \ldots \ldots \ldots \ldots \ldots \ldots \ldots \ldots \ldots \ldots \ldots \ldots \ldots \ldots \ldots \ldots \ldots$

EXECUTIVE SUMMARY $\ldots \ldots \ldots \ldots \ldots \ldots \ldots \ldots \ldots \ldots \ldots \ldots \ldots \ldots \ldots \ldots \ldots \ldots$

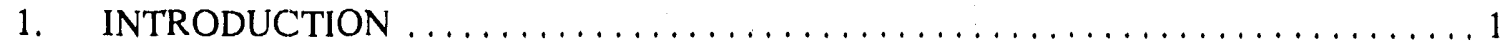

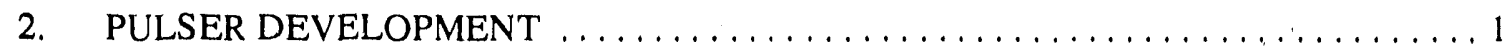

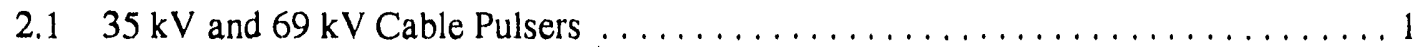

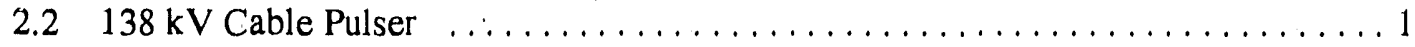

2.3 Two Stage Marx Pulser Made From $138 \mathrm{kV}$ Cable $\ldots \ldots \ldots \ldots \ldots \ldots \ldots \ldots \ldots 5$

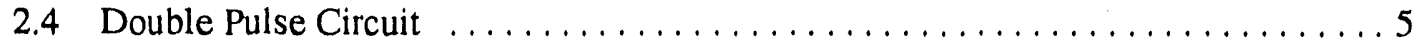

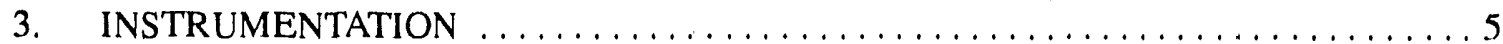

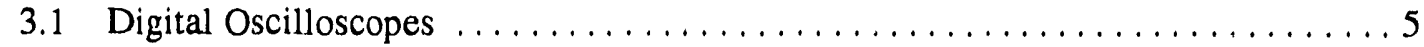

3.2 Voltage Dividers ................................... 14

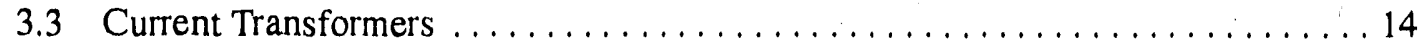

3.4 Fiber Optic Data Transmission ............................. 14

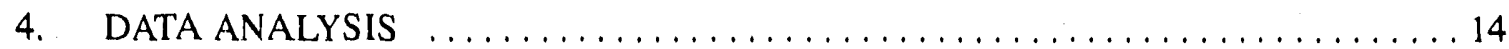

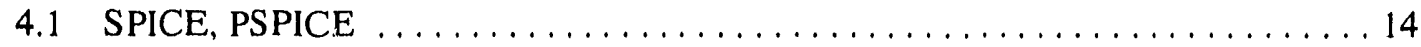

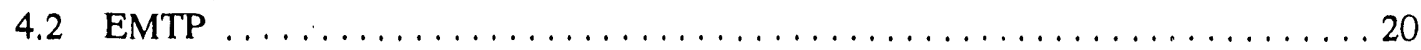

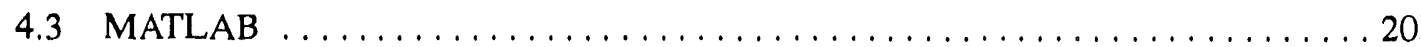

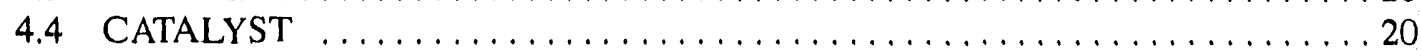

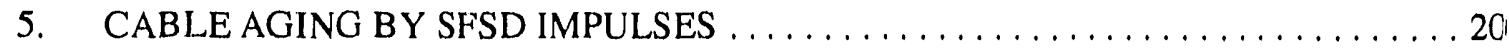

6. EFFECTS OF SFSD IMPULSES ON TERMINATORS $\ldots \ldots \ldots \ldots \ldots \ldots \ldots$

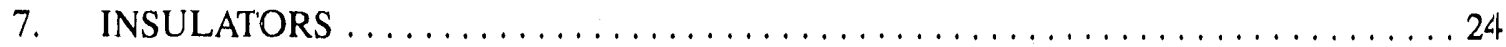

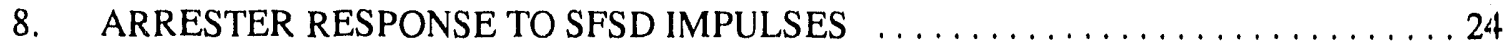

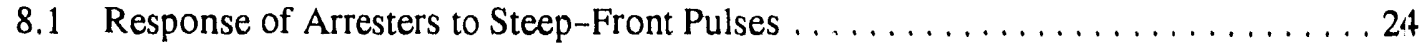

8.2 Transition of Arresters From Capacitive to Resistive Behavior

During Steep-Front Pulses ............................. 30

8.3. Recovery of Arrester Protective Characteristics After a Steep-

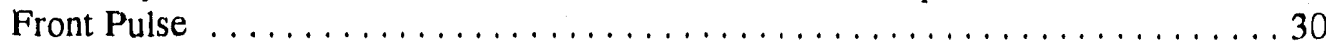

REFERENCES 34

APPENDIX A: Accuracy Evaluation and Calibration of Impulse

Measurement Tools $\ldots \ldots \ldots \ldots \ldots \ldots \ldots \ldots \ldots \ldots \ldots \ldots \ldots \ldots$

APPENDIX B: $\quad$ EMTP Simulation of the Steep-Front Circuit $\ldots \ldots \ldots \ldots \ldots \ldots$ B-1

APPENDIX C: Measurement Techniques to Reveal Arrester MOV

Response During Steep-Front Impulsing $\ldots \ldots \ldots \ldots \ldots \ldots \ldots \ldots$ C-1

APPENDIX D: Transition of MOV Distribution Arresters From

Capacitive to Resistive During Steep-Front Impulses $\ldots \ldots \ldots \ldots \ldots$ D-1 


\section{LIST OF FIGURES}

Fig. 1. Circuit diagram of revised steep-front simulation circuit used in

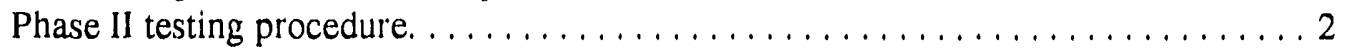

Fig. 2. Photograph of an early dual $69 \mathrm{kV}$ cable pulser. . . . . . . . . . . . . . . . 3

Fig. 3. Voltage pulse into $15 \mathrm{kV}$ terminator and terminated $15 \mathrm{kV}$ cable. $62.5 \mathrm{~ns} / \mathrm{div}, 35.5 \mathrm{kV} / \mathrm{div}(7 / 14 / 88$; shot \#1; no flash). . . . . . . . . . . . . 3

Fig. 4. Photograph of $138 \mathrm{kV}$ cable pulser. Tall impulse generator in background: pulser cable on reel. Wire wound and liquid dividers suspended from posts connected to input of test cable $(10 / 8 / 89) \ldots \ldots \ldots \ldots \ldots \ldots \ldots \ldots$

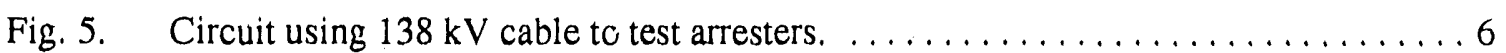

Fig. 6. Voltage delivered by $138 \mathrm{kV}$ cable pulser to a matched load. . . . . . . . . . . 7

Fig. 7. Voltage delivered by two 10 meter $138 \mathrm{kV}$ cables in parallel to a matched load. ..................................... 7

Fig. 8. Two stage Marx circuit. $\mathrm{C} 1$ and $\mathrm{C} 2$ are each $10 \mathrm{~m}, 138 \mathrm{kV}$ cable sections; $\mathrm{RI}=4$ ', $50 \mathrm{k} \Omega$ water resistors; $\mathrm{RL}=100 \Omega$;

$\mathrm{Rh} / \mathrm{R} l=3000 \& 400 / 3.11 \Omega \ldots \ldots \ldots \ldots \ldots \ldots \ldots \ldots \ldots \ldots \ldots$

Fig. 9. Photograph of the two stage Marx circuit using $10 \mathrm{~m}, 138 \mathrm{kV}$ cables

for the Marx capacitors. . . . . . . . . . . . . . . . . . . . . . . . . . . . . . . . . 9

Fig. 10. SFSD voltage pulse from the two stage Marx circuit.

Withstand, $55-2$ Pin insulator, $953 \mathrm{kV}$ peak. ................... 10

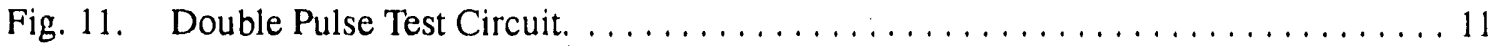

Fig. 12. Photograph of dual pulse system, showing $138 \mathrm{kV}$ reeled cable for first pulse on right, spark gaps and divider at center, and dc supply and second second pulse cable on left. ....................... 12

Fig. 13a. First pulse current waveform. Peak current: $10.09 \mathrm{kA} \ldots \ldots \ldots \ldots \ldots \ldots \ldots 13$

Fig. 13b. First pulse voltage waveform. Peak current: $10.09 \mathrm{kA} . \quad \ldots \ldots \ldots \ldots \ldots \ldots \ldots 13$

Fig. 14. Second pulse voltage and current waveform. Time delay: 80 us . . . . . . . 13

Fig. 15. Photograph of LeCroy digitizer on left and Analogic digitizer on

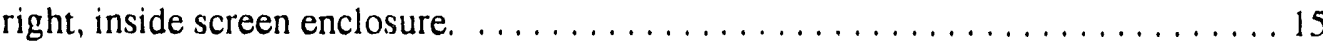

Fig. 16. Arrester test setup, showing wire wound divider on left, liquid divider on right, and 20000 A current transformer on floor in arrester ground line. . . . . . . . . . . . . . . . . . . . . . . . . . . . 16

17ig. 17. An early data acquisition set up in the screen enclosure, showing the Analogic digitizer with the Apple computer for data storage and analysis. The fiber optic receiver is located on $t$ sp of the digitizer. . . . . . . . 17

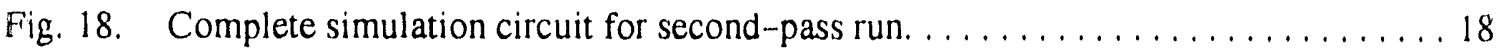

Fig. 19a. SPICE simulation at Node 8 (input to peaking gap). . . . . . . . . . . . . 19

Fig. 19b. Computer simulated and measured voltage waveforms of the

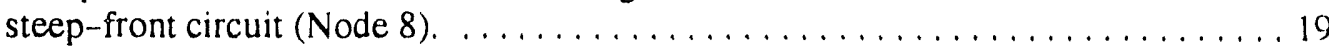

Fig. 20. Voltage (top) and current (bottom) during flashover of a 55-3 pin insulator using the Figure 28 test circuit; $256 \mathrm{kV}$ peak voltage. 
Fig. 21. Phase II voltage pulses applied at $80 \%$ of VBD. Upper, lower -

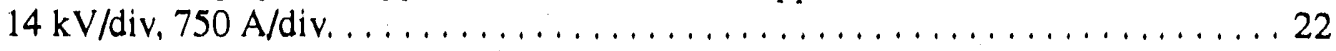

Fig. 22. Phase II current pulses applied at $80 \%$ of VBD. Upper, lower -

250 ns/div., $750 \mathrm{~A} / \mathrm{div}$.

Fig. 23. Terminator L-2 voltage waveforms for flashover and failure shots.

Top: Flashover, $295 \mathrm{kV}$ peak, $250 \mathrm{~ns} / \mathrm{div} ., 35.5 \mathrm{kV} / \mathrm{div}$.

Bottom: Failure, $295 \mathrm{kV}$ peak; Failure: $250 \mathrm{~ns} / \mathrm{div} ., 35.5 \mathrm{kV} / \mathrm{div}$.

Fig. 24. A typical voltage waveshape during insulator testing, $250 \mathrm{~ns} / \mathrm{div}$.,

$73.2 \mathrm{kV} /$ div. Note the long "tail" time after the SFSD front portion

of the pulse.

Fig. 25. Plot of time to flashover vs, peak pulse voltage for one, two and three

4-1/4" x 6-1/4" suspension insulators.

Fig. 26. Two stage Marx circuit. $\mathrm{C} 1$ and $\mathrm{C} 2$ are each $10 \mathrm{~m}, 138 \mathrm{kV}$ cable sections; $\mathrm{RI}=4{ }^{\prime}, 50 \mathrm{k} \Omega$ water resistors; $\mathrm{Rh} / \mathrm{R} l=3000=400 / 3.11 \Omega \ldots \ldots \ldots 26$

Fig. 27. SFSD voltage pulse, withstand, 55-2 Pin insulator, $953 \mathrm{kV}$ peak. . . . . . . . 26

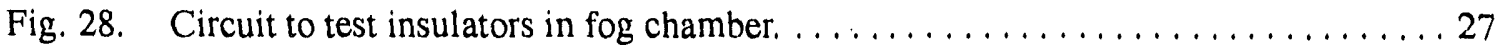

Fig. 29. Photograph of test facility with fog chamber to study SFSD response of wet, contaminated insulators.

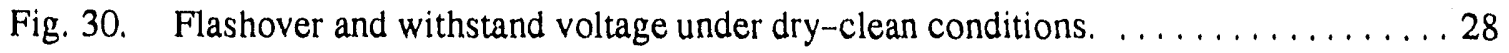

Fig. 31. Flashover and withstand V,I under contaminated conditions. . . . . . . . . 28

Fig. 32. Typical MOV arrester voltage (top) and current waveshapes, 24 inches total arrester lead length, $125 \mathrm{~ns} /$ div., $14.2 \mathrm{kV} / \mathrm{div}$. $1.20 \mathrm{kA} /$ div., $66.4 \mathrm{kV}$ peak, $4.2 \mathrm{kA}$ peak.

Fig. 33. Current waveshapes for the $9 \mathrm{kV}$ MOV arrester at approximately 5 and $20 \mathrm{kA}$ peak.

Fig. 34. MOV arrester voltages during the $5 \mathrm{kA}$ and $20 \mathrm{kA}$ current pulses shown in Fig. 33. . . . . . . . . . . . . . . . . . . . . . . . . . . . 31

Fig. 35. Aluminum tube voltage (extrapolated to $5 \mathrm{kA}$ equivalent peak current subtracted from the $5 \mathrm{kA}$. MOV voltage pulse in Fig. 34).

Fig. 36. Peak voltages for $10 \mathrm{kV}$ MOV and $\mathrm{SiC}$ arresters and the aluminum tube as a function of the maximum rate of rise of the current.

Fig. 37. Arrester voltage and current;

Top: Current 632 A/Div, Bottom: Voltage $33.4 \mathrm{kV} / \mathrm{Div}$

Time: $200 \mathrm{~ns} / \mathrm{Div} ; 10 \mathrm{kV}$ arrester.

Fig. 38. Second pulse current-voltage characteristics for four different time delays,

First pulse $=2.71 \mathrm{kA}$

Fig. A.1. Voltage divider ratio calibration circuit. $\ldots \ldots \ldots \ldots \ldots \ldots \ldots \ldots \ldots \ldots$

Fig. A.2. Voltage waves used for divider calibration, $118 \mathrm{kV} /$ div. . . . . . . . . . . A 4

Fig. A.3. Experimental unit step response. . . . . . . . . . . . . . . . . . .

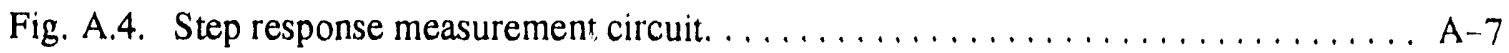

Fig. A.5. Step response data $-100 \mathrm{~ns} /$ div. $\ldots \ldots \ldots \ldots \ldots \ldots \ldots \ldots \ldots \ldots \ldots \ldots \ldots$ 


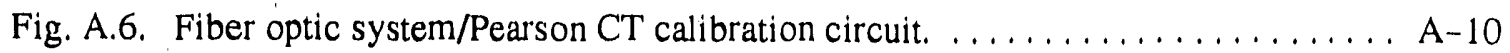

Fig. A.7. Calibration currents taken at $250 \mathrm{kV}$ input voltage. $500 \mathrm{~ns} / \mathrm{div}$.

Trace 1: $\quad 51.94 \times$ FOC multiplier A/div.

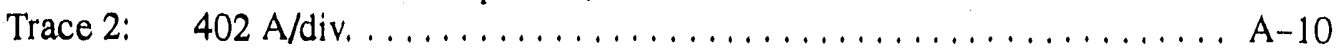

Fig. A.8. Voltage waveform at $250 \mathrm{kV}$ charge voltage. $500 \mathrm{~ns} / \mathrm{div} ., 19.1 \mathrm{kV} / \mathrm{div}, \ldots \ldots$. . A 11

Fig. A.9. Integration of current shots taken at $250 \mathrm{kV}$ charge voltage. . . . . . . . . A $\mathrm{A}-11$

Fig. A.10. Calibration currents taken at $500 \mathrm{kV}$ input voltage. $500 \mathrm{~ns} / \mathrm{div}$.

Trace 1: $157.21 \times$ FOC multiplier A/div.

Trace 2: 778 A/div. $(.25 \mathrm{~V} /$ div. $) \ldots \ldots \ldots \ldots \ldots \ldots \ldots \ldots \ldots \ldots \ldots$ A 13

Fig. A.11. Integration of current shots taken at $500 \mathrm{kV}$ charge voltage $\ldots \ldots \ldots \ldots \ldots . .13$

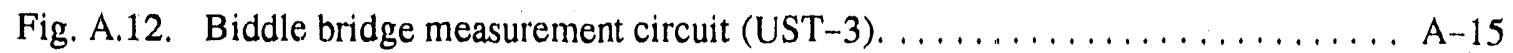

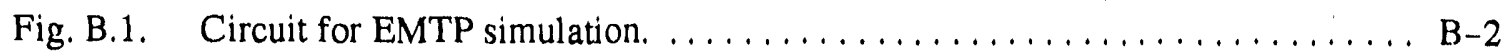

Fig. B.2. Voltage waveform at Node $4 . \ldots \ldots \ldots \ldots \ldots \ldots \ldots \ldots \ldots \ldots \ldots \ldots \ldots$

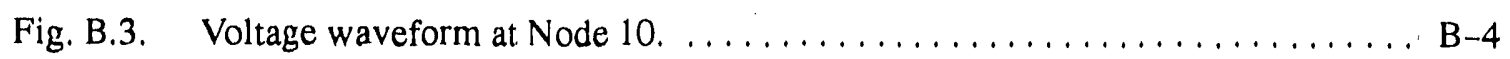

Fig. B.4. Voltage measured at Node $4 \ldots \ldots \ldots \ldots \ldots \ldots \ldots \ldots \ldots \ldots \ldots$

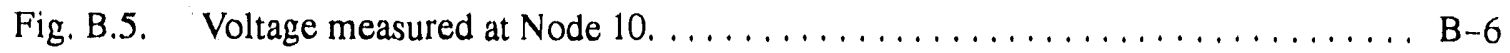




\section{LIST OF TABLES}

Table I. Critical Flashover Voltage (CFO - ten shots) $\ldots \ldots \ldots \ldots \ldots \ldots \ldots \ldots \ldots$

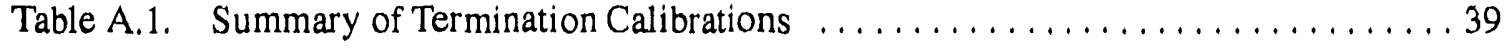

Table A.2. Results of Fiber Optic Calibration and Pearson CT Calibration . . . . . . . . . . 43

Table A.3. Results of Attenuator Calibration $\ldots \ldots \ldots \ldots \ldots \ldots \ldots \ldots \ldots \ldots \ldots$

Table A.4. Biddle Bridge Calibration Results . ..................... 46 


\begin{abstract}
Results are reported from experiments in which steep-front, short-duration (SFSD) voltage impulses were imposed on various electrical power distribution components. These pulses were generated by switching a section of charged, high voltage coaxial cable across the component urider study. Components included underground distribution cable, cable terminators, insulators and arresters. SFSD voltage needed to flashover $15 \mathrm{kV}$ polyethylene cable with a single pulse is approximately $625 \mathrm{kV}$ peak. Strength of polyethylene cable decreases with increasing number of SFSD pulses, indicating cumulative degradation of the polymer. For $15 \mathrm{kV}$ and $25 \mathrm{kV}$ cable terminators, the SFSD CFO was over twice the rated standard lightning BIL for the same units. Similarly, porcelain suspension insulators required more than a doubling of voltage to decrease time to flashover from 1 microsecond to 1 microsecond. Arresters were found to respond rapidly to steep-front current pulses, but the arrester material itself was found to result in a higher discharge voltage for SFSD pulses. Arresters also showed a delay in turn-on of current following the arrival of a steep-front voltage surge.
\end{abstract}




\section{EXECUTIVE SUMMARY}

The purpose of this study has been to establish a data base on the response of power system components to steep-front impulses. These data are needed in order to carry out accurate simulations to predict the effects of steep-front, short-duration impulses on electric power systems.

Power systems are subjected to electrical transients primarily due to lightning and switching events. The electrical surges generated by lightning discharges can have peak strengths of hundreds of thousands of volts, with front times and durations of approximately one and 100 microseconds, respectively. Switching surges have lower voltages but rise times and durations ten to one hundred times the lightning impulse. Both lightning and switching are known to generate much faster transients under conditions which may exist in electrical power systems. A high-altitude nuclear detonation generates a strong electromagnetic wave which also can induce a steep-front, short-duration surge on the terrestrial power systems.

Because of the time needed for the arc in an electrical breakdown to develop, and because this development time is inversely proportional to the voltage driving the growth of the arc, longer duration transients (e.g., switching surges) require less peak voltage to flash over a particular insulator than is needed for the shorter duration lightning transient. We would therefore expect by extrapolation that the very short duration impulses considered in this study will require much higher peak voltages to break down the same insulator.

There is the factor of degradation which also must be considered. The high voltage, steepfront, short-duration pulse will have very high frequencies and high rates of change of voltage, and these stresses can have a strong degrading influence on the dielectric materials of the insulations under study.

These expected influences guided the experiments performed during this research and were used to interpret the experimental results.

The following results are reported in detail for the indicated components:

1. Polyethylene cable for underground residential service: new and field aged: Impulse weakening of cable appears to be cumulative, with breakdown voltage decreasing with increasing number of pulses. There are no measurable changes in capacitance or dissipation factor during this multiple impulse process. Field aged cable already shows weakening.

2. Cable terminators ("potheads"): Steep-front, short duration (SFSD) withstand strength of terminators is much greater than standard lightning capability, but a high percentage of SFSD failures result in shattering. 


\section{$x$ Executive Summary}

3. Insulators: pin and suspension, porcelain and polymer: Insulators, like terminators, also show very high voltage withstand ability for SFSD pulses. An inverse relation was found between peak voltage and time to flashover, confirming that shorter pulses have much higher CFOs. Some interesting differences in flashover current and voltage waveshapes have been observed when comparing clean, dry insulators and wet, contaminated insulators.

4. Arresters: SiC and MOV: Arresters exhibit an inductive behavior which is very prominent during SFSD pulsing. This is due both to the geometric inductance of the arrester and its leads and to the fact that the arrester material has some lag in responding to rapidly applied voltage. These two effects were separated by a substitution technique, and the response of the arrester MOV material was shown to be quite fast. MOV arresters were shown to respond to closely following repeated surges almost as well as to initial pulses. Current flow in MOV arresters was also found to delay up to 150 ns after initiation of a steep-front voltage pulse in the turn-on or "knee" portion of the arrester $\mathrm{i}-\mathrm{v}$ characteristic.

Several pulsers were developed, and a variety of measurement and analysis techniques were employed to obtain these desired results. These techniques and results will be explained in detail in this report.

For all components tested, the SFSD CFOs were considerably higher than standard lightning CFOs. 


\section{INTRODUCTION}

Computer simulations must be used to assess the expected impact of nuclear electromagnetic pulses (EMP) on terrestrial electric power networks. Magnitude of the e-m wave generated by the explosion, coupling of this wave into the power system, and propagation of the coupled surge along the power transmission and distribution lines are amenable to analytical evaluation. Experimentation must be used, however, to determine the ability of power system components to sustain these very intense, steep-front, short-duration (SFSD) pulses. The purpose of this study is to contribute to this necessary data base on behavior of power distribution components during single and repeated steep-front EMP impulses for use in system assessments. Other possible sources of steep-front impulses are lightning and switching operations in gas-insulated substation.

These components have been studied:

1. Pol yethylene cable for underground residential service; new and field aged

2. Cable terminators ("potheads")

3. Insulators: pin and suspension, porcelain and polymer

4. Arresters; $\mathrm{SiC}$ and $\mathrm{MOV}$

Several pulsers were developed, and a variety of measurement and analysis techniques were employed to obtain these desired results. These techniques and results will be explained in detail in this report.

For all components tested, the SFSD CFOs were considerably higher than standard lightning CFOs. SFSD CFOs were found to be from over 2 to 10 times higher than lightning CFOs. depending on the characteristics of the SFSD impulse.

\section{PULSER DEVELOPMENT}

This section will report on the development of pulsers to generate the steep-front voltage and current pulses required to meet the various objectives of this program.

\section{$2.135 \mathrm{kV}$ and $69 \mathrm{kV}$ Cable Pulsers [Ref. 1, 2, 4-6]}

Figures 1 and 2 show the circuit diagram and a photograph of an early pulser made from $35 \mathrm{kV}$ cable. $69 \mathrm{kV}$ cable was also used in this type of pulser. Ten meter long cable sections were used. One to four of them were used in parallel in order to adjust the impedance and output voltage. 'The MSU impulse generator was used to pulse charge these "peaking" cables. When the peaking cable voltage reaches the breakdown voltage of the peaking gap, that gap fires and delivers the SFSD pulse to the test object. Figure 3 shows a typical voltage pulse delivered to a terminated $15 \mathrm{kV}$ cable.

These pulsers gave rise times in the 50-100 ns range. Since cable charging voltages of over 600 $\mathrm{kV}$ are required in order to deliver $300 \mathrm{kV}$ pulses to the test load, these pulse cables did not last very long. 

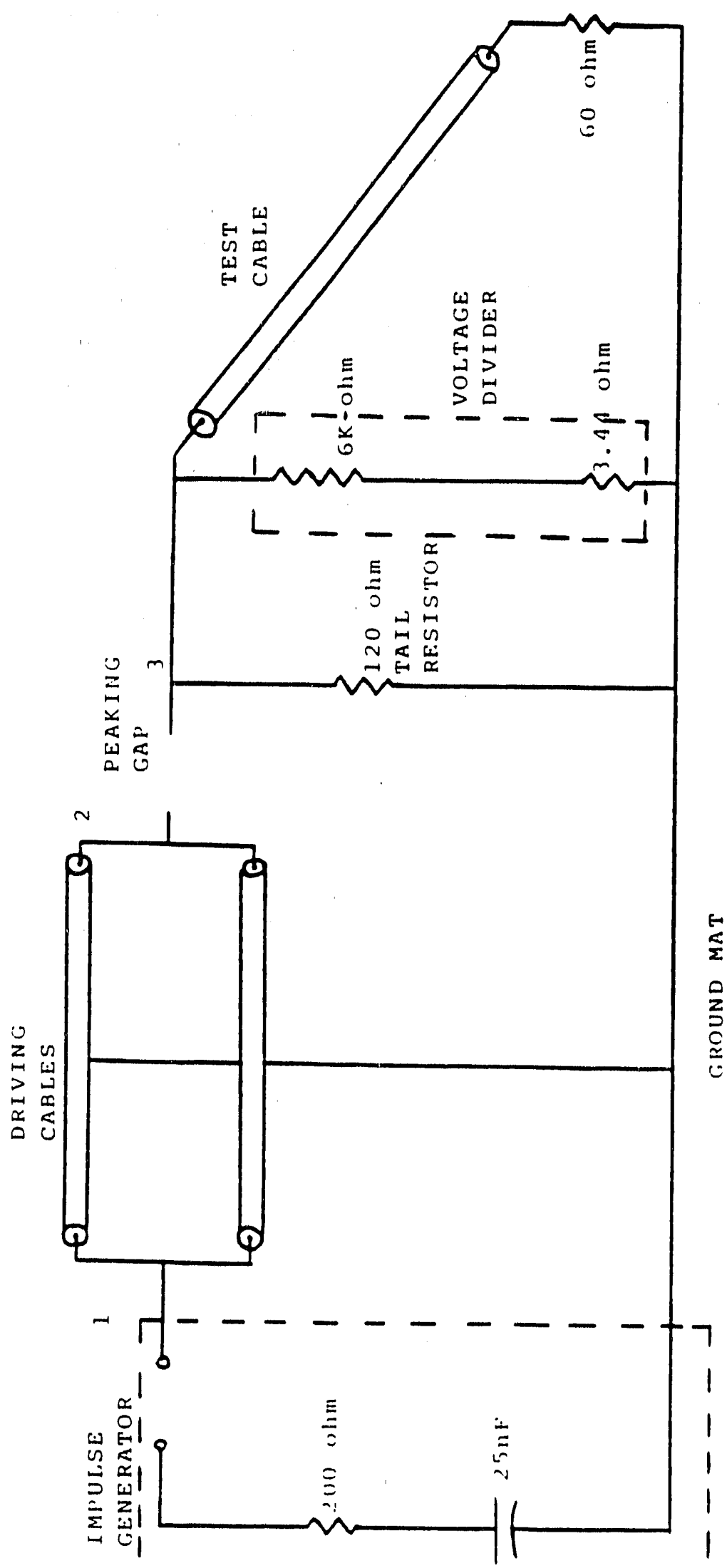

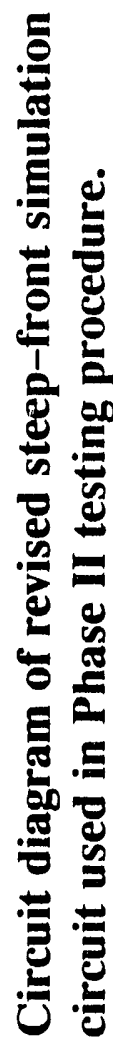




\section{$2.2138 \mathrm{kV}$ Cable Pulser $[3,7]$}

The Electric Power Research Institute donated an 80 meter piece of $138 \mathrm{kV}$ polyethylene cable to Mississippi State University in 1989. This allowed us to achieve longer pulser life and shorter rise times. Generally, the cable was kept on its reel, as shown in the Figure 4 photograph. Approximate dimensions and impedanice of this cable are shown below:

conductor diameter: $27 \mathrm{~mm}$

inner and outer semiconducting layer thickness: $1 \mathrm{~mm}$

insulation thickness: $28 \mathrm{~mm}$

shield outside diameter: $82 \mathrm{~mm}$

surge impedance: 42 ohms.

Later, two 10 meter sections were cut from this cable piece, leaving a 60 meter main section. These were used singly, in parallel or in a Marx circuit to obtain shorter, higher voltage or lower impedance circuits. The circuit drawing in Figure 1 is typical of these circuits. Figure 5 shows the 80 meter cable pulser circuits. The pulse from the 80 meter cable pulser into a matched load is presented in Figure 6 . Note that the rise time is now about 40 ns and duration is approximately 1 microsecond. When two 10 meter sections of this $138 \mathrm{kV}$ cable are used in parallel, the voltage pulse into a matched load is shown in Figure 7; now the rise time and pulse length are about 50 ns and 0.25 microseconds, respectively. This discharge circuit, including the output gap, the load and the ground return line, must be kept short in order to minimize inductance.

This pulser has been employed primarily to study arrester response to steep-front pulses.

\subsection{Two Stage Marx Pulser Made From 138 kV Cable}

The circuit in Figure 8 was developed in order to achieve higher voltages from the $138 \mathrm{kV}$ cable. A photograph of this circuit is shown in Figure 9. Now, the two 10 meter sections of cable end up in series and so their charge voltages add and their output impedance doubles. A very fast rising, short duration high voltage pulse is generated by this pulser, as shown in Figure 10.

This circuit is used in SFSD insulator CFO measurements. 


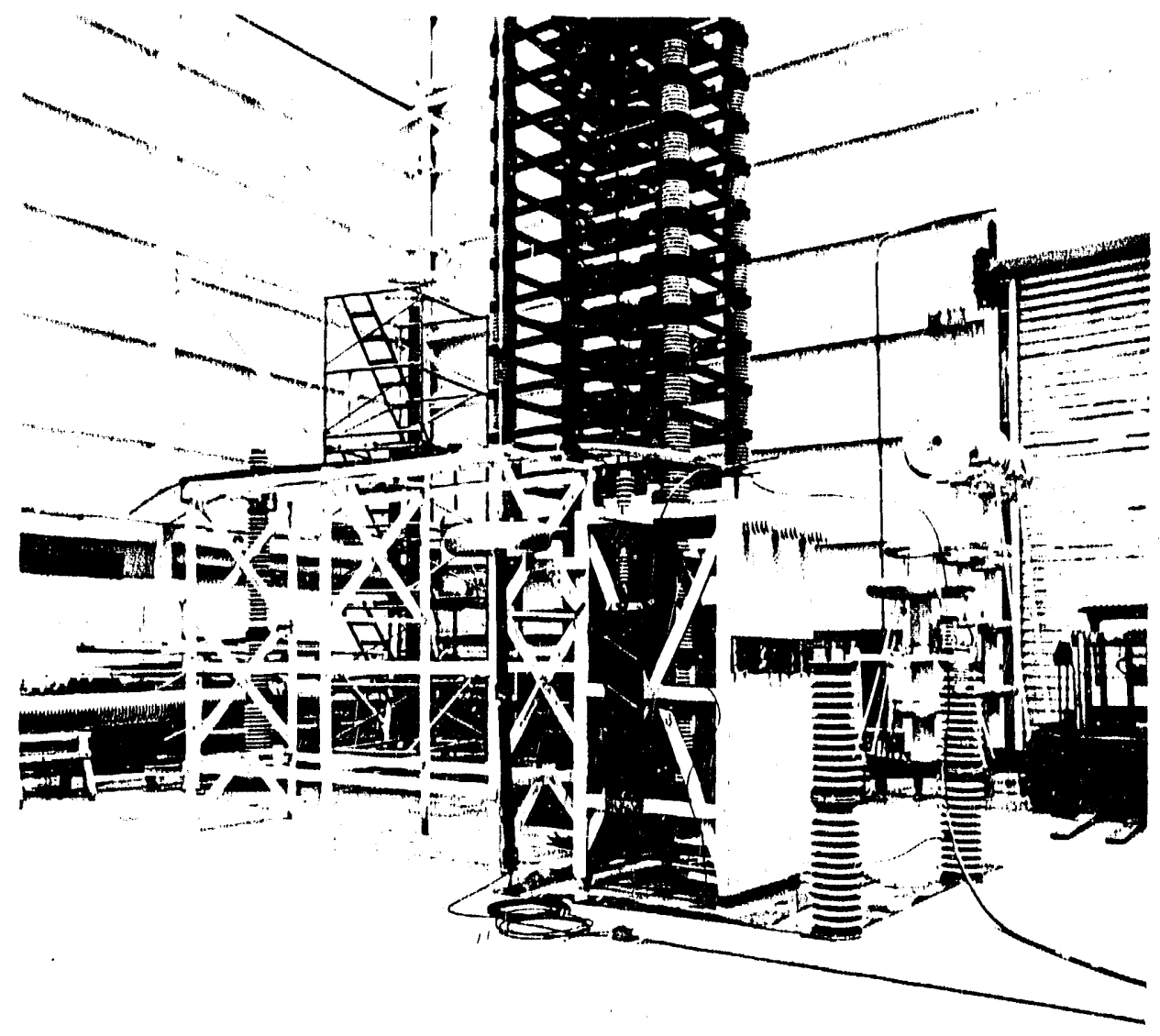

Figure 2: $\quad$ Photograph of an early dual $69 \mathrm{kV}$ cable pulser.

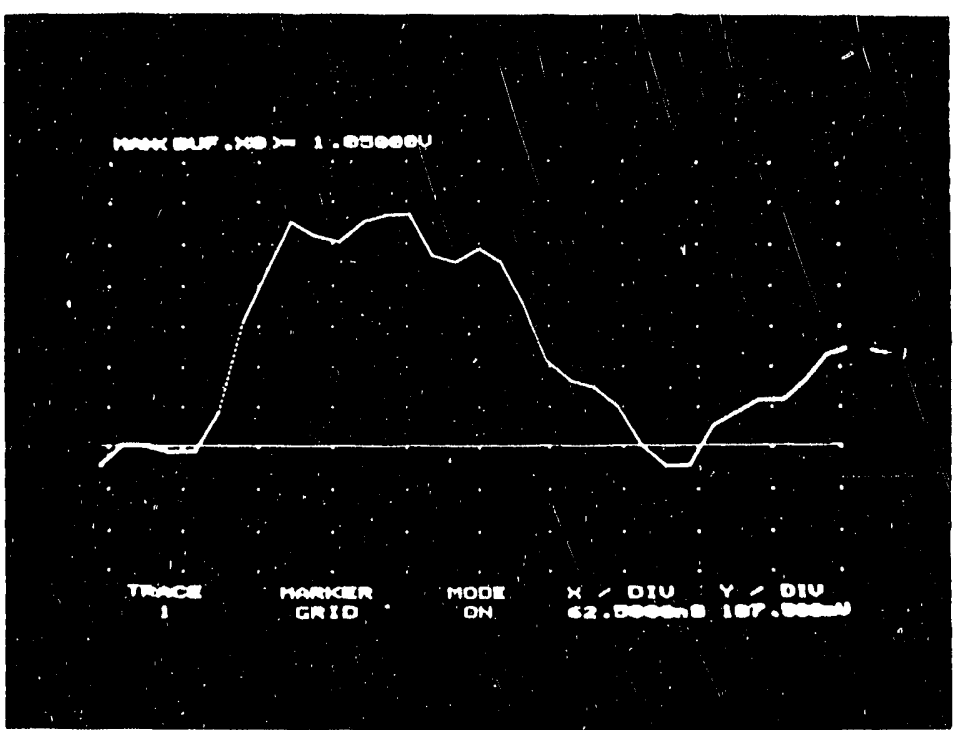

Figure 3: Voltage pulse into $15 \mathrm{kV}$ terminator and terminated $15 \mathrm{kV}$ cable.

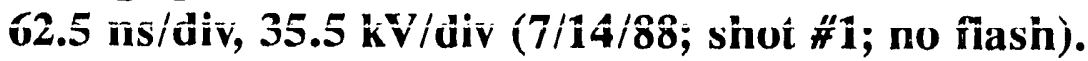




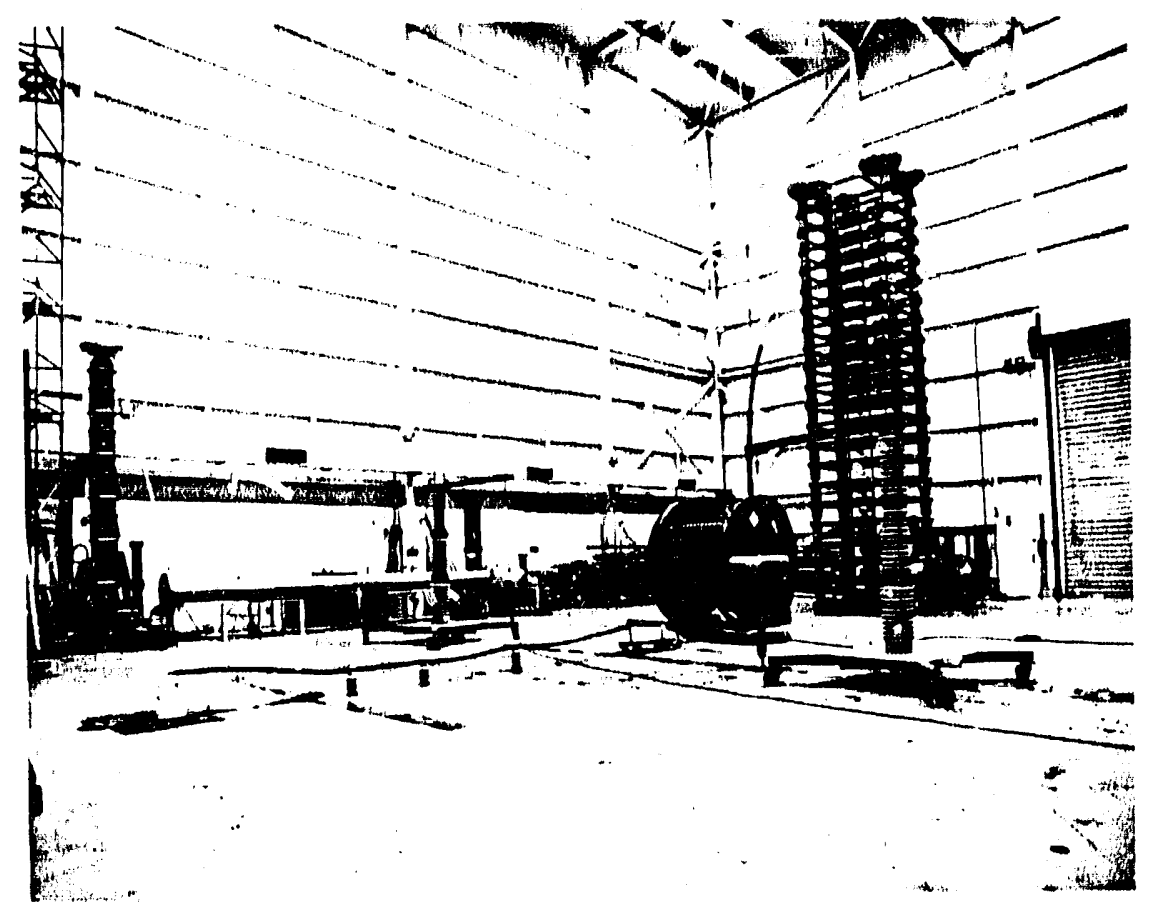

Figure 4: Photograph of $138 \mathrm{kV}$ cable pulser. Tall impulse generator in background; pulser cable on reel. Wire wound and liquid dividers suspended from posts connected to input of test cable $(10 / 8 / 89)$.

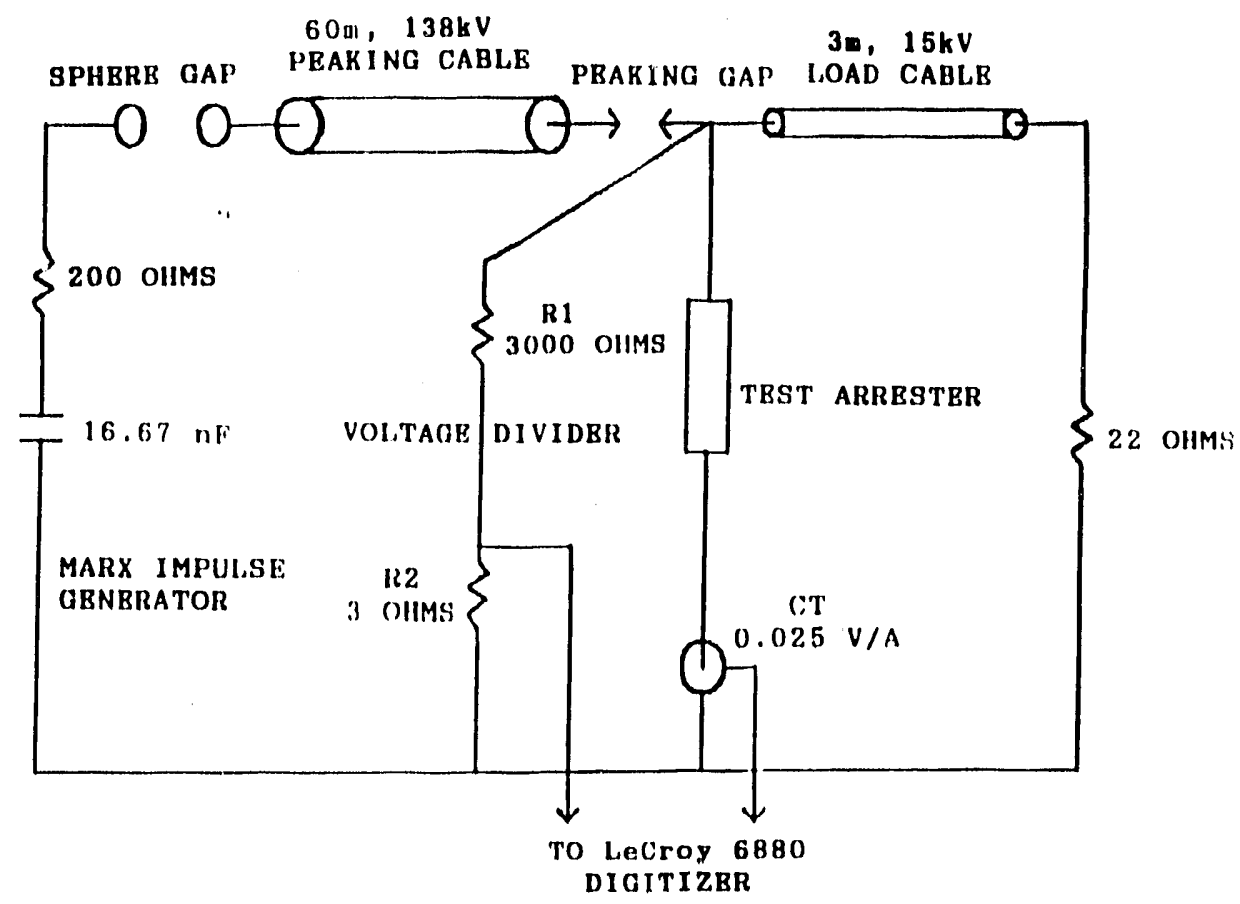

Figure 5: Circuit using $13 \overline{8} \overline{k V}$ cable to test arresters.

(Fig 1, Ref 12) 


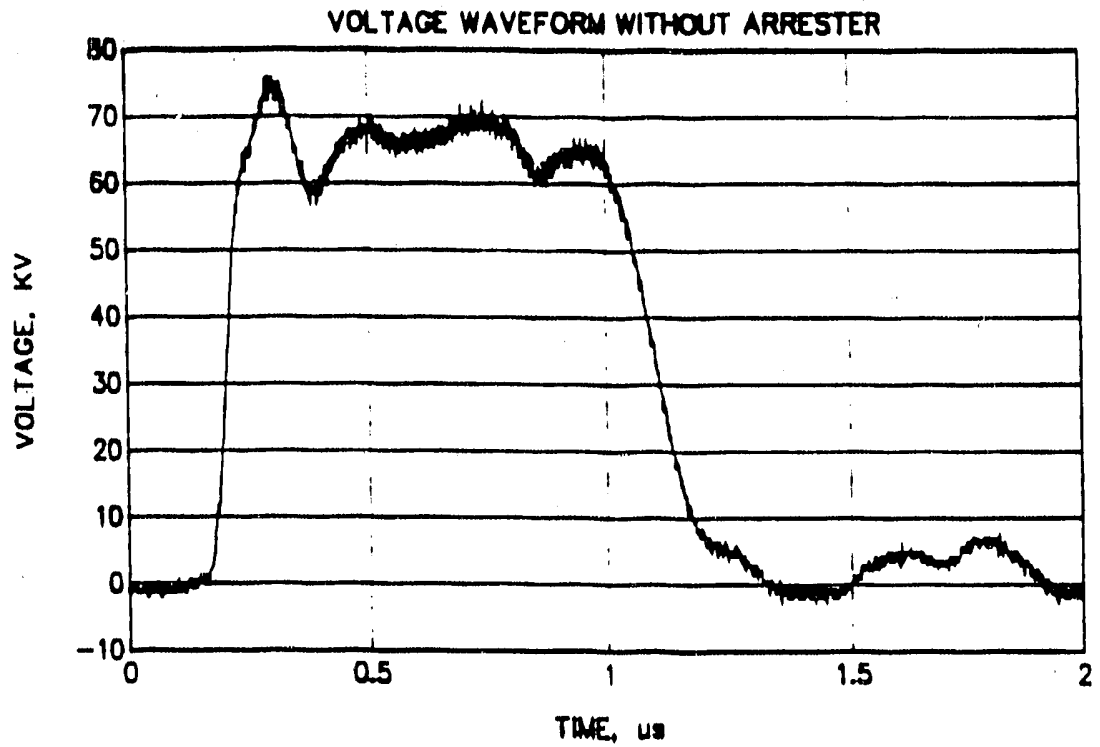

Figure 6: $\quad$ Voltage delivered by $138 \mathrm{kV}$ cable pulser to a matched load.

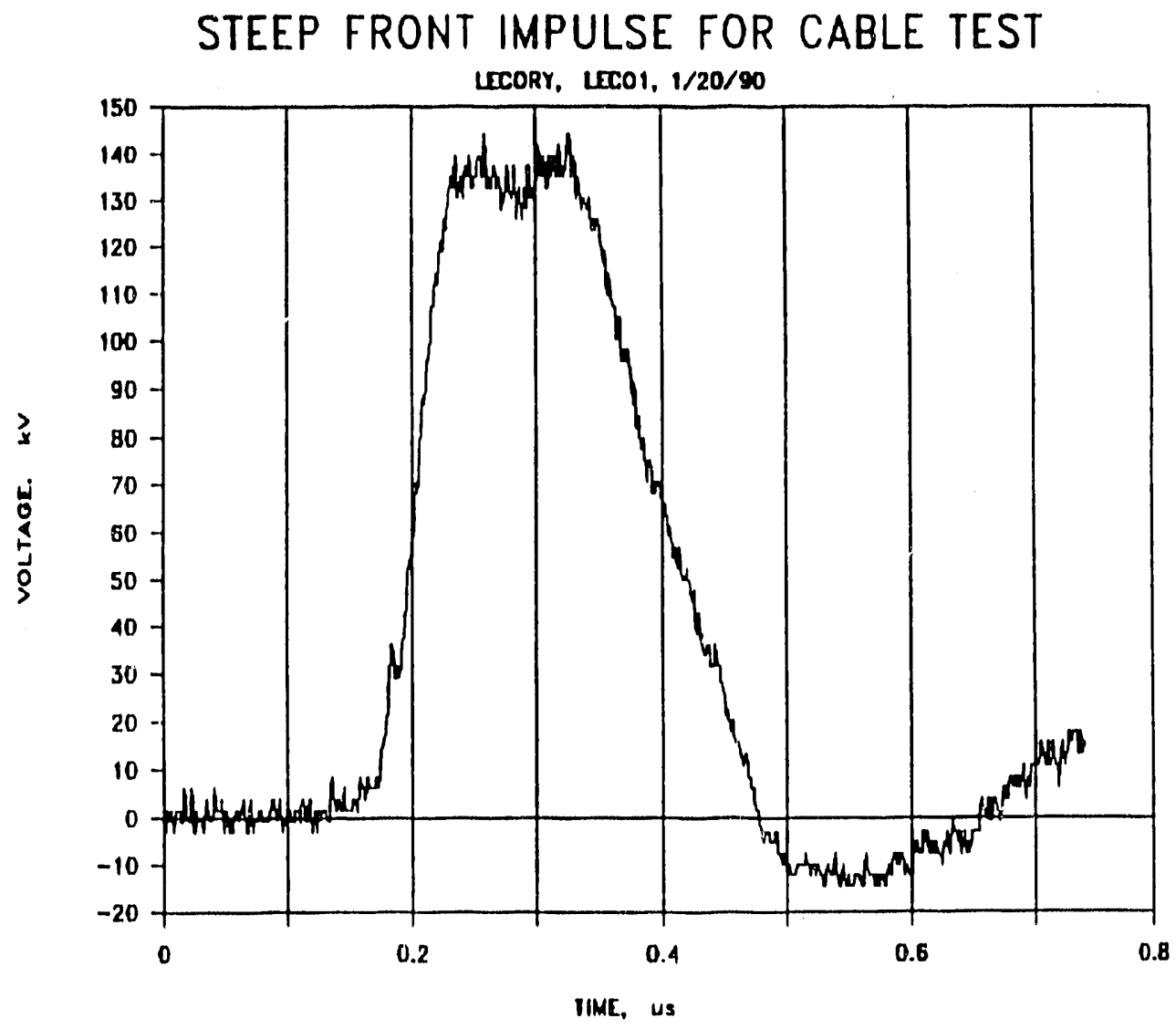

Figure 7: Voltage delivered by two 10 meter $138 \mathrm{kV}$ cables in parallel to a matched load. 


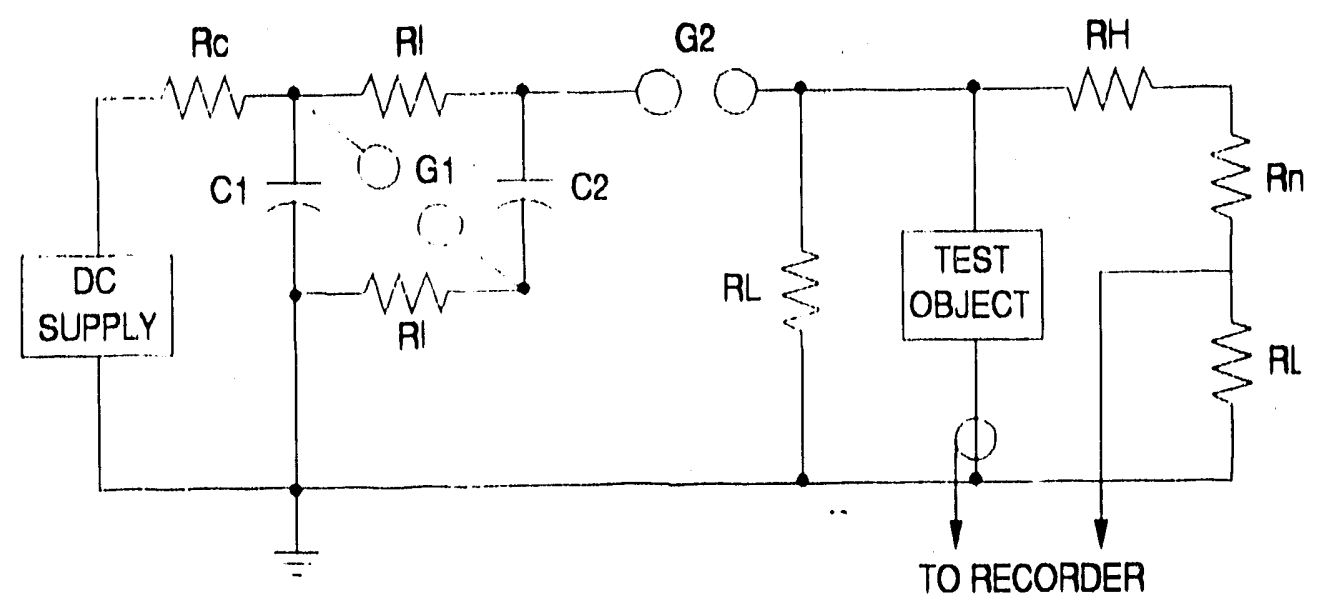

Figure 8:

(Fig 1, Ref 16)

Two stage Marx circuit. C1 and C2 are each $10 \mathrm{~m}, 138 \mathrm{kV}$ cable sections; $R I=A^{\prime}, 50 \mathrm{k} \Omega$ water resistors; $R L=100 \Omega$; $\mathrm{Rh} / \mathrm{Rl}=3000 \& 400 / 3.11 \Omega$.

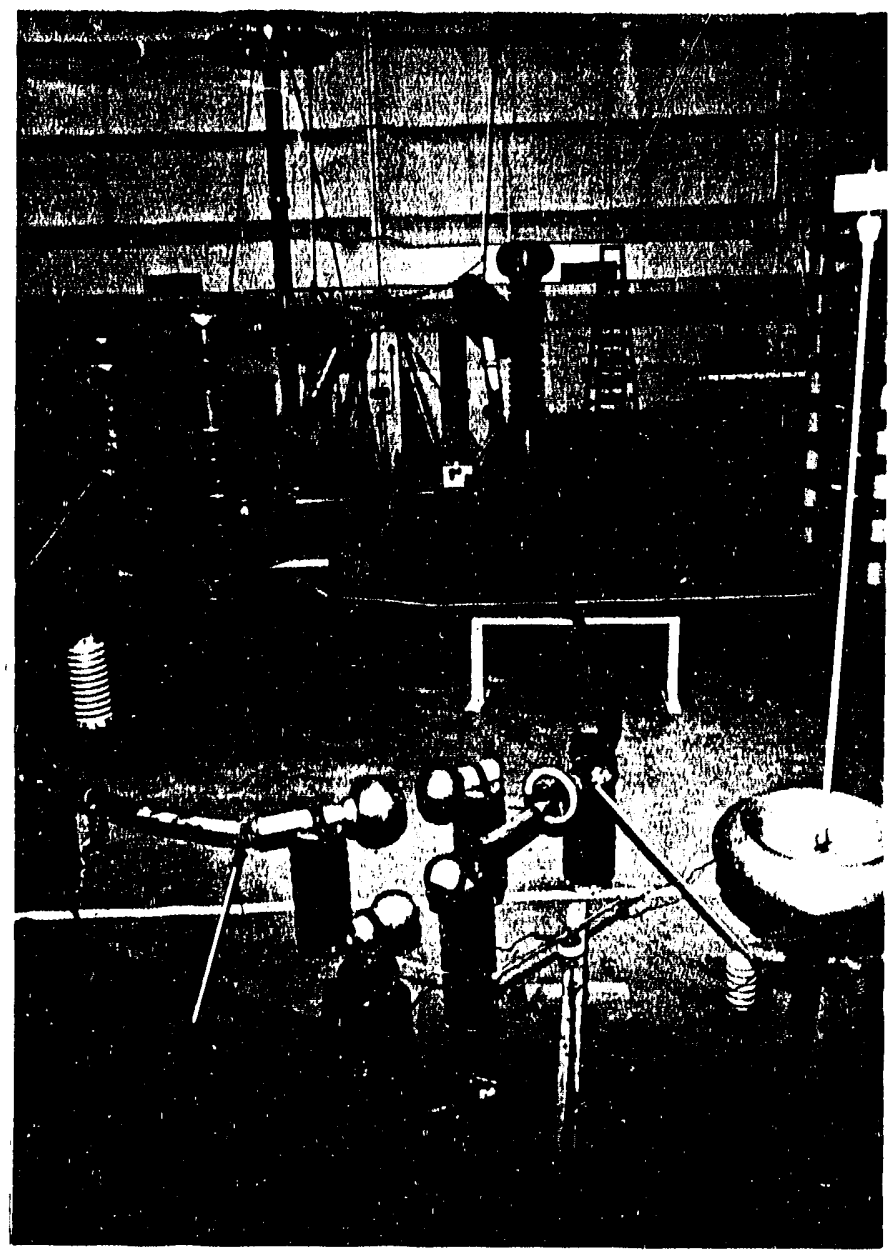

Figure 9: Photograph of the two stage Marx circuit using $10 \mathrm{~m}, 138 \mathrm{kV}$ cables for the Marx capacitors. 


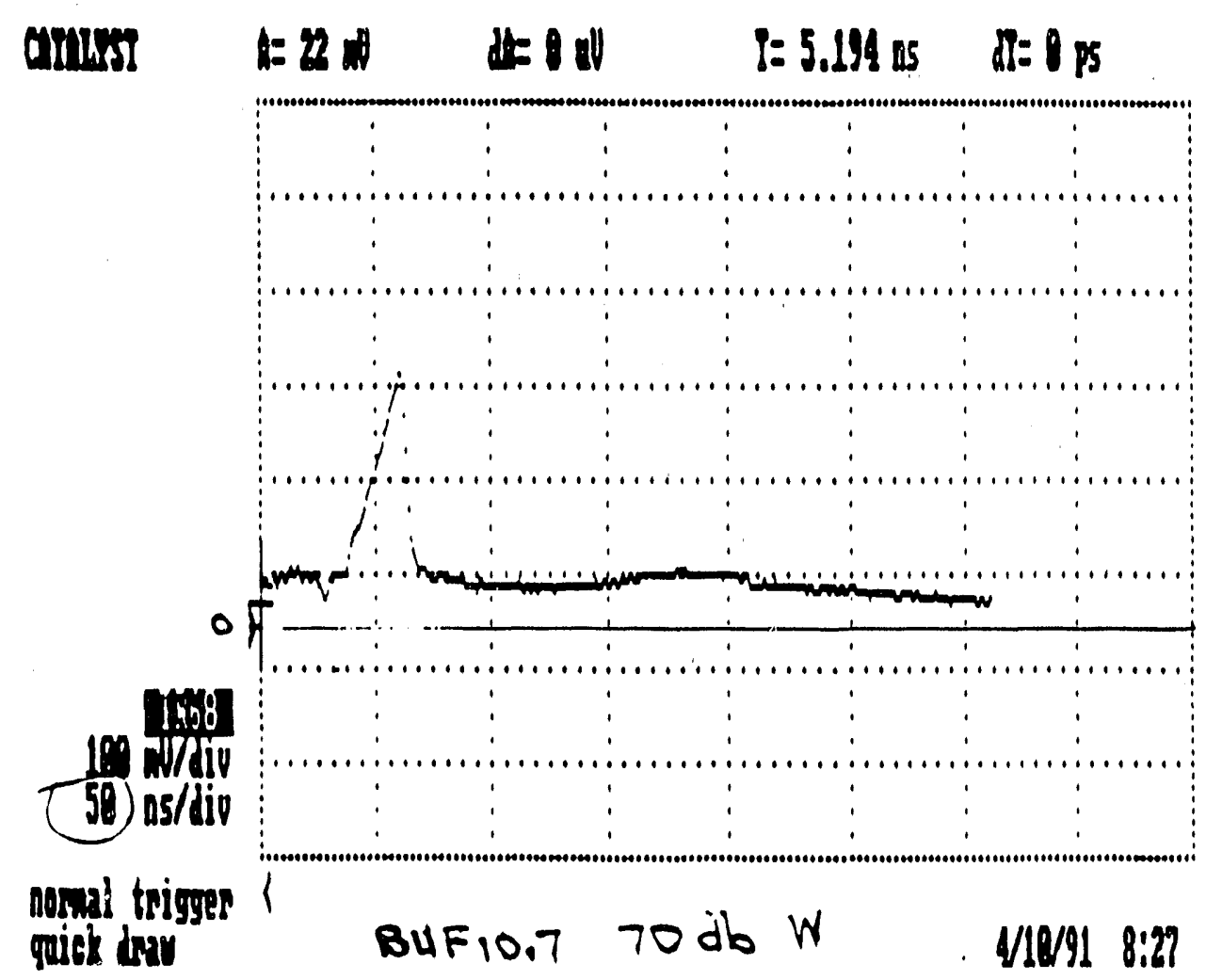

Figure 10: $\quad$ SFSD voltage pulse from the two stage Marx circuit.
Withstand, 55-2 Pin insulator, $953 \mathrm{kV}$ peak.

\subsection{Double Pulse Circuit [8]}

In order to study the recovery of a surge arrester immediately after a high current pulse, the double pulse circuit shown in Figures 11 and 12 was developed. This uses the 60 meter $138 \mathrm{kV}$ cable for the initial, high current pulse. After a controlled time delay (20 microseconds to 2 seconds), the second pulse, from the dc-charged, ten meter section of $138 \mathrm{kV}$ cable, is delivered through the triggered spark gap switch to the arrester. Voltage and current waveforms for the first and second pulses are shown in Figures 13 and 14. 


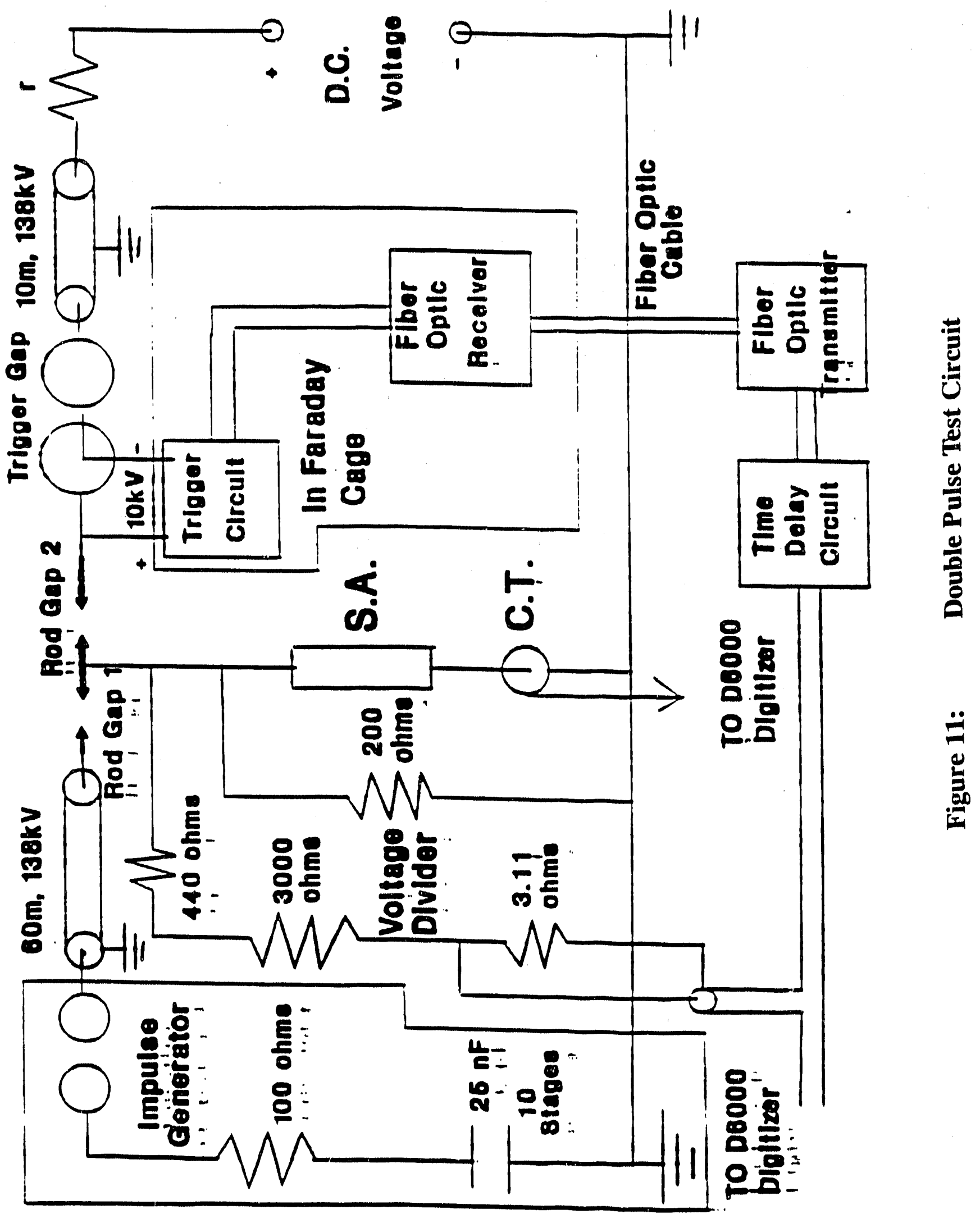




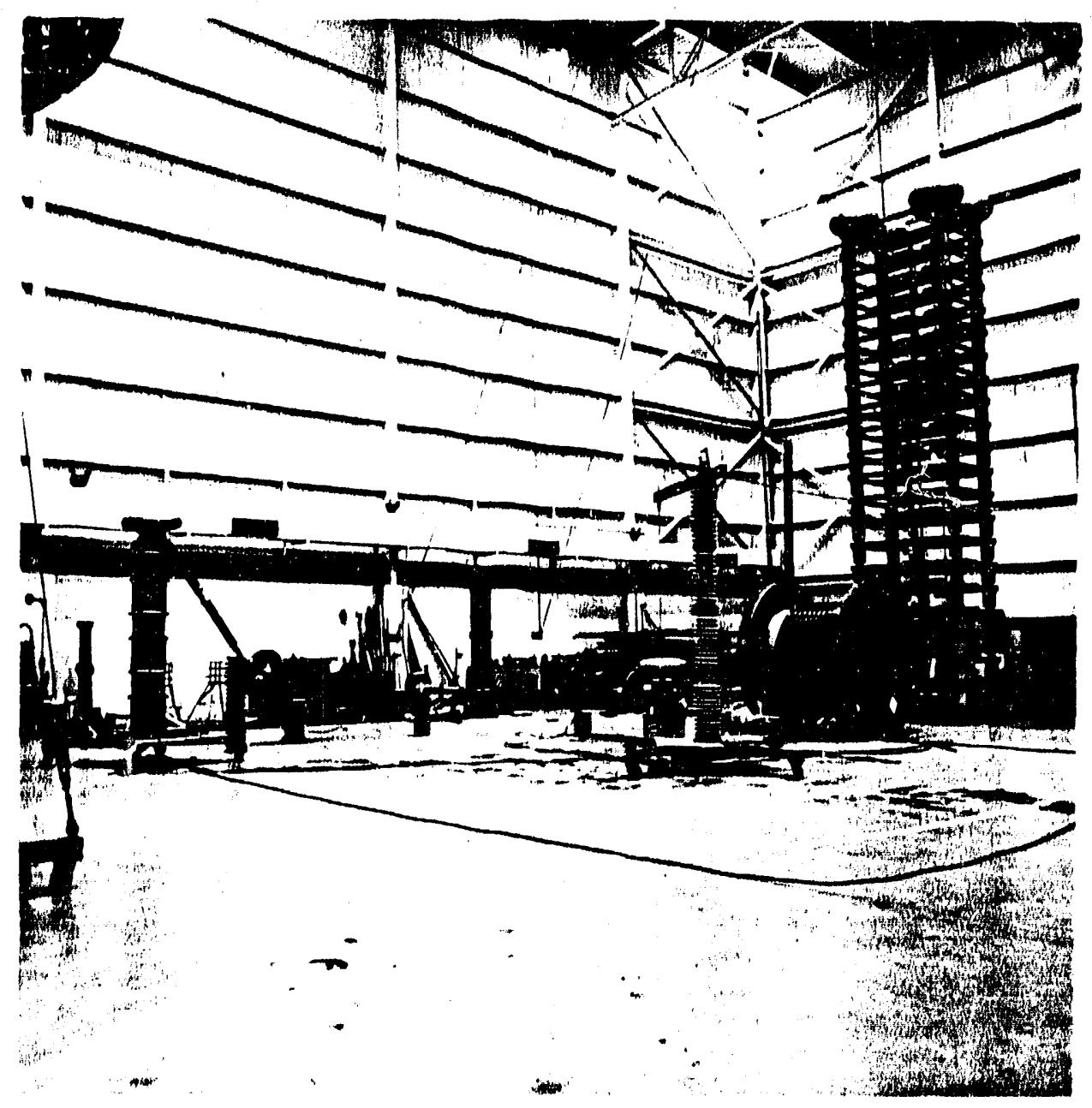

Figure 12: Photograph of dual pulse system, showing $138 \mathrm{kV}$ reeled cable for for first pulse on right, spark gaps and divider at center, and dc supply and second pulse cable on left. 


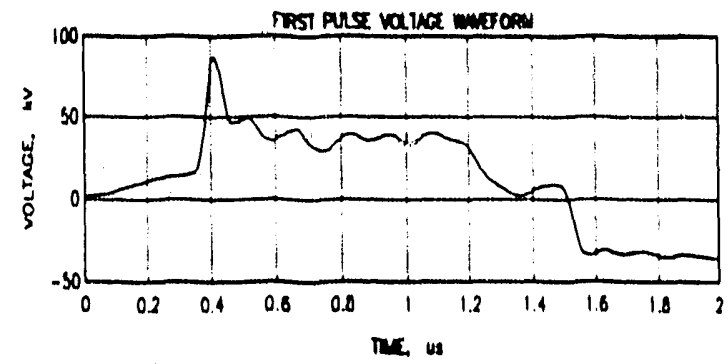

Figure 13a: First Pulse Current Waveform. Peak Current: 10.09 kA.

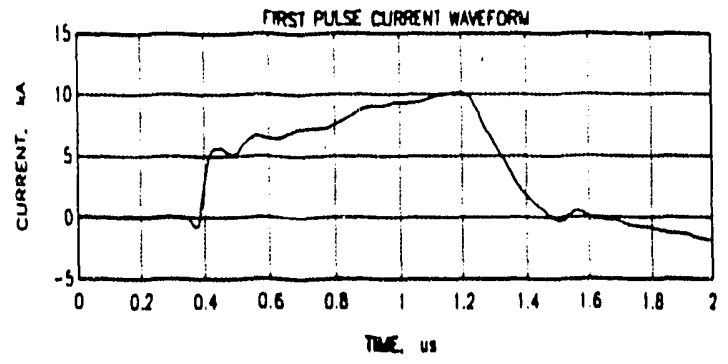

Figure 13b: First Pulse Voltage Waveform. Peak Current: 10.09 kA.
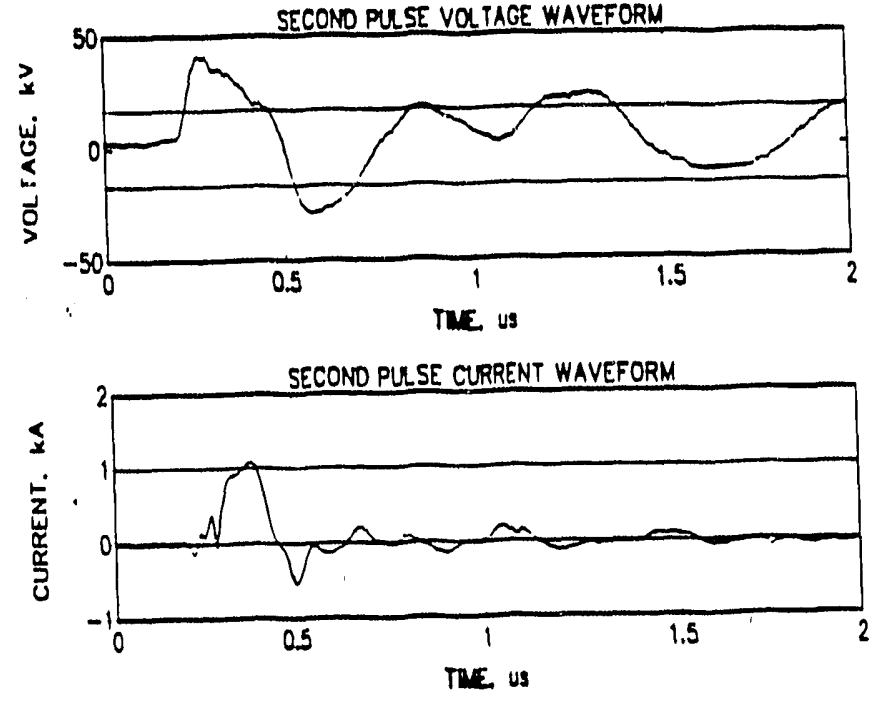

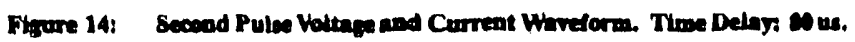




\section{INSTRUMENTATION}

\subsection{Digital Oscilloscopes}

The following two oscilloscopes were employed during these tests:

$\begin{array}{lcccc}\text { Scope } & \text { Bits } & \text { Max Sample Rate } & \text { F.S. Volts } & \text { Data Transfer } \\ \begin{array}{l}\text { LeCroy } \\ 6800+\end{array} & 8 & 1.3 \mathrm{Gs} / \mathrm{s} & .5 & 488 \text { (CATALYST) } \\ \begin{array}{l}6010 \\ \text { Analogic }\end{array} & 8 & 100 \mathrm{Ms} / \mathrm{s} & 7.2 & \text { RS-232 (XTALK) } \\ \text { D6000 } & & & & \end{array}$

These oscilloscopes are visible in the special shielding screened enclosure in Figure 15.

\subsection{Voltage Dividers}

All significant voltage data taken during this investigation has been obtained using resistive dividers, where the high voltage arm is made up of one or more series stages of counter-wound (low inductance) resistance wire, each stage being 3000 ohms. The low voltage arm is a carbon resistor with coaxial connector output. Such a divider is visible in Figures 2,4 and 16. The shortest (3000 $\mathrm{ohm}$ ) divider has step response of about $30 \mathrm{~ns}$. Calibration of the high and low voltage branches of these dividers is described in Appendix A.

Occasionally, solid dividers made of conducting materials such as carborundum and liquid dividers using dilute copper sulfate solution were tried, but only in comparisor. with the wire-wound units. A liquid divider is visible in Figure 16.

\subsection{Current Transformers}

Currents have been measured using the following Pearson wide band current transformers:

$\begin{array}{lll}110 & 5,000 \mathrm{~A} & 20 \mathrm{~ns} \\ 110 \mathrm{~A} & 10,000 & 20 \\ 1025 & 20,000 & 100\end{array}$

The 1025 CT can be seen in Figures 9 and 16.

\subsection{Fiber Optic Data Transmission}

A commercial $50 \mathrm{MHz}$ fiber optic data transmission system made by Manage, Inc., Chicopee, MA, was used to measure current in to test pieces during cable degradation tests. This system was required since the pulse injection connection into the cable is at high voltage and so must be 


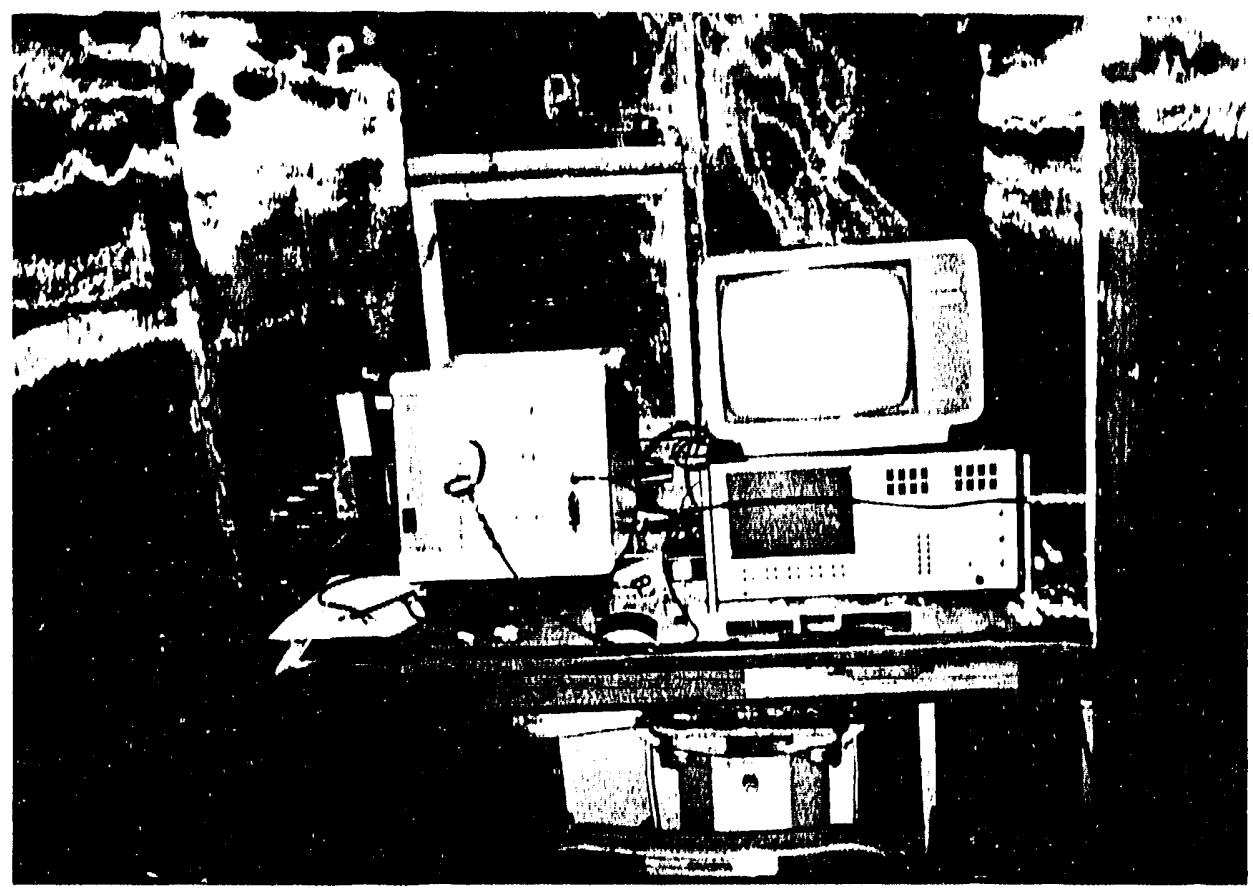

Figure 15: Photograph of LeCroy digitizer on left and Analogic digitizer on right, inside screen enclosure.

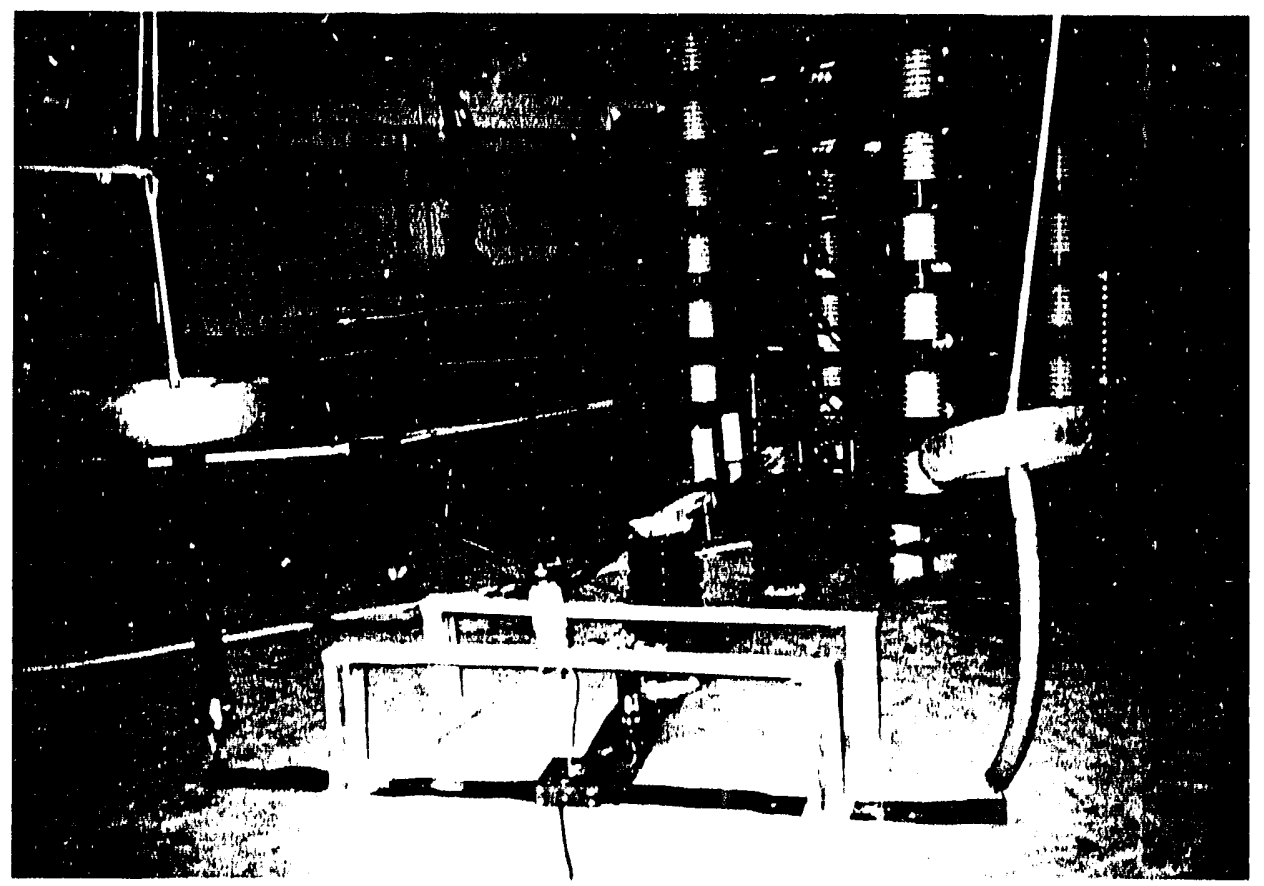

Figure 16: Arrester test setup, showing wire wound divider on left, liquid divider on right, and 20000 A current transformer on floor in arrester ground line. 
electrically isolated from ground. The optical fiber cable provides this isolation. Calibration of this system, in comparison with directly connecting the CT to the oscilloscope, is described in Appendix A. The fiber-optic receiver is seen in Figure 17 on top of the D6000 digitizer.

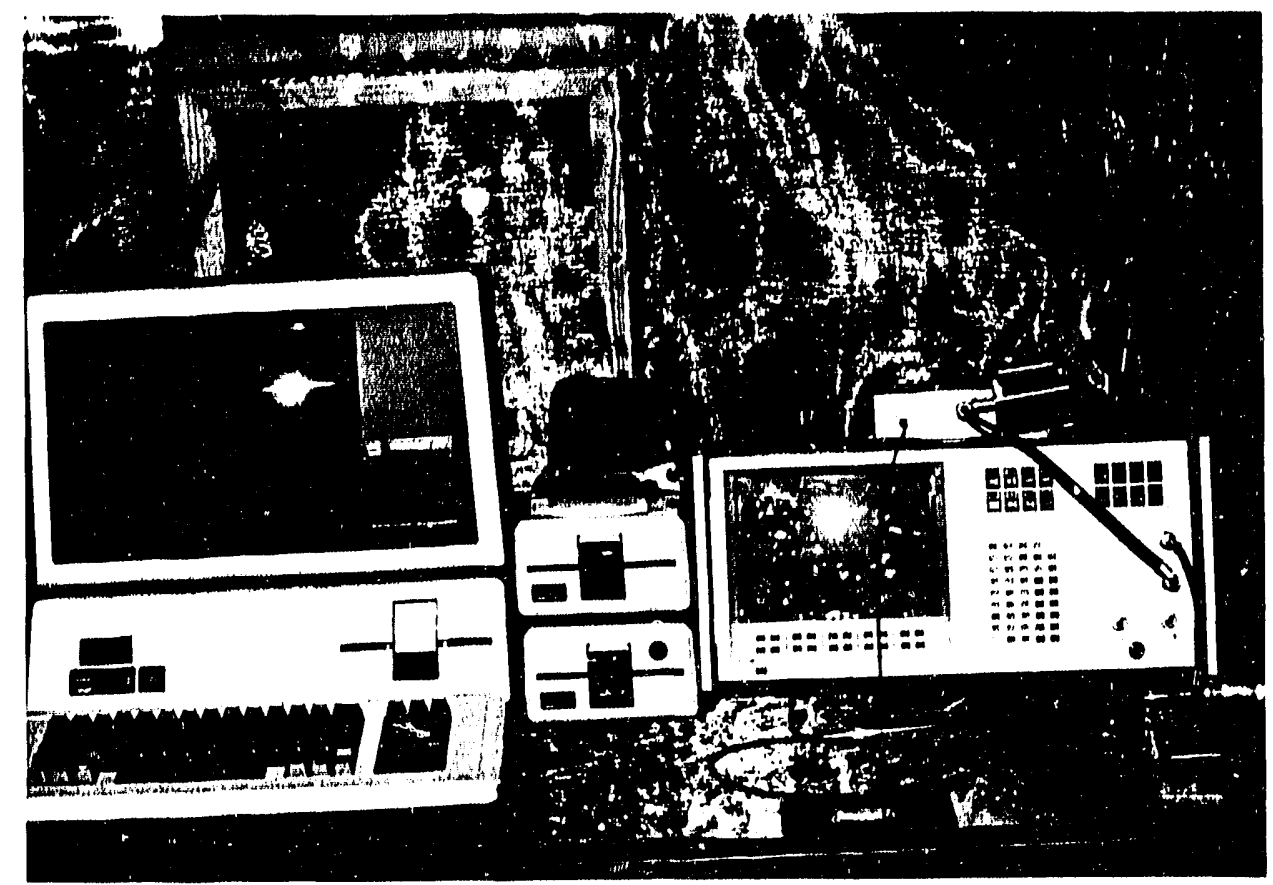

Figure 17: An early data acquisition set up in the screen enclosure, showing the Analogic digitizer with the Apple computer for data storage and analysis. The fiber optic receiver is located on top of the digitizer. 


\section{DATA ANALYSIS}

The following software routines have been used to analyze the data obtained during this study:

\subsection{SPICE, PSPICE}

The SPICE circuit simulation program was used to design and better understand the operation of our cable pulser circuits. Figure 18 shows the simulated circuit, and Figure 19 shows that SPICE simulations and actual measurements compare very closely to one another.

\subsection{EMTP $[9,10]$}

The EPRI version of the ElectroMagnetic Transients Program [9, 10], implemented on the Engineering College VAX computer, has been used in a similar fashion to SPICE to aid in design and analysis of our fast puise circuits. Some representative EMTP calculations show good agreement with actual pulser waveforms, as presented in Appendix B.

\subsection{MATLAB}

The PC-MATLAB (TM) program, purchased from The Mathworks Co., South Natick, MA, has been very useful in plotting and analyzing EMTP and experimental data. Some typical examples are shown in Appendix C.

\subsection{CATALYST}

C.ATALYST is a computer software routine supplied by LeCroy for use with the LeCroy digital oscilloscope. This program is used to set 'scope parameters, to transfer acquired data to computer file, and to display and plot the resulting data. Some typical steep-front impulses acquired by the LeCroy $1.3 \mathrm{Gs} / \mathrm{s}$ recorder and plotted using the CATALYST software are shown in Figure 20. 


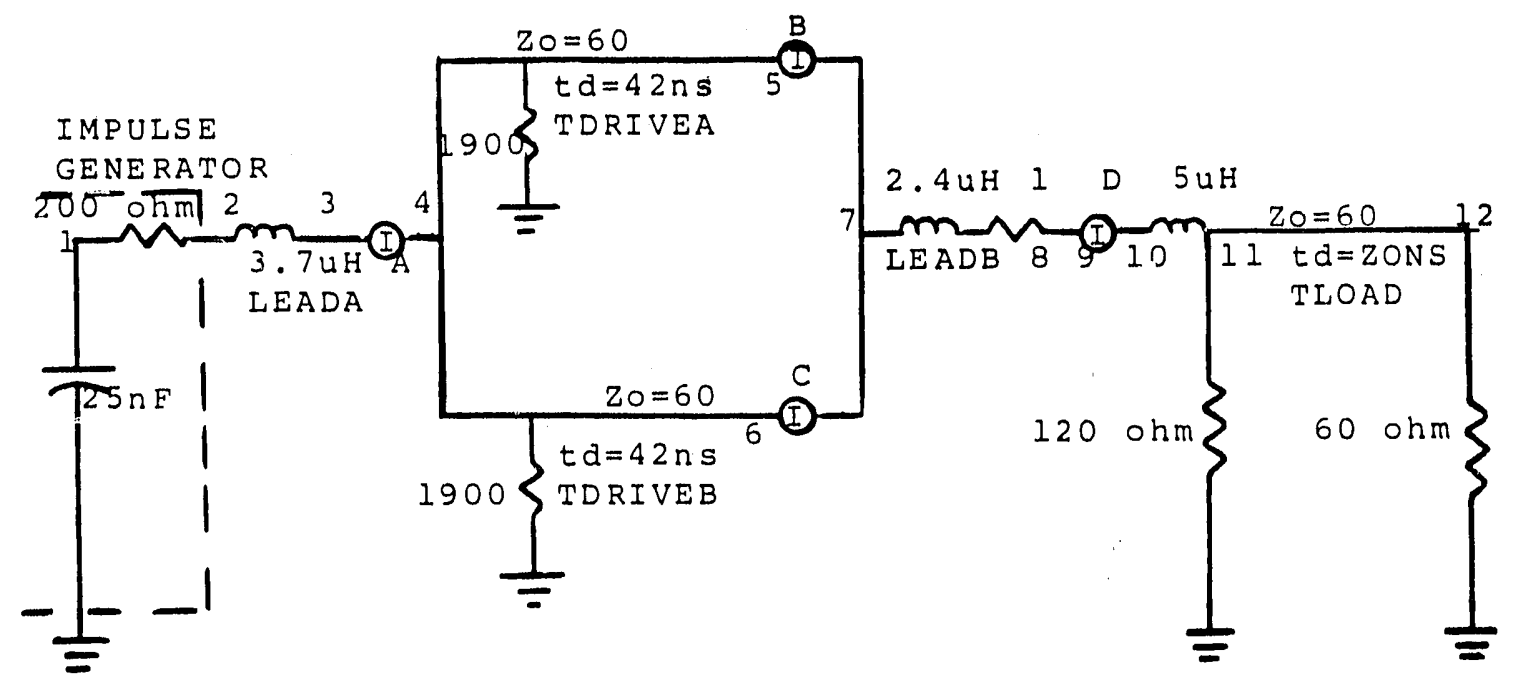

Figure 18: Complete Simulation Circuit for Second-Pass Run. 


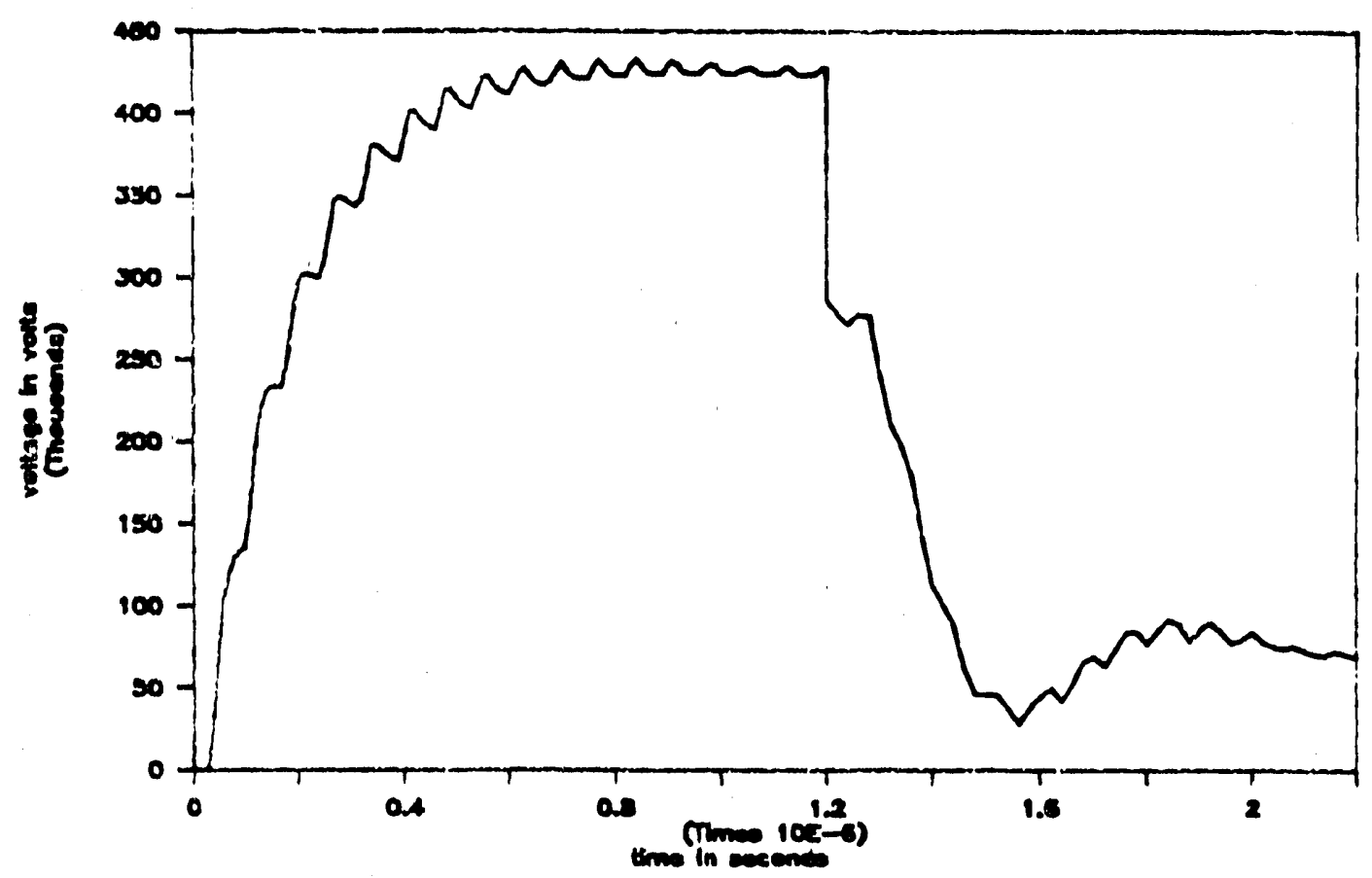

(a) SPICE Simulation at Node 8 (input to peaking gap).

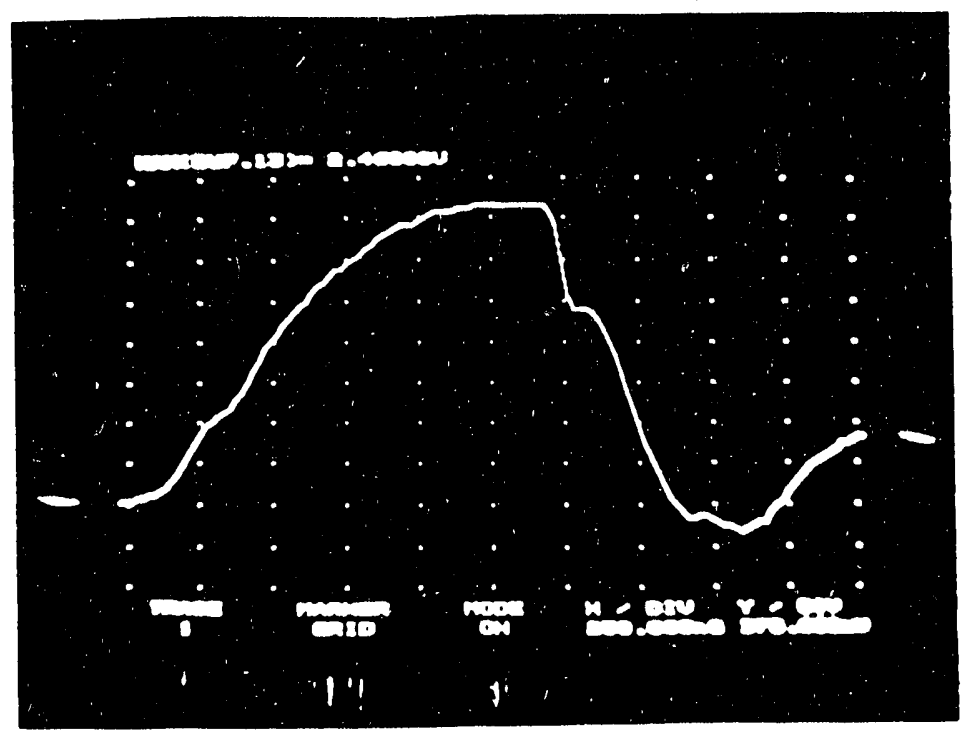

(b) Repeat of Figure 19a, actual voltage transient. $57 \mathrm{kV} / \mathrm{div}, 250 \mathrm{~ns} / \mathrm{div}$.

Figure 19: $\quad$ Computer Simulated and Measured Voltage Waveforms of the Steep-Front Circuit (Node 8). 

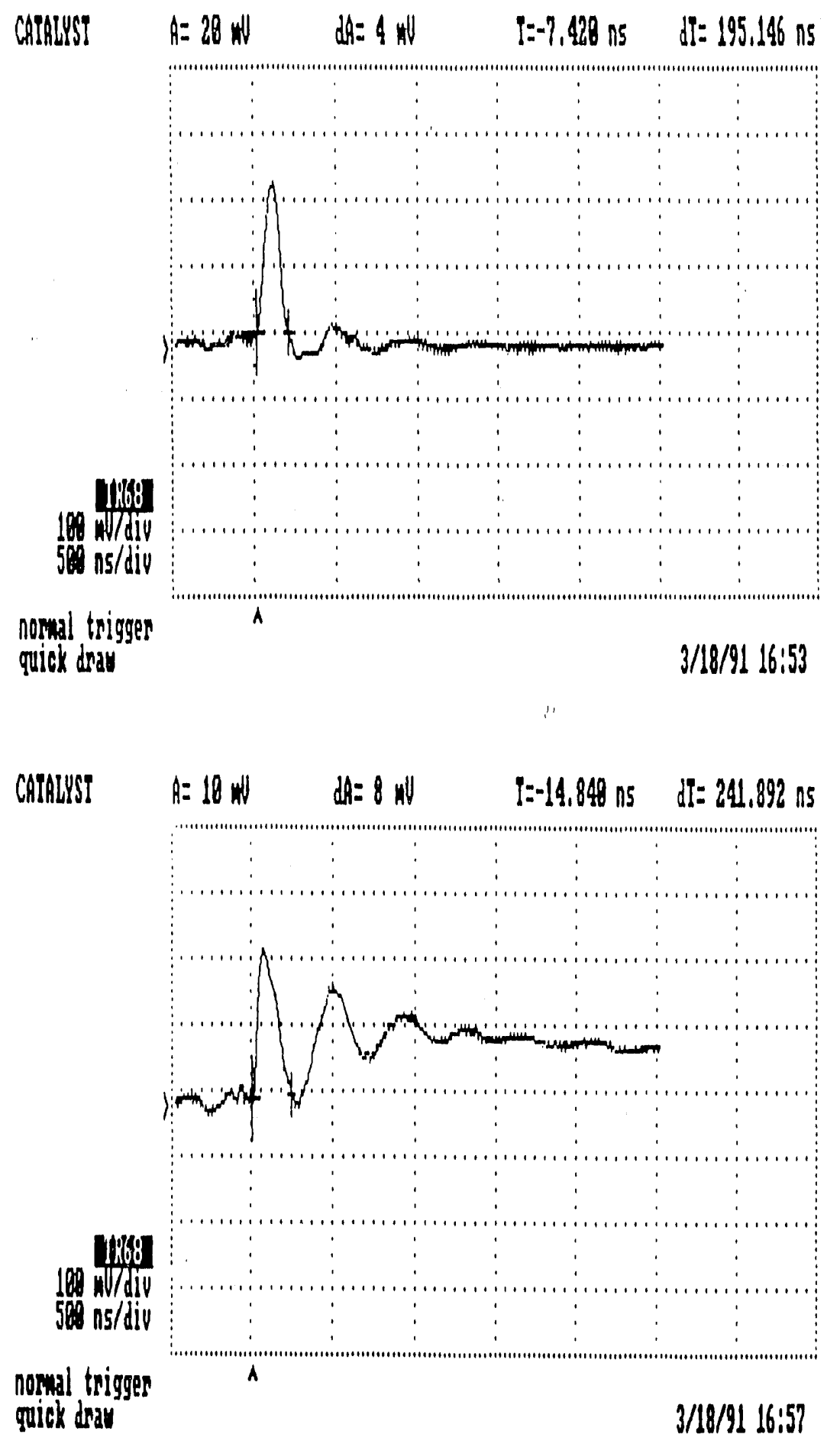

Figure 20: Voltage (top) and current (bottom) during flashover of a 55-3 pin insulator using the Figure 28 test circuit; $256 \mathrm{kV}$ peak voltage. 


\section{EXPANDED RESULTS}

\subsection{Cable Aging by SFSD Impulses [1-5]}

An early objective of this research program was to study the aging of distribution cable by multiple SFSD impulses. Cable pulsers of the type shown in Figures 1 and 2 were used. Typical voltage and current waveshapes during cable testing are shown in Figures 21 and 22. The results of this study are reported in References 1 through 5 . These results are summarized as follows:

1. The number of consecutive equal impulses required to breakdown a particular cable (kV rating and manufacturer) decreases as the peak voltage of the impulse increases.

2. Shorter duration impulses cause more rapid degradation to breakdown, for a given peak voltage.

3. There were no measurable changes in capacitance or dissipation factor which could clearly be ascribed to increasing number of impulses, even right up to the breakdown shot.

4. Field agcd cable appeared to have already lost some impulse withstand capability and exhibited much more scatter in correlation between peak impulse voltage and number of shots to breakdown at a voltage.

\subsection{Effects of SFSD Impulses on Terminators}

Terminators and insulators are critical components in the voltage integrity of any distribution system, and these devices were therefore also included, along with cables and arresters, in determining the ability of distribution systems to withstand electromagnetic pulses originating from nuclear explosions.

Cable pulsers of the form shown in Figure 1 were used for these tests. Typical voltage waveshapes during insulator and terminator testing are shown in Figure 23. The results of these terminator tests are listed in Table I. The reader will note from this table that the withstand voltage for SFSD impulses is much higher than the rated BIL of each unit, but that the failure mode is more often shattering or puncture rather than a recoverable arc.

\subsection{Insulators}

Three sets of tests were run to measure the withstand capability of insulators to steep-front pulses: 1) long duration pulses, 2) short duration pulses, and 3) medium duration pulses with insulators in a fog chamber.

For the long duration tests, a pulser of the Figure 1 form was used, but without the matching termination at the output of the cable. This raicod the duration of the pulse to hold up longer, as 


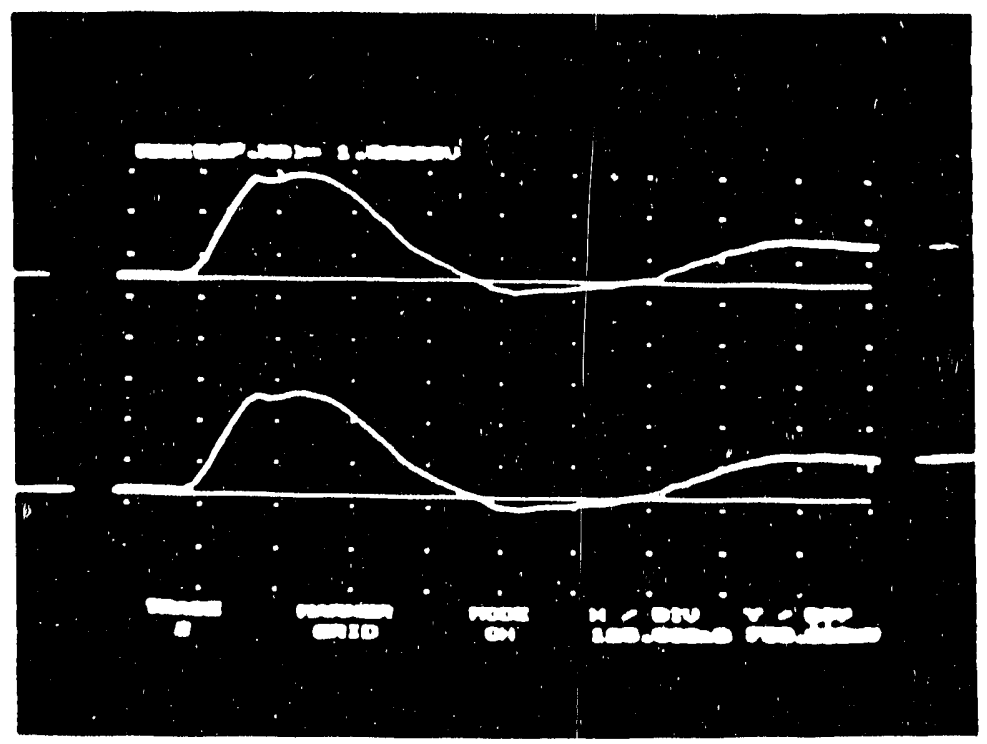

Figure 21: Phase II voltage pulses applied at $80 \%$ of VBD. Upper, lower $14 \mathrm{kV} / \mathrm{div}, 750 \mathrm{~A} / \mathrm{div}$.

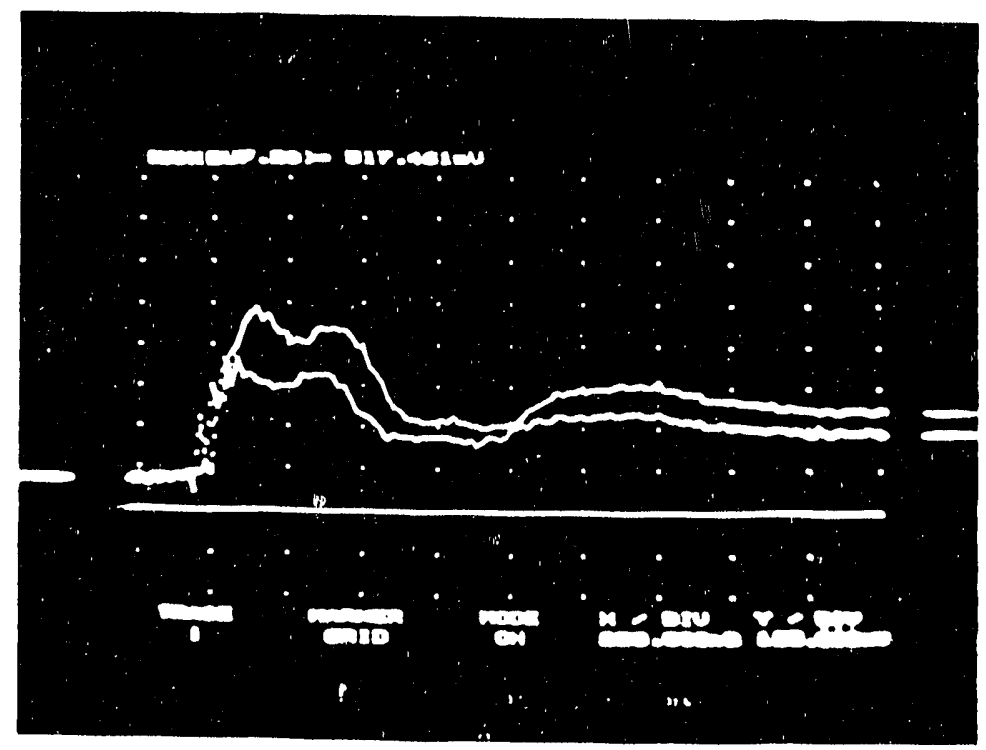

Figure 22: Phase II current pulses applied at $80 \%$ of VBD. Upper, lower 250 ns/div., 750 A/div. 


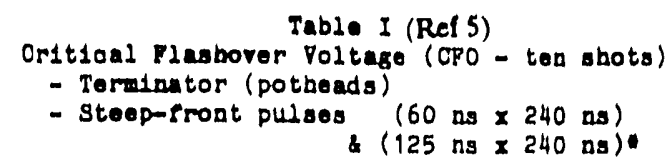

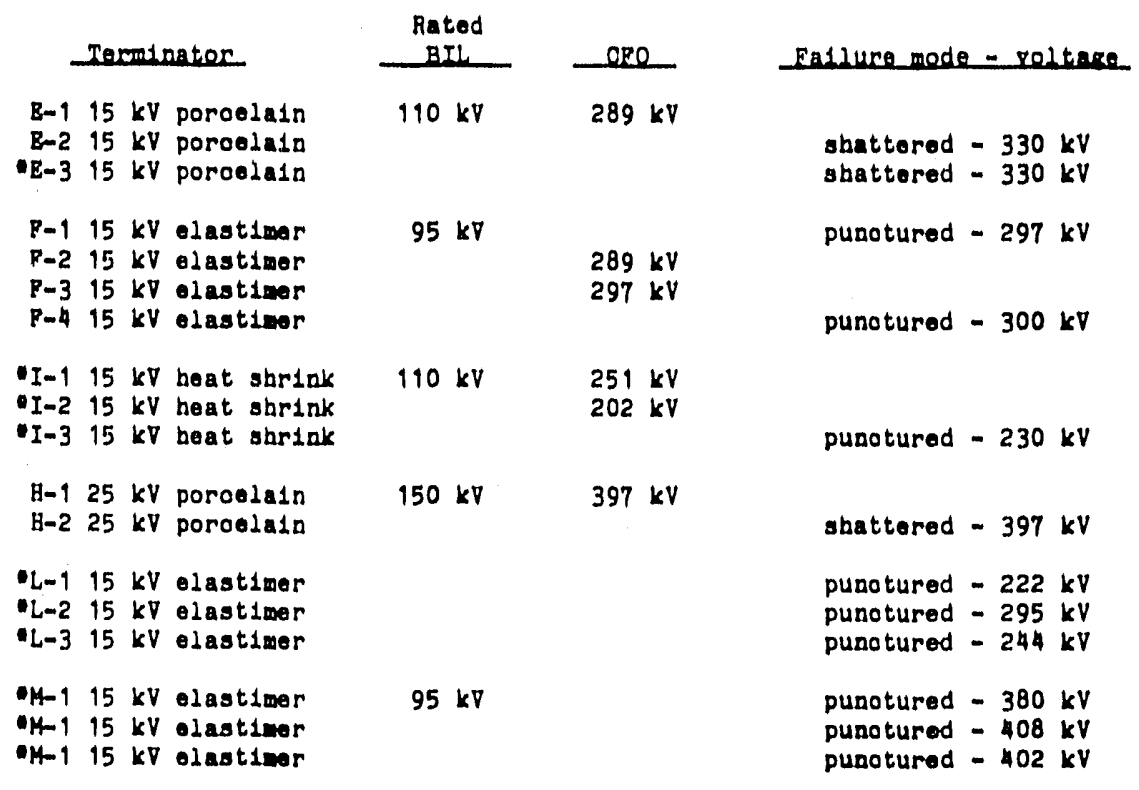

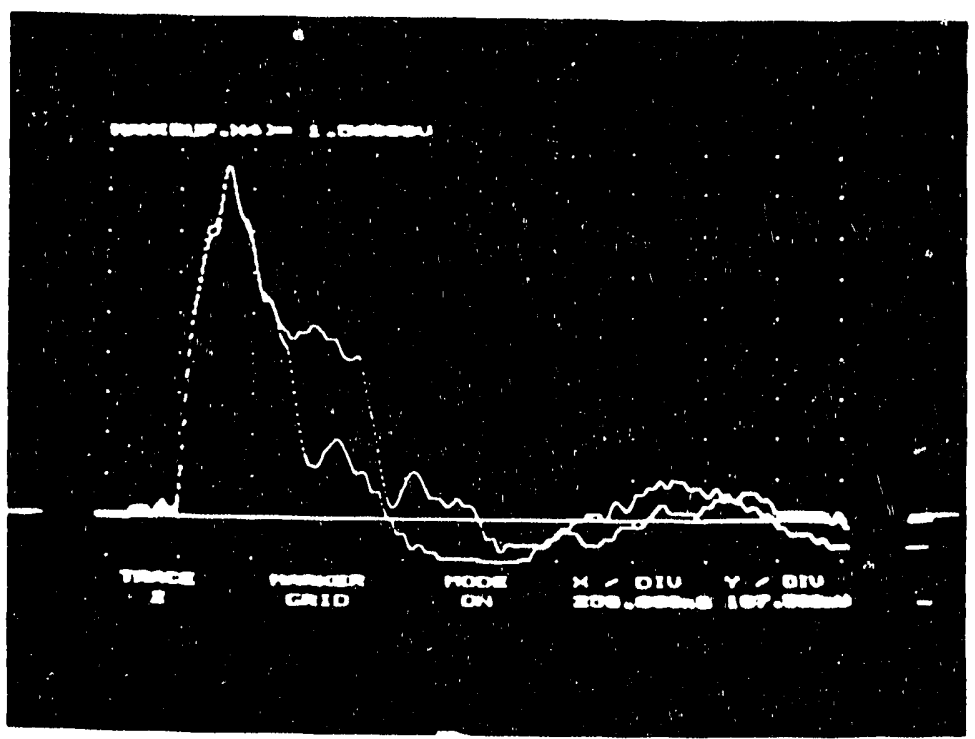

Figure 23:

Terminator L-2 Voltage Waveforms for Flashover and Failure Shots. Top: Flashover, $295 \mathrm{kV}$ peak, $250 \mathrm{~ns} / \mathrm{div}, 35.5 \mathrm{kV} / \mathrm{div}$. Bottom: Failure, $295 \mathrm{kV}$ peak; Failure: $250 \mathrm{~ns} / \mathrm{div}, 35.5 \mathrm{kV} / \mathrm{div}$. 
shown in the voltage waveform of Figure 24. In this way, the time-to-flashover was measured as a function of voltage, for different insulator configurations, as shown in Figure 25. The turn-up of these curves at very short times indicates that the CFO for very short pulses will be considerably higher than for longer pulses. For flashover times of 500 ns, the SFSD CFO $:=2$ to 3 times that of the standard lightning impulse.

In order to quantify the conclusion of the previous paragraph, the two stage Marx circuit shown in Figure 26 was used to generate short duration pulses. Note that this circuit uses two ten-meter, $138 \mathrm{kV}$ cables, which, after the Marx gaps fire, wre stacked so that the net result is a single ten-meter cable with double the characteristic impectance of either cable. This was switched into a matching load, giving the very short voltage pulse plotted in Figure 27. This was used to test a 55-2 pin insulator [21]. The SFSD CFO for a $20 \mathrm{~ns} \times 30 \mathrm{~ns}$ impulse appears to be in the range 900-950 kV, compared with $75 \mathrm{kV}$ for a standard $1.2 \times 50$ lightning pulse.

The 60 meter, $138 \mathrm{kV}$ cable pulser was used to study surface conduction and flashover of wet, contaminated insulators. The test circuit is cliagrammed in Figure 28 and photographed in Figure 29. Figure 30 shows the voltage and current for a dry-clean 55-4 pin insulator. The withstand current is negligible, flashover current does not appear until flashover occurs, and flashover voltage chops rapidly and oscillates at the instant of flashover.

In contrast, the current is noted to rise betore the instant of flashover for wet, contaminated conditions (Figure 31 ), and the voltage after flashover is more strongly damped.

\subsection{Arrester Response to SFSD Impulses}

Three types of SFSD tests were performed on arresters:

1. Rise time and discharge voltage for a variety of MOV and $\mathrm{SiC}$ arresters, using single steep-front pulses.

2. Transition from capacitive to resistive behavior at lower currents, using single steepfront pulses.

3. Recovery of protective characteristics immediately following a high current steep-front pulse, using a delayed second probing pulse.

\subsubsection{Response of Arresters to Steep-Front Pulses [4, 7]}

The arrester tests presented in Reference 4 employed a cable pulser in which the cable consisted of two parallel $35 \mathrm{kV}$ power cables, each $10.7 \mathrm{~m}$ long. This generated the current and voltage waves shown in Figure 32. The duration of the current is about $250 \mathrm{~ns}$, and the voltage pulse, which responds primarily to the inductance of the circuit, is about $125 \mathrm{~ns}$ long. 


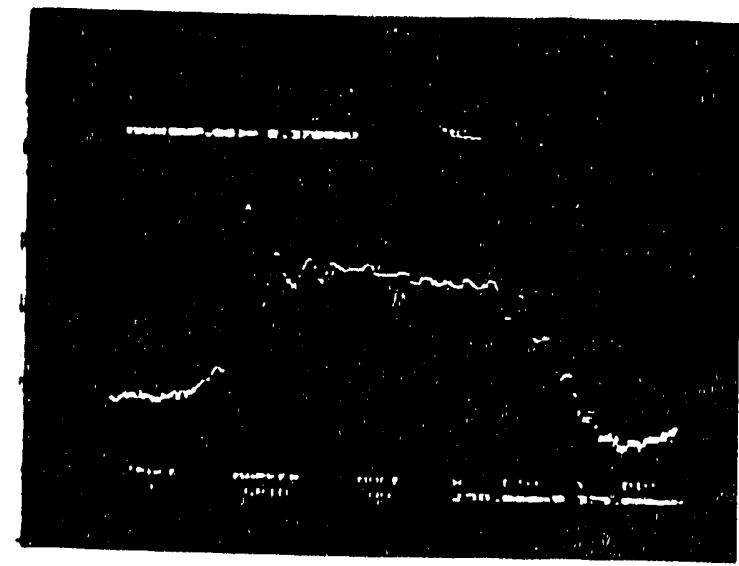

Figure 24: A typical voltage waveshape during insulator testing, $250 \mathrm{~ns} / \mathrm{div}$, $73.2 \mathrm{kV} / \mathrm{div}$. Note the long "tail" time after the SFSD front portion
of the pulse.

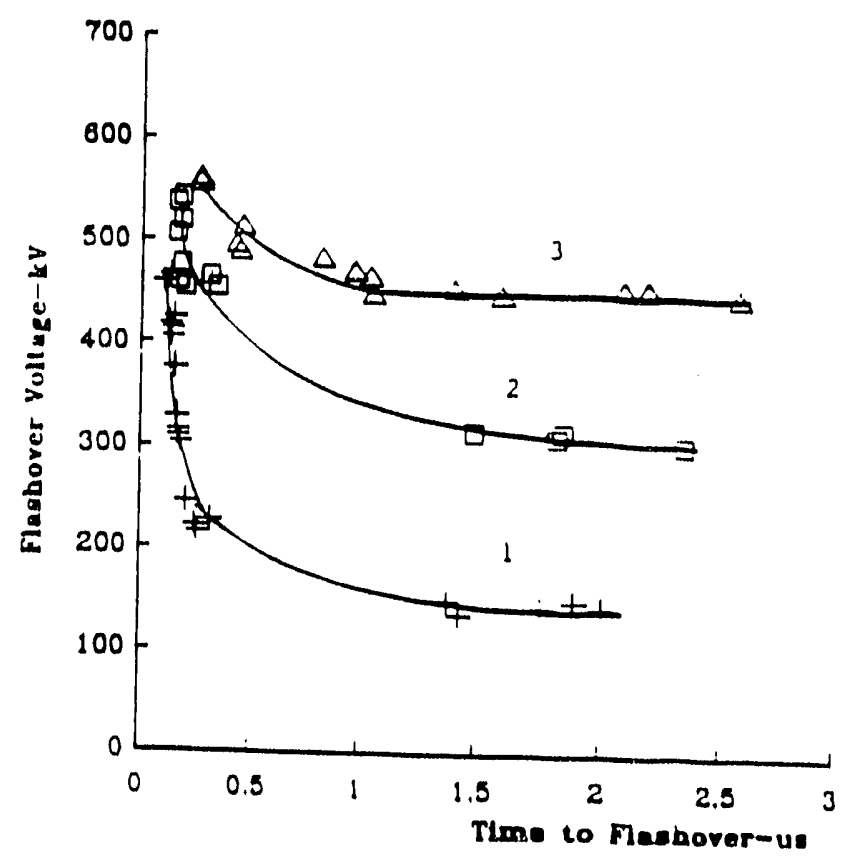

Figure 25:

Plot of time to flashover vs. peak pulse voltage for one, two and three 4-1/4" x 6-1/4" suspension insulators. 


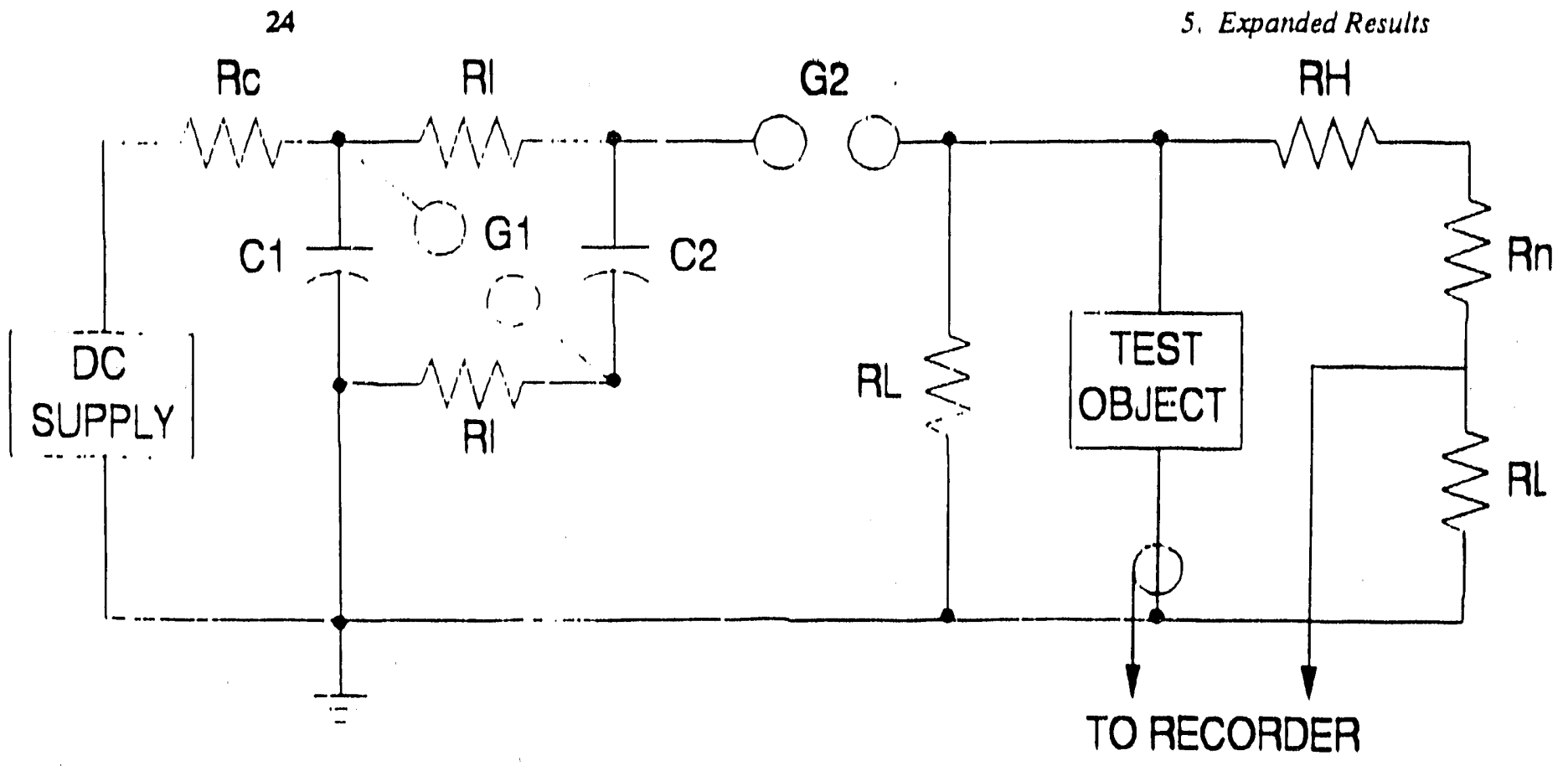

Figure 26: Two stage Marx circuit. $\mathrm{C} 1$ and $\mathrm{C} 2$ are each $10 \mathrm{~m}, 138 \mathrm{kV}$ cable sections; $R I=4,50 \mathrm{k} \Omega$ water resistors;

$R h / R l=3000+400 / 3.11 \Omega$.

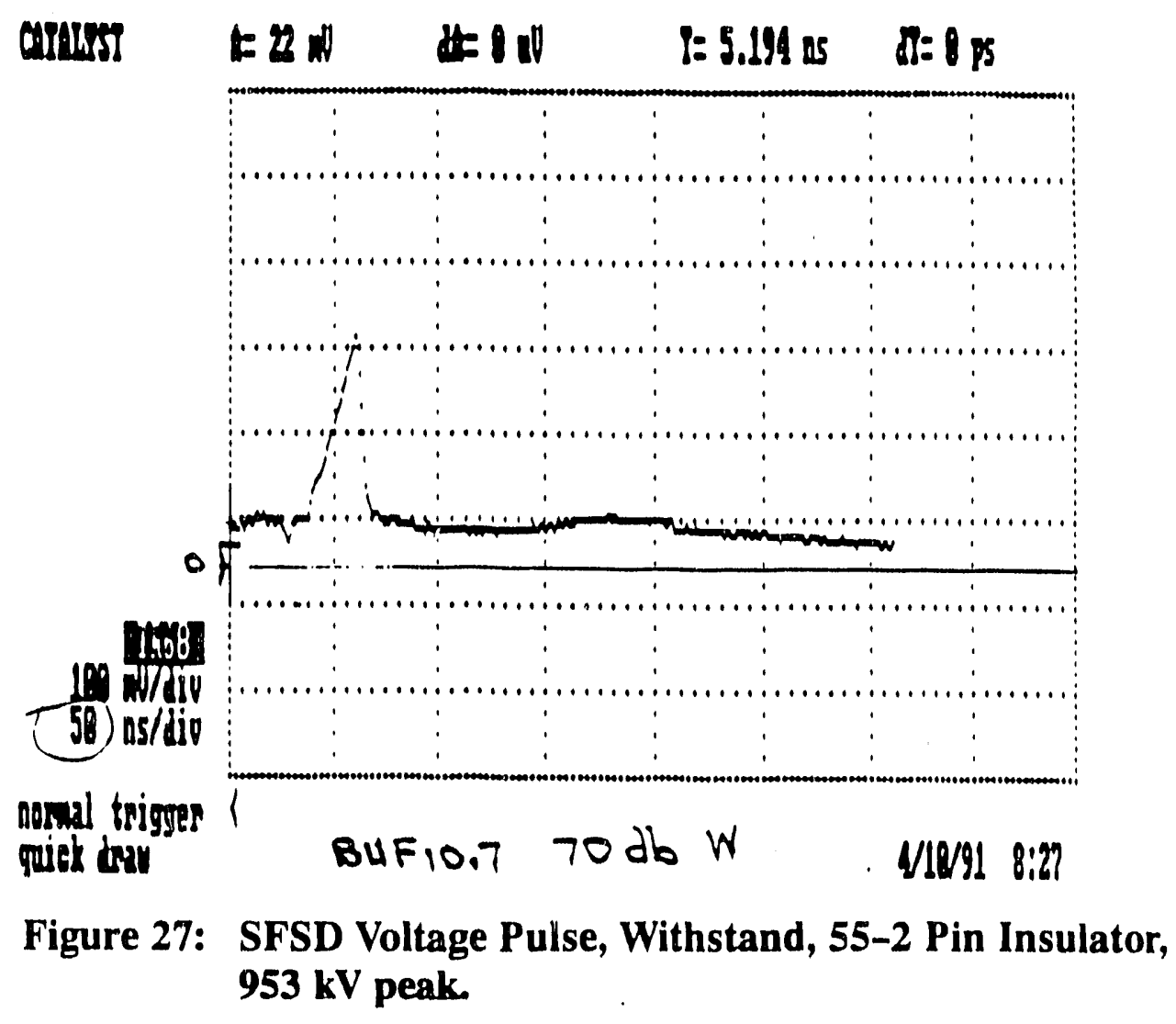




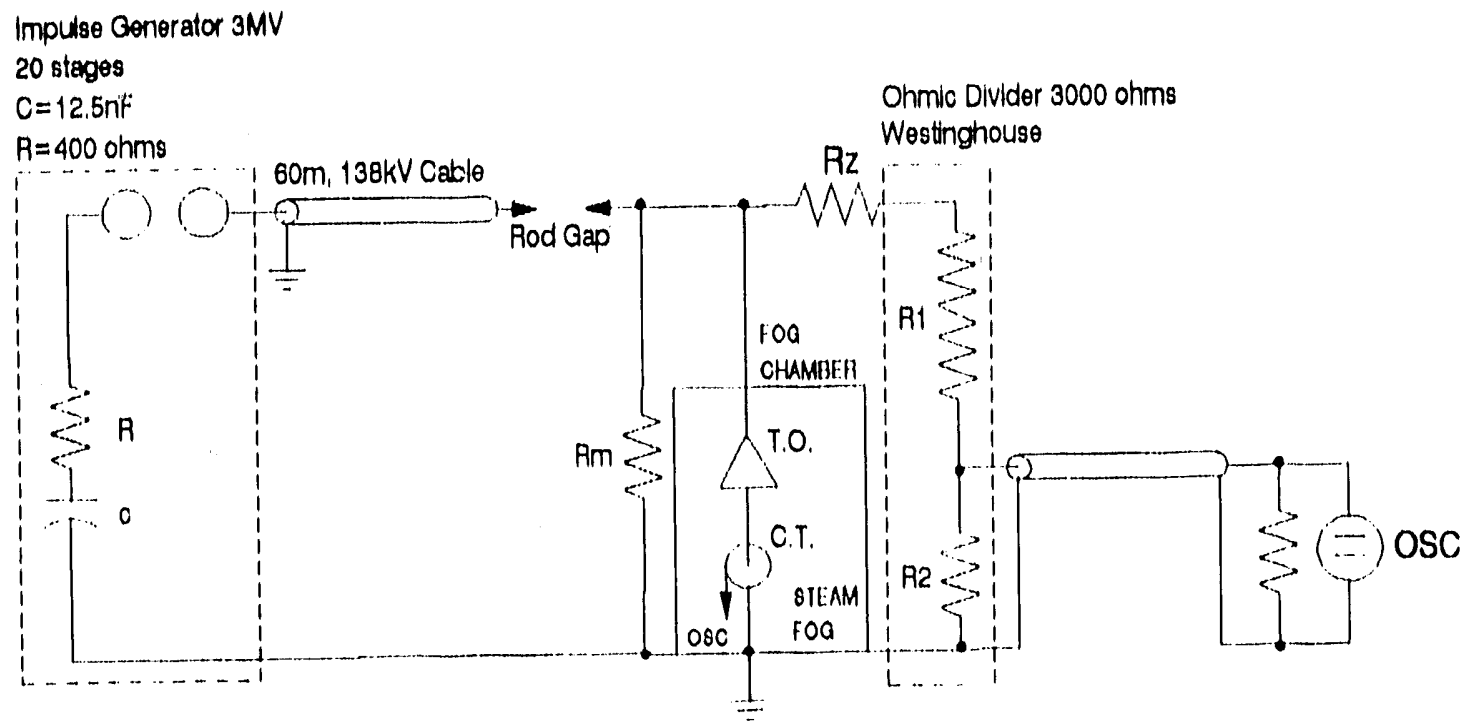

Figure 28: Circuit to Test Insulators in Fog Chamber.

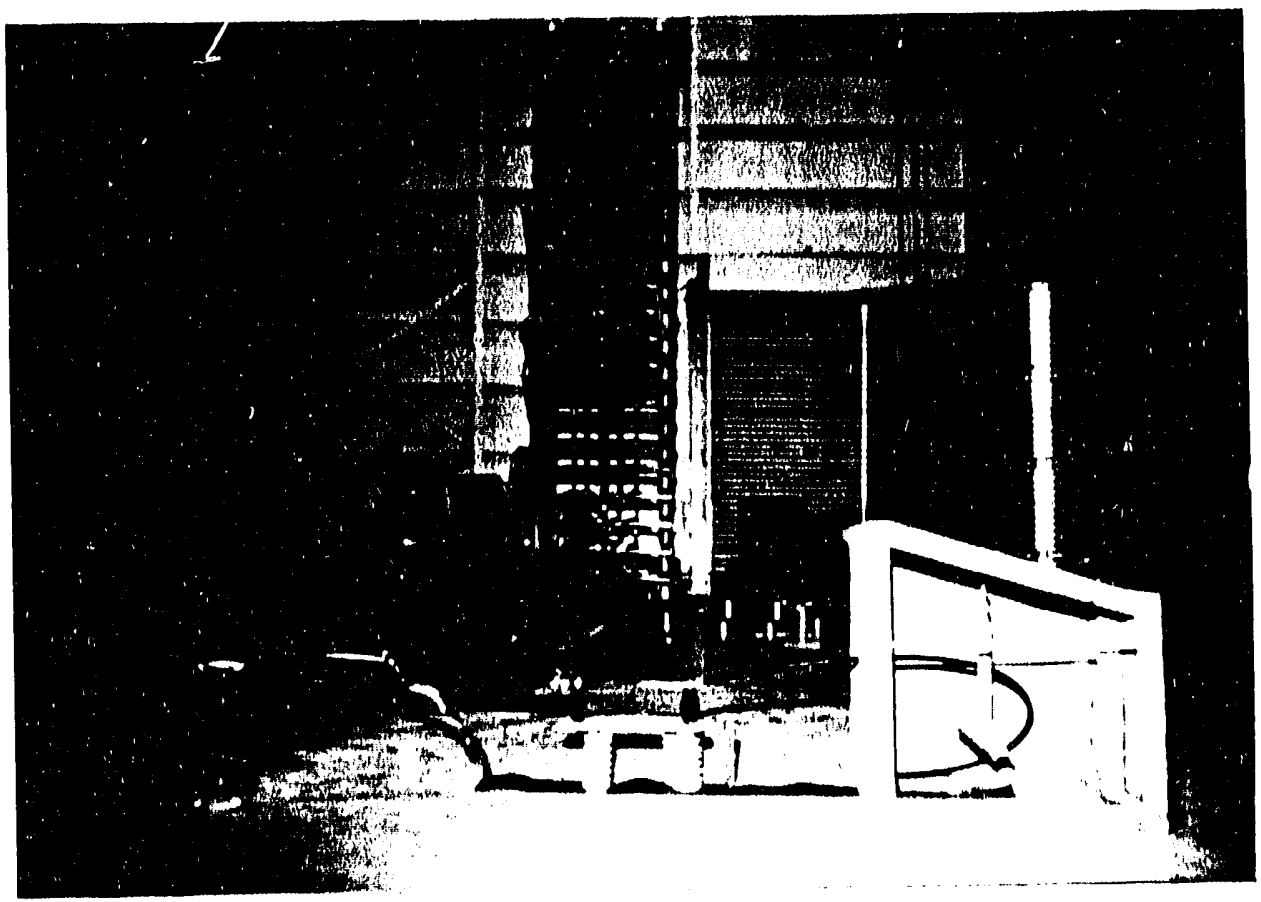

Figure 29: Photograph of test facility with fog chamber to study SFSD response of wet, contaminated insulators. 


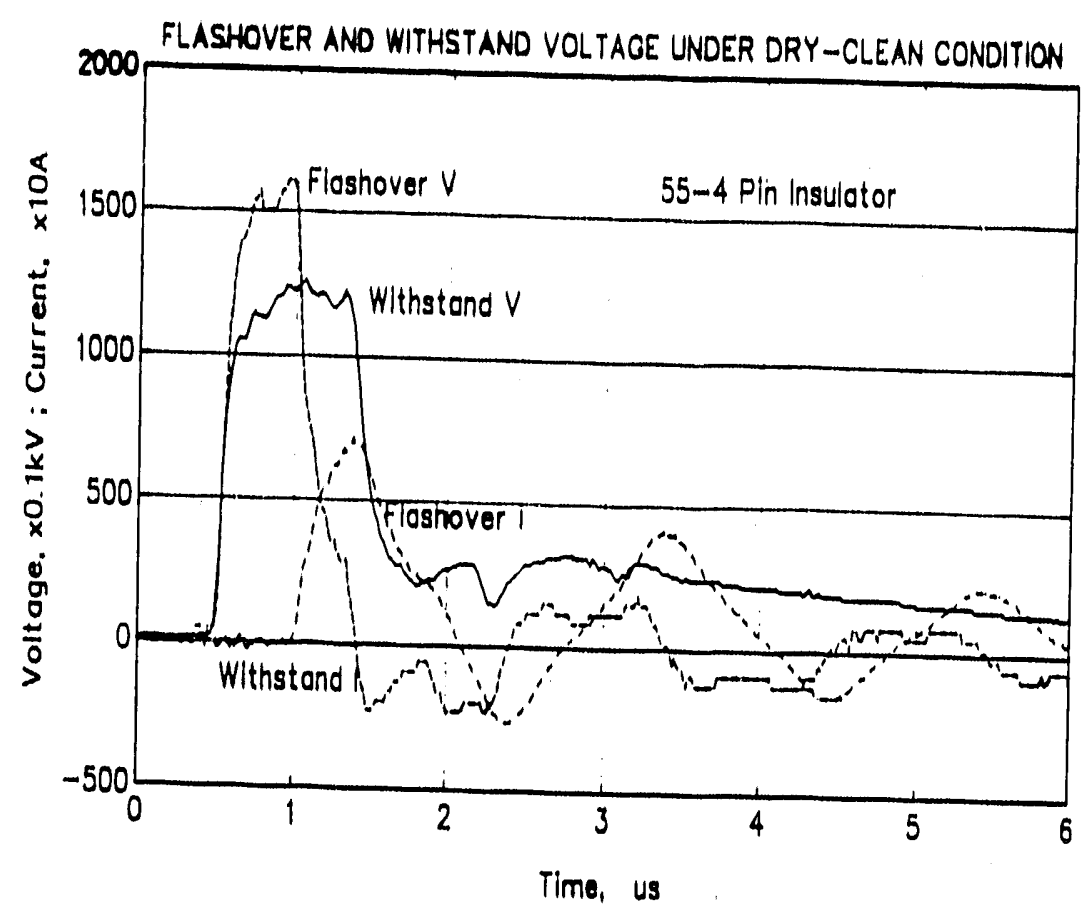

Figure 30: Flashover and Withstand Voltage Under Dry-Clean Conditions.

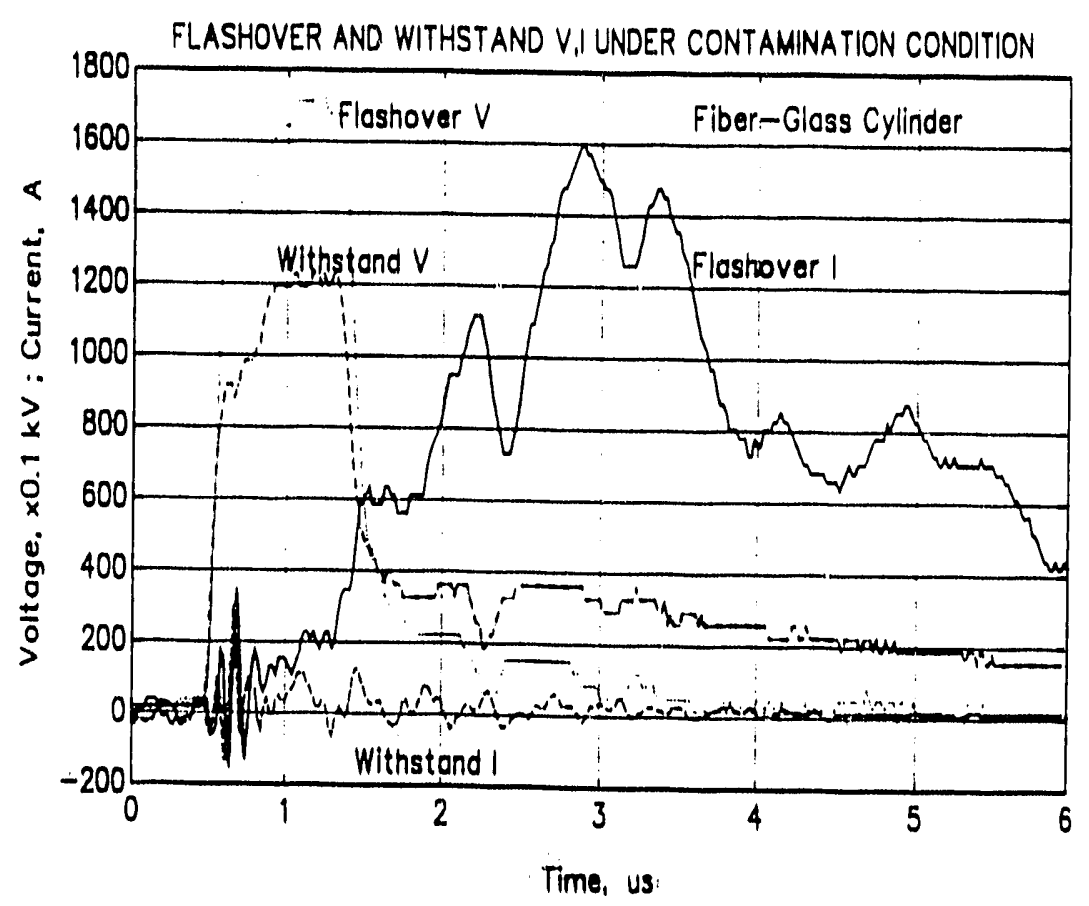

Figure 31: Flashover and Withstand V,I Under Contaminated Conditions. 
In the Reference 7 tests, the cable used in the pulser was an $80 \mathrm{~m}$ section of $138 \mathrm{kV}$ transmission cable. This allowed more reliable high voltage operation and longer pulse time. Typical voltage and current waveshapes are shown in Figures 33 and 34. The voltage still exhibits an inductive spike during the steeply rising portion of the current wave, but then settles to a "residual" voltage, which is representative of the protective (resistive) behavior of the arrester.

In order to explore the rate at which the arrester MOV material was responding to the steep-front input pulse, an aluminum tube was substituted for the arrester, and the voltage across this tube was then subtracted from the voltage measured across the arrester. This would then remove the inductive portion of the arrester voltage waveshape and leave the resistive portion, which is shown in Figure 35. As reported in Reference 7, the arrester MOV block resistance rises in about 60 ns, only slightly slower than the current pulse.

Even with the arrester inductive voltage removed, noise prevents a clear, quantitative evaluation of the MOV material behavior. The MATLAB software is used to remove this noise from the current and residual voltage waveforms [12]. After this is done, the peak voltages and rates of change of current at peak voltage can be accurately measured. The resulting plot (from Reference 12) is sown as Figure 36. Although the slopes of the MOV and $\mathrm{SiC}$ lines are approximately the same as the aluminum tube slope, the residual voltage (at zero $\mathrm{di} / \mathrm{dt}$ ) of the $\mathrm{SiC}$ device is higher than the residual voltage of the MOV arrester.

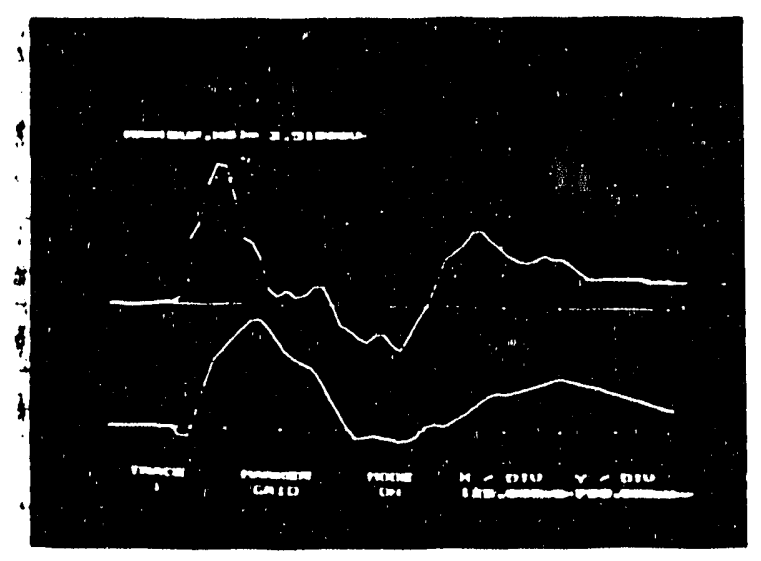

Figure 32: Typical MOV arrester voltage (top) and current waveshapes, 24 inches total arrester lead length, $125 \mathrm{~ns} / \mathrm{div}, 14.2 \mathrm{kV} / \mathrm{div}$, $1.20 \mathrm{kA} / \mathrm{div}, 66.4 \mathrm{kV}$ peak, $4.2 \mathrm{kA}$ peak. 


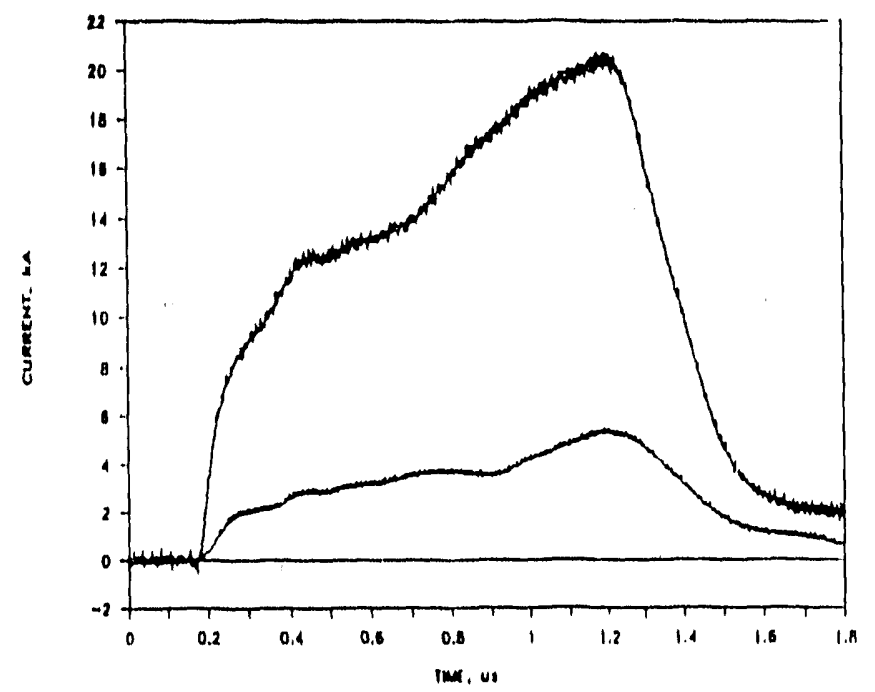

Figure 33: Current waveshapes for the $9 \mathrm{kV}$ MOV arrester at approximately 5 and $20 \mathrm{kA}$ peak.

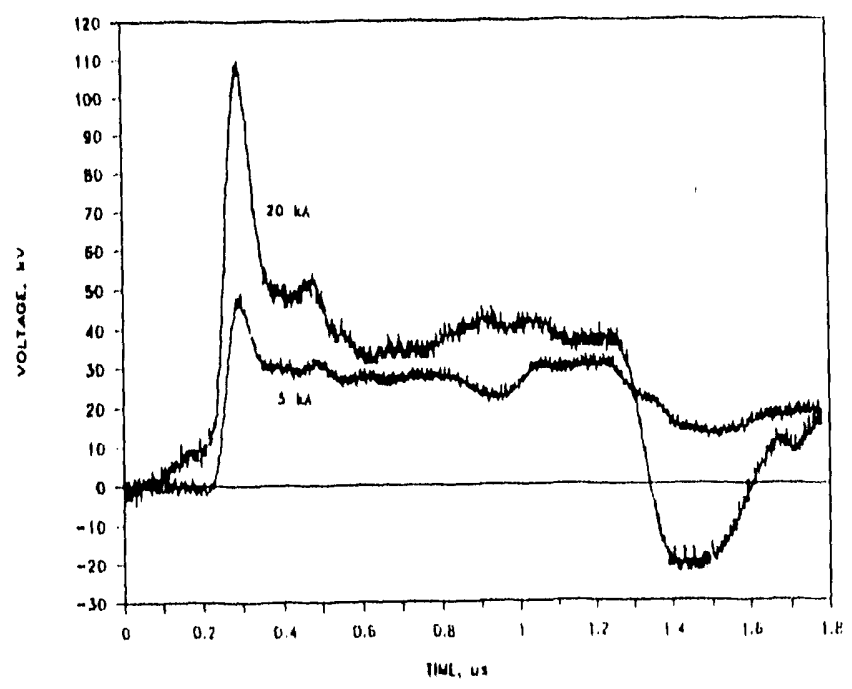

Figure 34: MOV arrester voltages during the $5 \mathrm{kA}$ and $20 \mathrm{kA}$ current pulses shown in Figure 33. 


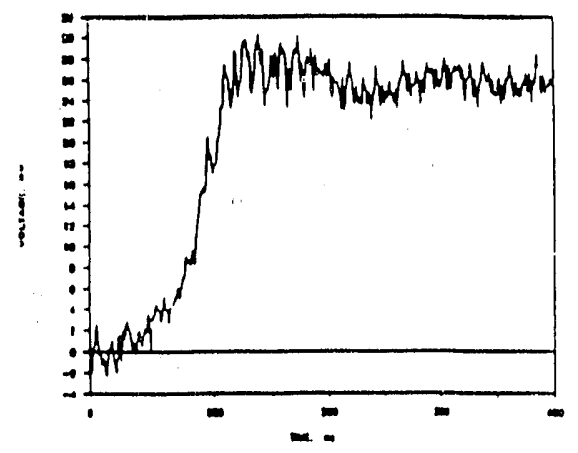

Figure 35: $\quad$ Aluminum tube voltage (extrapolated to $5 \mathrm{kA}$ equivalent peak current subtracted from the $5 \mathrm{kA}$ MOV voltage pulse in Figure 34.

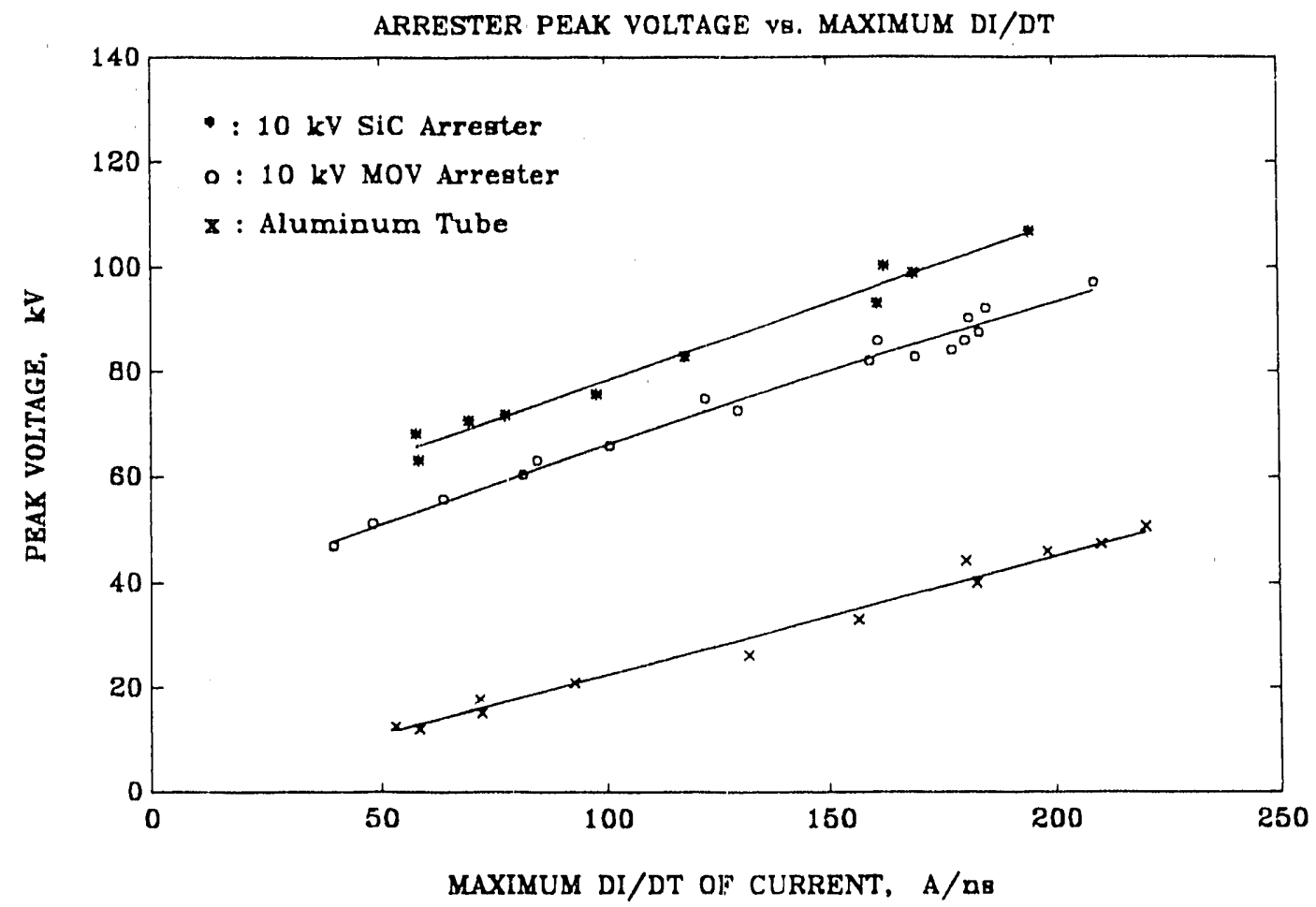

Figure 36: Peak Voltages for $10 \mathrm{kV}$ MOV and SiC Arresters and the Aluminum Tube as a Function of the Maximum Rate of Rise of the Current. 


\subsubsection{Transition of Arresters From Capacitive to Resistive Behavior During Steep-Front Pulses [11]}

In order to fully understand the behavior of MOV arresters during steep-front events, it is important to identify their response during low as well as high current impulses. The tests which are described in Reference 13 had this objective. The same $138 \mathrm{kV}$ cable pulser circuit was used as in the Section 8.1 tests, except that the cable was now only $60 \mathrm{~m}$ long.

Testing involved six MOV arresters, rated 9, 10,15 and $21 \mathrm{kV}$, from three manufacturers. Pulse voltages were varied from low levels, where only capacitive current flowed, up to high enough voltages so that the resistive component of current dominated. Figures 2, 3 and 4 of Reference 13 show typical voltages and currents from low to high current levels.

These figures show that the voltage has a nearly rectangular wave shape, with a steeply - rising front and end. The current exhibits several interesting characteristics:

1. In a certain percentage of cases, for all arresters tested, the start of current flow was delayed for a period of time after the application of voltage, as seen in Figure 37.

2. Thert: is always an initial spike of current, caused by the capacitive arrester reacting to the large $d v / d t$ of the front end of the voltage wave.

3. The conductive current always shows a finite (exponential) rate of rise, as if it were flowing into an inductive circuit. This is probably due to the fact that the arrester circuit does have finite inductance, and also possibly influenced by finite growth time for the MOV material to convert from dielectric to conductive.

The decrease in capacitance with increasing pulse voltage also suggests that the MOV junction regions are widening.

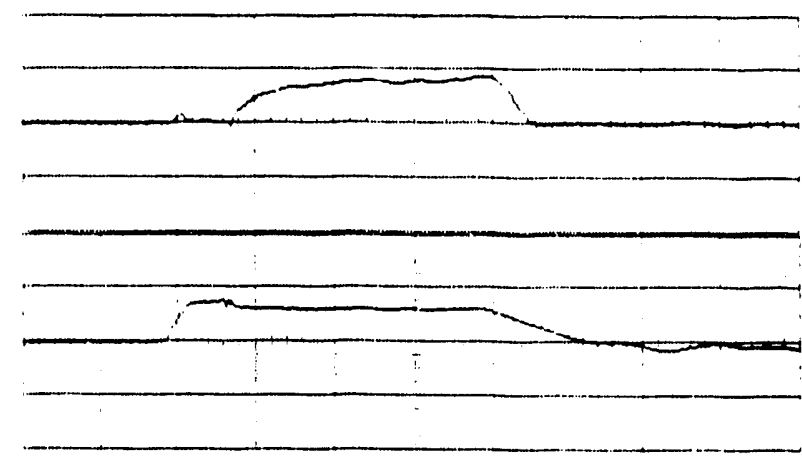

Figure 37: Arrester Voltage and Current

Top: Current, $632 \mathrm{~A} / \mathrm{Div}$

Bottom: Voltage, $33.4 \mathrm{kV} / \mathrm{Div}$

Time: $200 \mathrm{~ns} / \mathrm{Div}$

$10 \mathrm{kV}$ Arrester. 


\subsubsection{Recovery of Arrester Protective Characteristics After a Steep-Front Pulse [8]}

Lightning and switching activity often generate multiple, closely spaced surges. Modine and Wheeler [11] have shown that low voltage MOV varistors have a memory characteristic which can reduce the voltage clamping ability of the unit after an operation. It is therefore important to investigate whether such a process is active and reducing arrester performance in high voltage power arresters. To answer this question, the double pulse circuit shown in Figure 11 was developed. One cable pulser section of this circuit generates the high voltage, high current pulse used in single pulse tests. A second cable pulser, charged by the dc supply, is triggered a controlled time delay after the first pulse. This second pulse delivers current pulses of over a kiloampere and so will give a good indication of the arrester's electrical condition at the chosen delay time. Delays from 20 microseconds to two seconds can be achieved.

Figure 38 shows that, after about .6 milliseconds, the arrester responds as if there had not been a first pulse ("manual"), but at 80 microseconds, the discharge voltage is actually slightly lower. This would indicate that the surge protection is slightly better, but that the arrester is liable to pass higher ac power current.

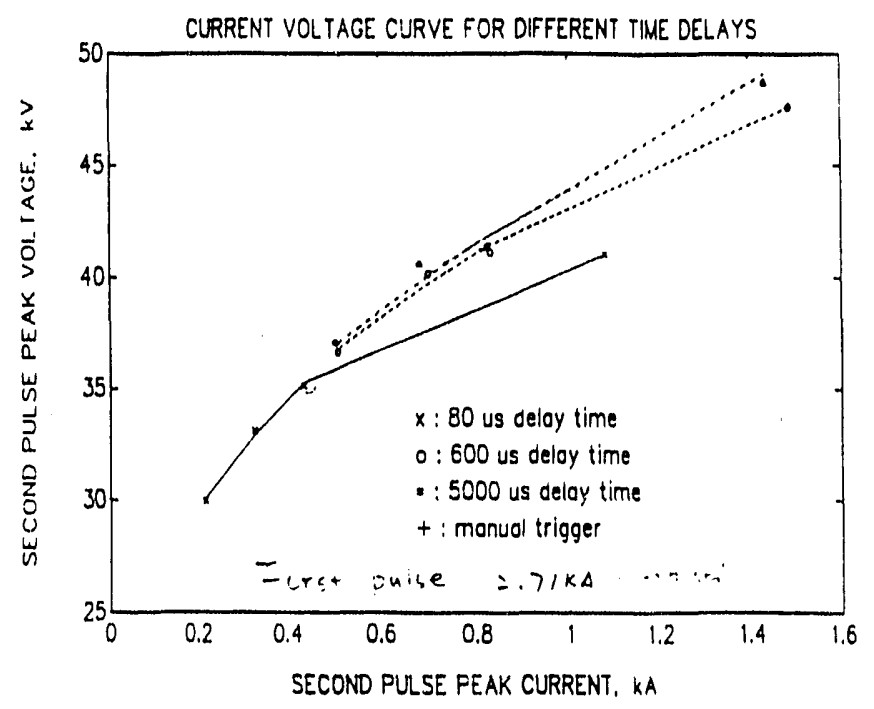

Figure 38: Second Pulse Current-Voltage Characteristics for Four Different Time Delays, First Pulse $=2.71 \mathrm{kA}$. 


\section{REFERENCES}

1. "Generation of Steep-Front Impulses and Measurement of Their Effect on Power Distribution Cable Polyethylene Insulation," David 'L. Kempkes, Master's Thesis, Mississippi State University, December 1987.

2. "The Effect of Steep-Front, Short-Duration Pulses on Polyethylene Cable Insulation," Andre E. Lux, David B. Miller, David L. Kempkes, Proceedings, IEEE Southeastcon'89, April 10-13, 1989.

3. "Pulsed Power Education at Mississippi State University," D. B. Miller, S. Grzybowski, A. L. Libby, Proceedings, IEEE Seventh Pulsed Power Conference, Monterey, California, June 12-14, 1989.

4. "The Effects of Steep-Front, Short-Duration Impulses on Power Distribution Components," David B. Miller, Andre E. Lux, Stanislaw Grzybowski, Paul R. Barnes, IEEE Transactions on Power Delivery, Vol. 5, No. 2, April 1990.

5. "The Effect of Steep-Front, Short-Duration Impulses on Distribution System Components," Andre E. Lux, Master's Thesis, Mississippi State University, August 1989.

6. "Design of Steep-Front Pulsers for Distribution Component Testing," Andre E, Lux, David L. Kempkes, David B. Miller, Proceedings, Sixth International Symposium on High Voltage Engineering, New Orleans, Louisiana, August 28 - September 1, 1989.

7. "The Response of MOV and SiC Arresters to Steep-Front Longer-Duration Pulses," David B. Miller, Hong Bo Fan, Paul R. Barnes, IEEE Transactions on Power Delivery, Vol. 6, No. 2, April 1991.

8. "The Response of MOV Arresters to Repeated Steep-Front Impulses," David B. Miller, Hong Bo Fan, M. Paul Murray, Qing Yu, SEPRI'92 Symposium, November 12-13, 1992, New Orleans.

9. "EMTP, A Powerful Tool for Analyzing Power System Transients," Willis Long, David Cotcher, Dan Ruiu, Philippe Adam, Sang Lee, Rambabu Adapa, IEEE Computer Applications in Power.

10. "Electromagnetic Transients Program (EMTP) Workbook, F. L. Alvarado, R. H. Lasseter, W. F. Long, Electric Power Research Institute Publication EL-4651, September 1986.

11. "Pulse Response Characteristics of ZnO Varistors, " F. A. Modine, R. B. Wheeler, J. Appl. Phys. 67(10), 6560-6566, 15 May 1990.

12. "Measurement Techniques to Reveal Arrester MOV Response During Steep-Front Impulsing," Hongbo Fan and David B. Miller, Proceedings of the 1992 IEEE Southeast Conference, Birmingham, Alabama, April 13-15, 1992.

13. "Transition of MOV Distribution Arresters From Capacitive to Resistive During Steep-Front Impulses," Hongbo Fan and David B. Miller, Proceedings of the 1992 IEEE International Symposium on Electrical Insulation, Baltimore, Maryland, June 7-10, 1992. 


\section{APPENDIX A \\ Accuracy Evaluation and Calibration \\ of Impulse Measurement Tools*}

Before any experimental testing can be attempted, an evaluation of the tools to be used for detecting and measuring experimental data must be made. This was especially important in the acquisition of the data presented in this report. The experimental procedures involve sensing very intricate and subtle changes, and the instruments must be as accurate as possible to have any faith in the acquired results. For this reason, a fairly in-depth presentation of the calibration procedures of all measurement tools used is presented in this chapter. Although these tests were time consuming, it was felt that they were necessary in order to provide quality results.

Before presenting the calibration procedures and results, a list of the measurement and sensing tools used is given below. The items used were:

1. Westinghouse $6000 \Omega$ oil-filled resistive voltage divider

2. $3.44 \Omega$ resistive low voltage shunt

3. $50 \Omega$ terminations

4. Pearson model 110 precision current transformer

5. Fiber-optic transmitter/cable/receiver isolation system

6. $20 \mathrm{~dB}, 10 \mathrm{~dB}$, and $6 \mathrm{~dB} 50 \Omega$ attenuators

7. Biddle Capacitance and Dissipation Factor Bridge

The calibration test procedures and results for all of the instruments listed above are now presented in the order in which they appear.

* Based on Refurence [1] 


\section{Westinghouse Divider}

The Westinghouse voltage divider had to be evaluated in two aspects. First of all, the division ratio of the divider, using the $3.44 \mathrm{ohm}$ low voltage shunt, had to be verified. Also, the unit step response of the divider had to be measured, since it was needed to measure the steeply rising waveforms of the simulation circuits.

The divider ratio was calibrated by use of the sphere gap calibration method. This test basically involved the circuit shown in Figure A.1. The impulse generator was set at five stages, giving an equivalent internal impedance of $50 \mathrm{nF}$ capacitance and $200 \mathrm{ohm}$ resistance. The $6000 \mathrm{ohm}$ divider actually consists of two $3000 \mathrm{ohm}$ pieces connected in series. The $50 \mathrm{~cm}$ sphere gaps were set at 10 $\mathrm{cm}$ spacing according to the given test procedure. First of all, the atmospheric correction factor was calculated from the conditions given above and is shown following Figure A.1.

The flashover voltage of $50 \mathrm{~cm}$ spheres spaced $10 \mathrm{~cm}$ apart at standard temperature and pressure is given as $263 \mathrm{kV}$. Applying the correction factor calculated previously gives:

$$
V=K d V_{0}=.99(203)=200 k V
$$

According to IEEE Std \#4, at this corrected critical flashover voltage, the applied voltage to the divider was $260 \mathrm{kV}$ when subjected to a standard $1.2 \times 50$ microsecond impulse. The test results are shown in Figure A.2.

The waveforms shown in Figure A.2 contain two flashovers and two withstands, and this was considered to be the critical flashover voltage. These shots were taken on the Tektronix 507 oscilloscope, and converting this data into an actual voltage value is shown in the following calculation:

$$
\begin{aligned}
& \text { Divider ratio }=\frac{304+3003+3.305}{3.3051175}=1898.7 \\
& \text { Voltage }=\frac{(2.2 \mathrm{div})(50 \mathrm{~V} / \mathrm{div} .)(1898.7)}{.8}=201.1 \mathrm{kV}
\end{aligned}
$$




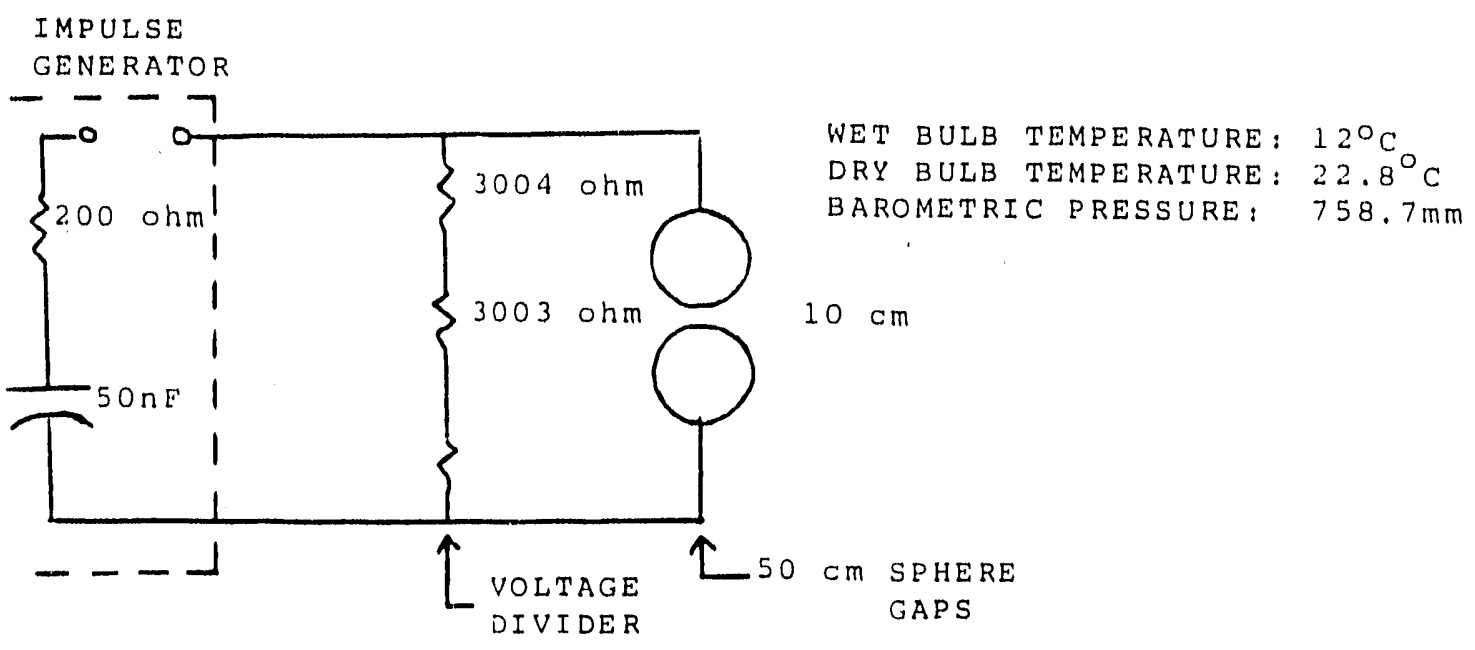

Figure A.1: Voltage Divider Ratio Calibration Circuit

$$
\begin{aligned}
& K d=\frac{P}{P_{0}} \quad \frac{273+t o}{273+t} \\
& =\frac{758.7}{760} \quad \frac{273+20}{273+22.8} \\
& =.99
\end{aligned}
$$


36

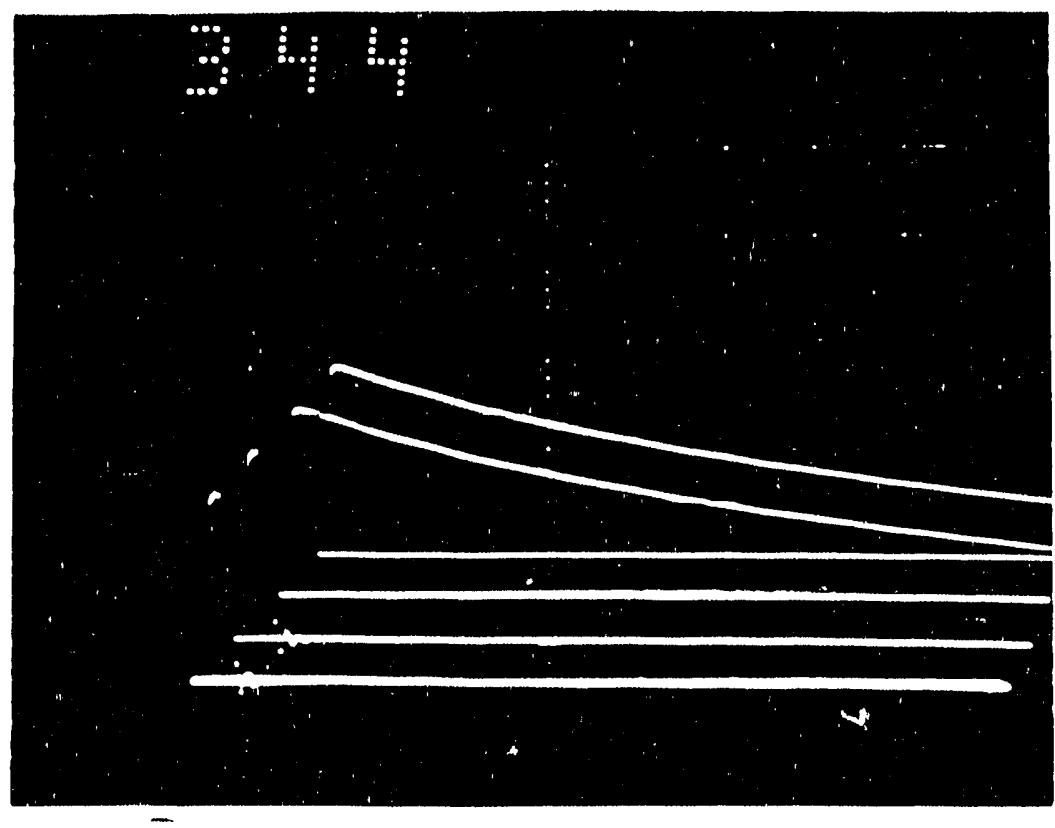

Inpritix

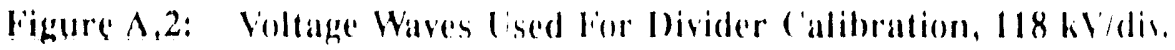

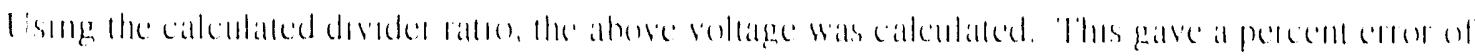

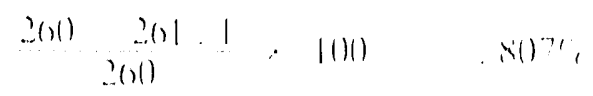

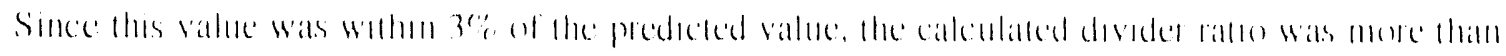
adequalle:

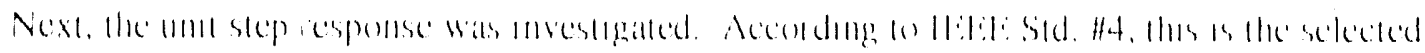

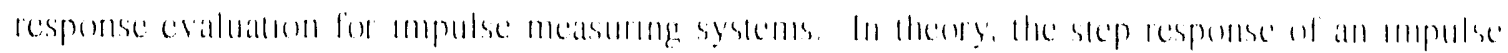

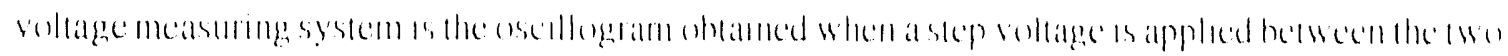

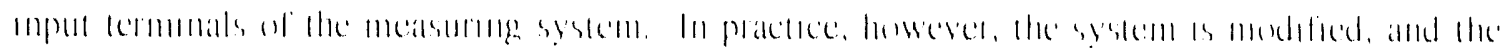

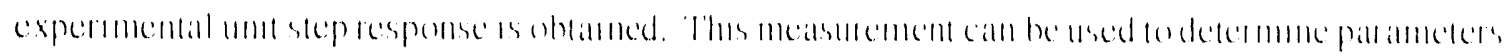

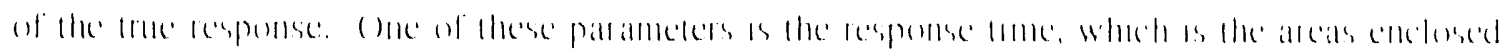

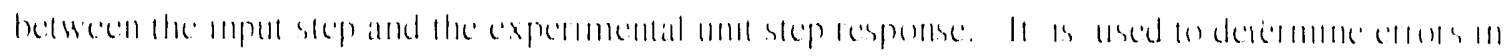

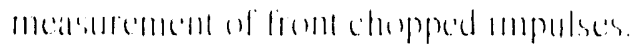


A sample experimental unit step response and response time is shown in Figure A.3. The circuit used to measure the unit step response, which conforms to the procedure outlined in IEEE Std. \#4, is shown in Figure A.4. The Haefly 90 volt step generator was used to provide the input step. It is rated at a 5 nanosecond rise time. The Tektronix 555 dual trace oscilloscope was used to measure both the input and response. Two $75 \mathrm{ohm}$ resistances were placed at the scope to provide matching to the input cables. The $400 \mathrm{ohm}$ resistance was placed in the circuit in order to provide matching to the overhead line. The recorded data is shown in Figure A.5.

By investigating the data, the step response was observed to be about 100 nanoseconds. However, the input step rise was about 40 nanoseconds. If an approximation correction is made:

$$
\text { Responsc Actual }-\left[(100)^{2}-(40)^{2}\right]^{1 / 2}-92 n s
$$

This value is the more accurate step response. The actual step response of the divider is most likely faster than this, as indicated by the test data presented later. 'This is acceptable since the test circuit is quite different from the measurement circuit shown here.

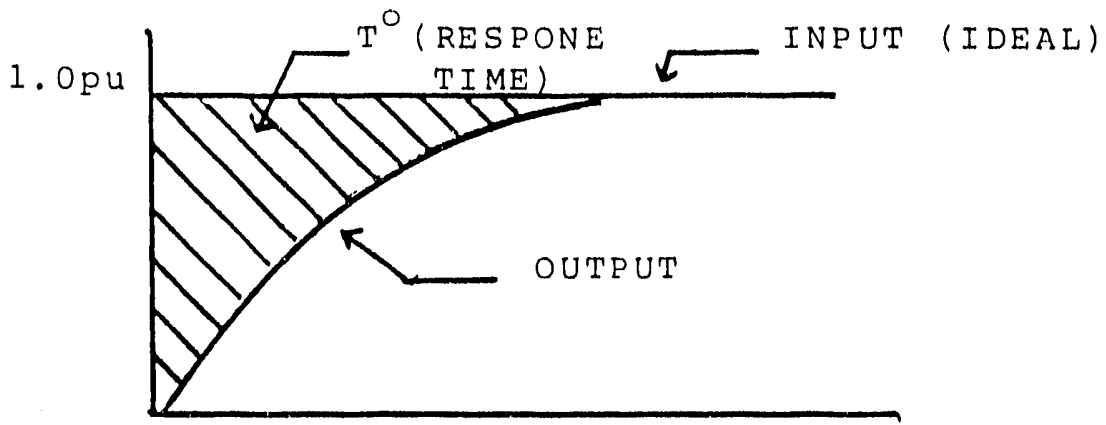

Figure A.3: Experimental Unit Step Response 


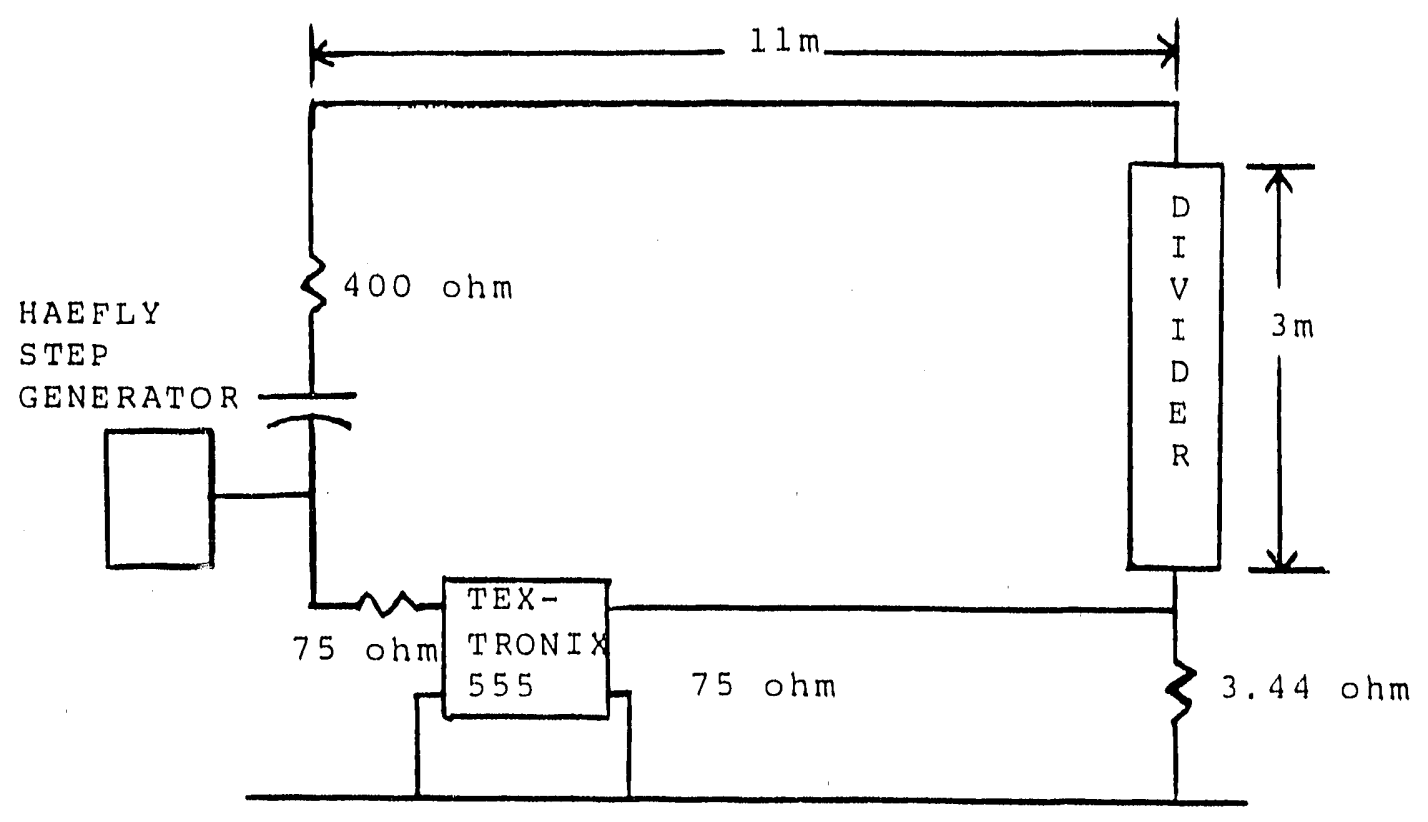

Figure A.4: Step Response Measurement Circuit

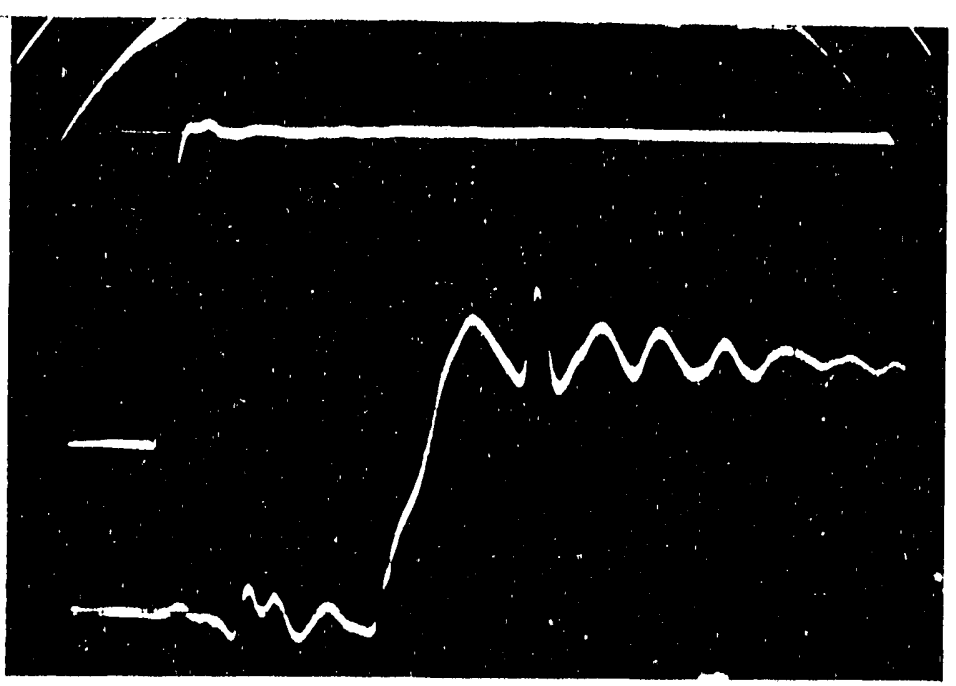

Figure A.5: Step Response Data - 100 ns/div. 


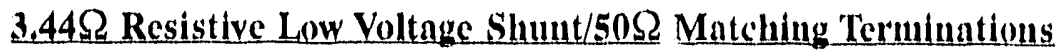

The low voltage shunt used throughout testing was a 3.44 ohm resistive shunt. To check the accuracy of this value, the MSU Automated Network Analyzer was used. This apparatus will measure the s-parameters of an attenuator or termination and print out the results for a range of frequencles. The measurements for all of the attenuators used, as well as the terminations, were made by Dr. Jim Akers. The $3.44 \mathrm{ohm}$ shunt was measured using a $50 \mathrm{ohm}$ reference impedance. The value of the data at $5 \mathrm{MHz}$ was used since this was the closest frequency to the frequency of the impulses used during testing. The calculation of the actual shunt resistance is shown below:

$$
\begin{aligned}
& P=\text { voltage reflection cocfficiont }=\frac{Z-Z O}{Z+Z O}
\end{aligned}
$$

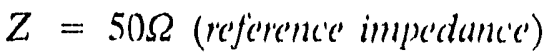

Rearranging the equation yields,

$$
\begin{aligned}
& \frac{Z}{Z O}=\frac{1+P}{1-P} \\
& P=.870 \text { (from data given in Appendix } A, S 11 \text { ) } \\
& \quad \frac{50}{Z O}=\frac{1+.870}{1-.876}=Z O=3.30490 \mathrm{hms}
\end{aligned}
$$

The three $50 \mathrm{ohm}$ matching terminations used were also measured, and their actual impedances were calculated in the same manner as the $3.44 \mathrm{ohm}$ termination shown above. The s-parameters of these terminations labeled 13,14 and 15, are also shown in Appendix $A$, and the resulting impedances are tabulated in Table A.1 for comparison.

\section{Termination Given Impedance Actual Impedance Percent Error}

$\begin{array}{rrrr}\mathrm{S} 1 & 3.44 \Omega & 3.3049 \Omega & 4.1 \\ 13 & 50 \Omega & 49.6 \Omega & .81 \\ 14 & 50 \Omega & 48.81 \Omega & 2.44 \\ 15 & 50 \Omega & 49.5 \Omega & 1.01\end{array}$

Table A,1: Summary of Termination Calibrations 
The three 50 ohm terminations were used for matching of the Pear'son current transformer, the fiber optic system, and the RG-8 coaxial voltage measurement cable. These terminations were very close to their given values: however, the low voltage shunt showed a significant error which gave a notable change in the divider ratio.

\section{Mearson CT/Fiber Optic_System Calibration}

The next measuring tool evaluated was the current measuring system. This system was actually made up of several components: the Pearson current-transformer, the fiber optic isolation system, $50 \mathrm{ohm}$ attenuators, and the $50 \mathrm{ohm}$ terminations mentioned previously. The calibration of the attenuators is explained later so the current transformer and fiber optic system will be concentrated on here.

The calibration process was performed by a comparative method. Two Pearson 110 current-transformers were connected in the circuit shown in Figure A.6. One CT signal was fed into a RG-8 coaxial cable, and the other was fed into the fiber optic system. Both of these signals were examined on the Data 6000 digital oscilloscope for several impulse shots at different voltages. The data taken was examined and calculations were made to determine the accuracy of the system. The attenuator multipliers used were the actual values that were calculated on the s-parameter analyzer. Impulse voltage shots were applied at generator charging voltages of $500 \mathrm{kV}$ and $250 \mathrm{kV}$. The currents through the fiber optic system and the coaxial cable are shown in Figure A.7 for a $250 \mathrm{kV}$ input voltage, and a sample of the $250 \mathrm{kV}$ voltage waveform is shown in Figure A.8. The top current waveform was through the fiber optic system, and the bottom waveform was through the coaxial cable.

The current measured via the coaxial cable was $11.50 \mathrm{~A}$. Using the measured voltage of $119 \mathrm{kV}$, and the known circuit resistance of 120 ohms, the current is estimated at $119 \times 10^{3} / 120=993 \mathrm{~A}$, so this value is reasonable.

The fiber optic multiplier was calculated in two ways. First, using the calculated current from the coaxial cable circuit, the fiber optic multiplier was calculated. Secondly, the two current waveforms were integrated, as shown in Figure A.9, and their integral values were 


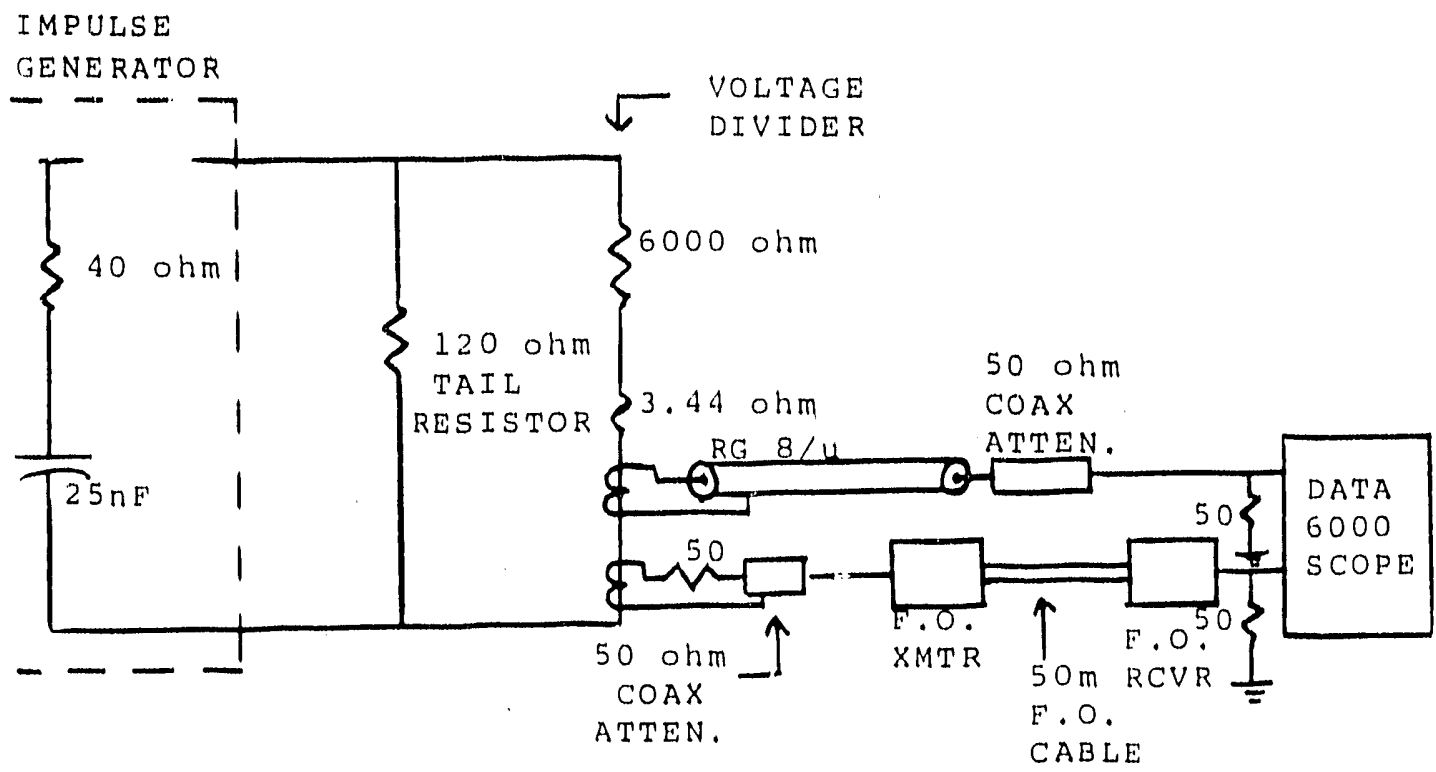

Figure A.6: Fiber Optic System/Pearson CT Calibration Circuit

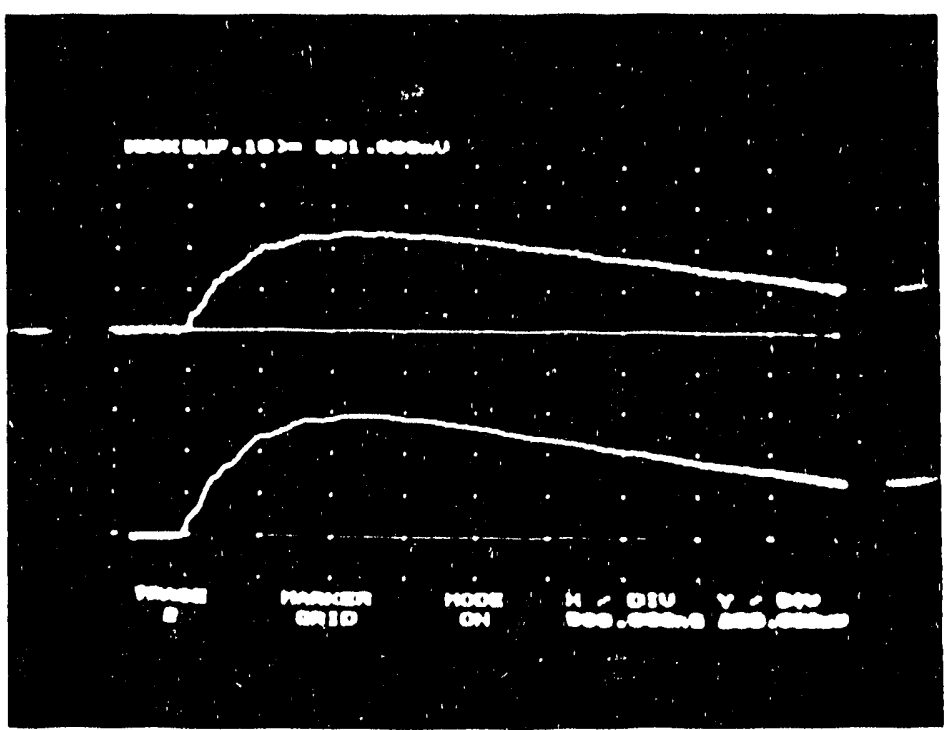

Figure A.7: Calibration Currents Taken at $250 \mathrm{kV}$ Input Voltage. $500 \mathrm{~ns} / \mathrm{div}$. Trace 1: $\quad 51.94 \times$ FOC multiplier A/div.

Trace 2: $402 \mathrm{~A} / \mathrm{div}$. 


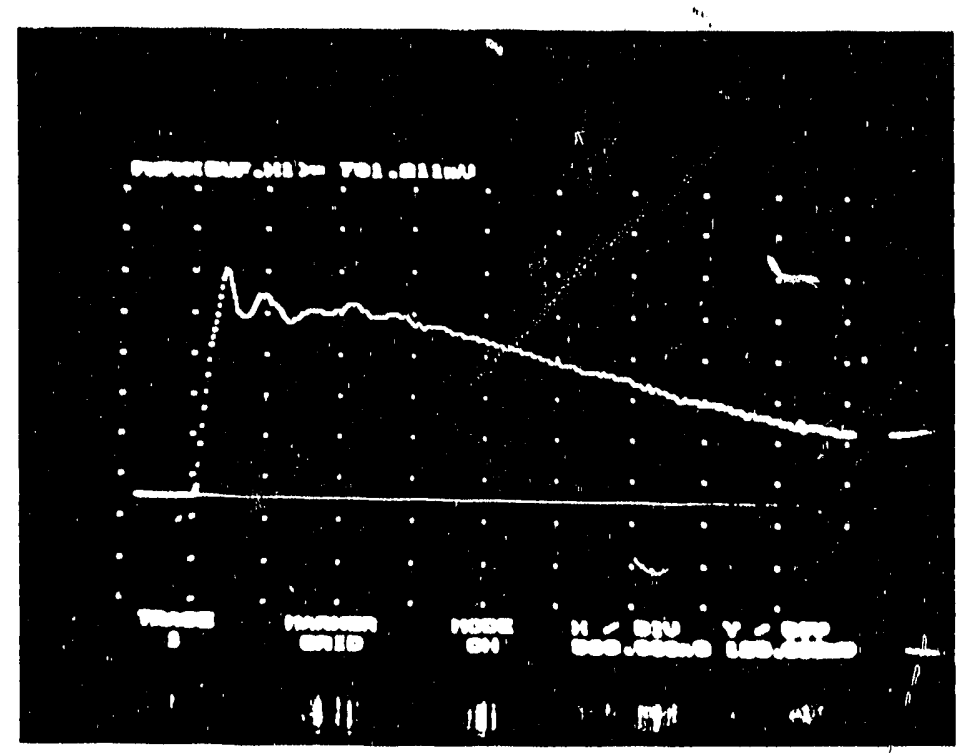

Figure A.8: Voltage Waveform at $250 \mathrm{kV}$ Charge Voltage. $500 \mathrm{~ns} / \mathrm{div}, 19.1 \mathrm{kV} / \mathrm{div}$.

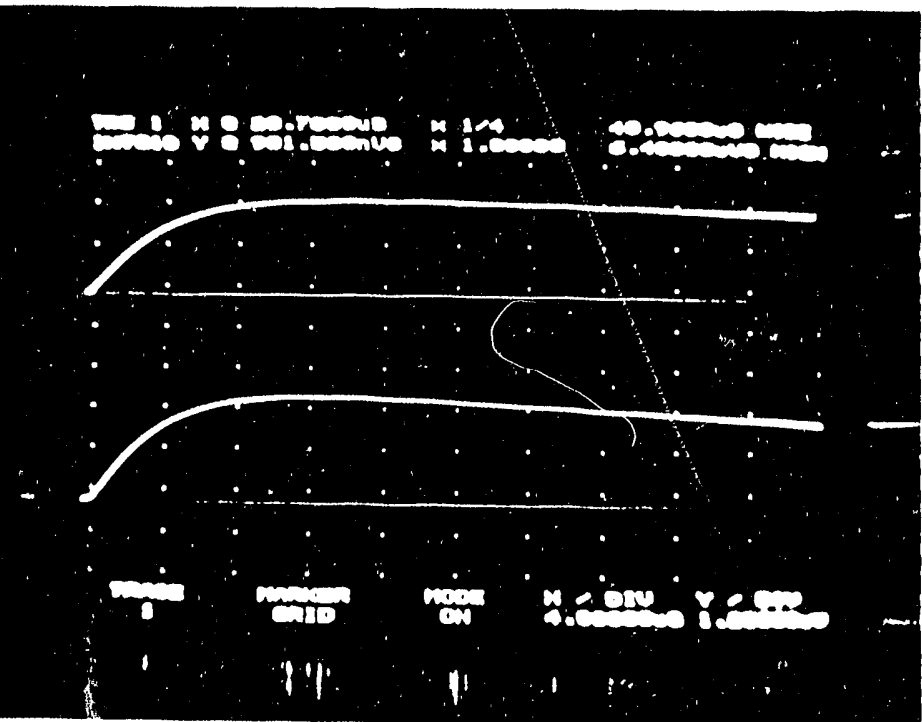

Figure A.9: Integration of Current Shots Taken at $250 \mathrm{kV}$ Charge Voltage. 
used to calculate the fiber optic system gain. These two calculations are shown below for comparison.

Current through coaxial cable $=1150 \mathrm{~A}$

Current through fiber optic system $=(2.33 \mathrm{div})(51.94 \mathrm{~A} / \mathrm{div}$.

(FOC multiplier)

$$
\begin{array}{ll}
\text { Multiplier }=\frac{1150}{[(2.3272)(51.94)]} & \\
\text { Integral of coaxial cable current } & =2.51 \mathrm{uVs}+(40.96 \mathrm{uV})(.032 \mathrm{~s}) \\
& =(3.81 \mathrm{uVs})(2)(10)(80.35) \\
& =6.14 \mathrm{mC} \\
& =2.59 \mathrm{uVs}+(40.96 \mathrm{uV})(.01 \mathrm{~s}) \\
& =(3.008 \mathrm{uVs})(2)(10)(10.39) \\
\text { Integral of FOC current } & \text { (FOC mult) } \\
& =.6249 \mathrm{mC} \times \text { FOC multiplier }
\end{array}
$$

Multiplier $=\frac{0.14}{.6249}=9.82$

Also, the accuracy of the Pearson CT can be checked. The recovered charge from the integral calculation above is $6.14 \mathrm{mC}$. The initial generator charge is easily calculated by:

$\mathrm{q}: \mathrm{CV}$

$q=\left(25 \times 10^{9}\right)\left(2.50 \times 10^{3}\right)=6.25 \mathrm{mC}$

percent $\mathrm{crror}=1.76 \%$

Similar calculations were done for the shots taken at $500 \mathrm{kV}$ inpl'i voltage. The current shots and integrations of these currents are shown in Figures A.10 and A.11, respectively. The results of these calculations and the ones shown previously are summarized in Table A.2 below.

$\begin{array}{cccccc}\begin{array}{c}\text { Coax } \\ \text { Current }\end{array} & \begin{array}{c}\text { FOC } \\ \text { Mult. }\end{array} & \begin{array}{c}\text { Coax } \\ \text { Charge }\end{array} & \begin{array}{c}\text { FOC } \\ \text { Mult. }\end{array} & \begin{array}{c}\text { Input } \\ \text { Charge }\end{array} & \begin{array}{c}\% \\ \text { Error }\end{array} \\ 1150 \mathrm{~A} & 9.51 & 6.1382 \mathrm{mC} & 9.82 & 6.25 \mathrm{mC} & 1.79 \% \\ 2316 \mathrm{~A} & 8.92 & 12.35 \mathrm{mC} & 9.182 & 12.5 \mathrm{mC} & 1.2 \%\end{array}$

Table A.2: Results of Fiber Optic Calibration and Pearson CT Calib ratior: 


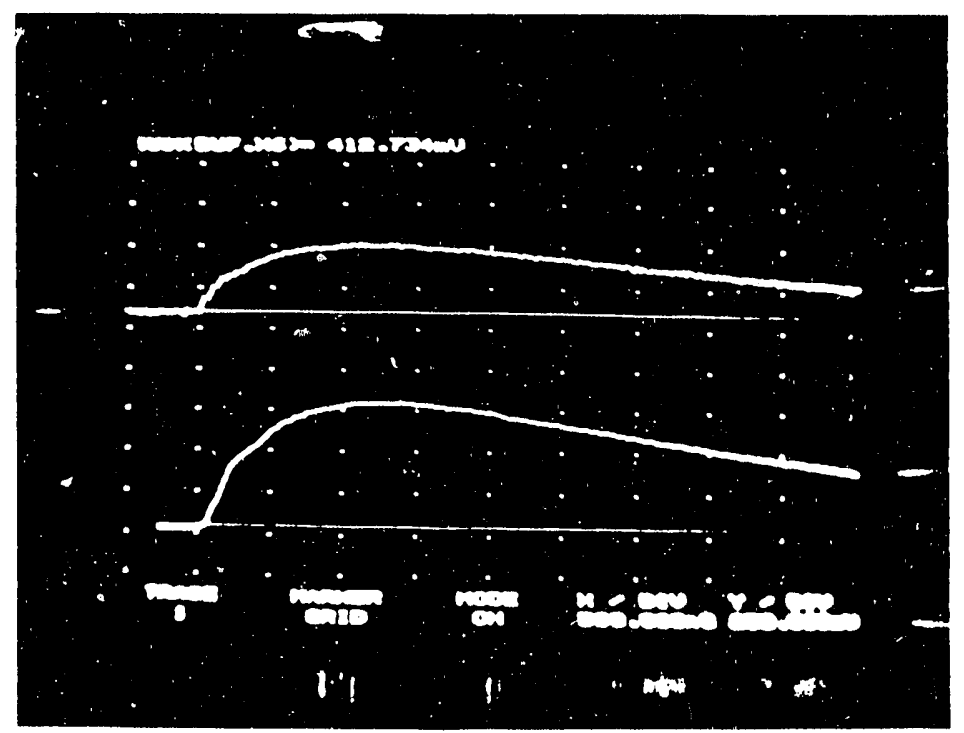

Figure A.10: Calibration Currents Taken at $500 \mathrm{kV}$ Input Voltage. $500 \mathrm{~ns} / \mathrm{div}$. Trace 1: $157.21 \times$ FOC Multiplier A/div.

Trace 2: $778 \mathrm{~A} /$ div. $(.25 \mathrm{~V} / \mathrm{div})$

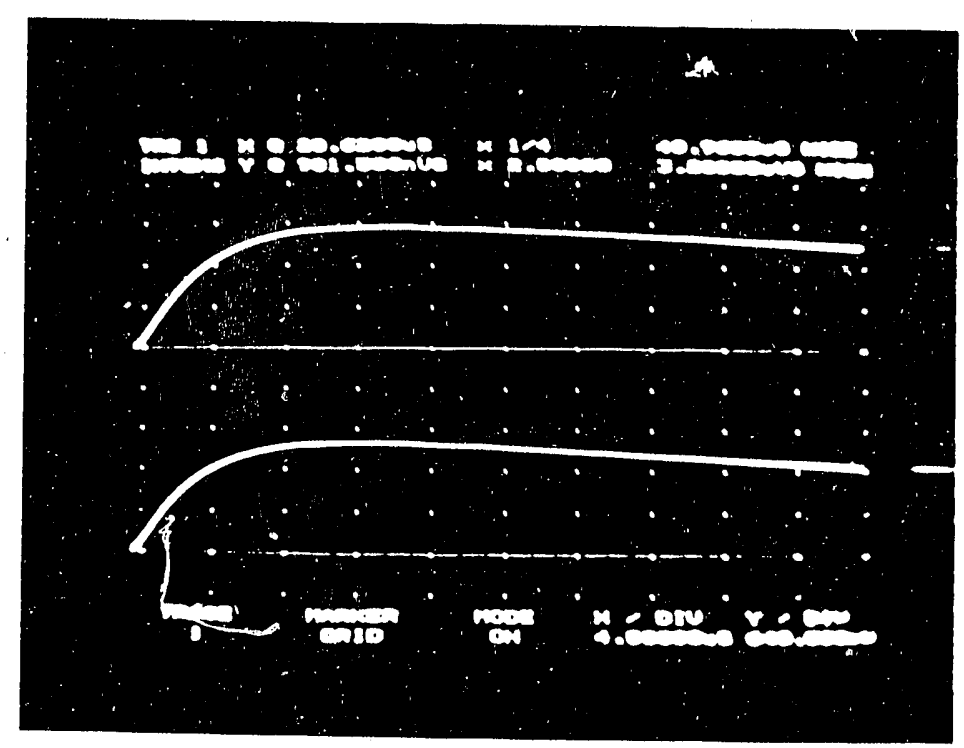

Figure A.11: Integration of Current Shots Taken at $500 \mathrm{kV}$ Charge Voltage 
From the data shown above, several conclusions can be drawn. First of all, by examining the recovered charge from the measured coaxial current, the Pearson CT showed a high degree of accuracy with more than $98 \%$ of the input charge recovered. Secondly, it is obvious that the calculated fiber optic system gain from the data above shows some variations. For the $250 \mathrm{kV}$ test data, the fiber optic system multiplier was found to be 9.51 from the current calculation and 9.82 from the current integration calculation. For the $500 \mathrm{kV}$ test data, the fiber optic system multiplier was found to be 8.92 from the current calculation and 9.182 from the current integration calculation. However, even though these variations seem significant, they can be attributed to minor measurement errors. A slight calculation error of the measured current could cause such variations. Also, since these values average at about 9.4 , this system gain could be used and reasonable accuracy could be expected.

\section{Attenuator Calibration}

The attenuators used during testing were calibrated basically the same way as the $50 \mathrm{ohm}$ matching terminations. Again, the MSU Automated Network Analyzer was employed to measure the s-parameters of the attenuators, and this was done for each of the attenuators used in the testing procedure. The data printouts of these attenuators are also given in Appendix A. To give a summary, Table A.3 gives the actual values of attenuation obtained as well as the given value and attenuator number. Once these measurements were made, the actual attenuator multipliers were used throughout testing.

$\begin{array}{cccc}\text { Attenuator } & \begin{array}{c}\text { Given } \\ \text { Value }(\mathbf{d B})\end{array} & \begin{array}{c}\text { Actual } \\ \text { Value (dB) }\end{array} & \begin{array}{c}\text { Percent } \\ \text { Error }\end{array} \\ \text { \#4 } & & & \\ \# 5 & 20 & 19.46 & 2.8 \\ \# 6 & 3 & 2.75 & 9.1 \\ \# 7 & 6 & 5.75 & 4.35 \\ \# 9 & 10 & 9.61 & 4.1 \\ \# 12 & 20 & 20.33 & 1.62 \\ & 20 & 18.65 & 7.24\end{array}$

Table A.3: Results of Attenuator Calibration 


\section{Biddle Bridge}

Last, the Biddle Capacitance and Dissipation Factor Bridge was calibrated. To accomplish this, the Hartmann and Braun Standard gas capacitor, serial number 6712832, was considered a constant and measured by the Biddle Bridge. The bridge has several measuring circuits, and the UST- 3 circuit was used here and throughout testing. This circuit is shown in Figure A.12. The standard capacitor was connected as the specimen in the figure shown below.

The results of the measurement are shown in Table A.4 below. The Biddle Bridge gave good measurements, although it is not precise enough to measure the extremely low dissipation factor of the standard capacitor.

\begin{tabular}{llc}
$\begin{array}{c}\text { Hartmann \& Braun Capacitor } \\
\text { Standards }\end{array}$ & \multicolumn{1}{c}{$\begin{array}{c}\text { Biddle Bridge } \\
\text { Measurements }\end{array}$} & $\begin{array}{c}\text { Percent } \\
\text { Error }\end{array}$ \\
$\begin{array}{l}\mathrm{C}=49.57 \mathrm{pF} @ 20^{\circ} \mathrm{C} \\
\text { and gas fill of } 14 \mathrm{kp} / \mathrm{cm}^{2}\end{array}$ & $\begin{array}{l}\mathrm{C}=50.34 \mathrm{pF} @ 23^{\circ} \mathrm{C} \text { and gas } \\
\text { fill of } 14.3 \mathrm{kp} / \mathrm{cm}^{2}\end{array}$ & $1.6 \%$ \\
$\mathrm{DF}=.000001$ & $\begin{array}{l}\mathrm{DF}<.00001 \\
\text { (measurement limit of bridge) }\end{array}$ &
\end{tabular}

Table A.4: Biddle Bridge Calibration Results

The above and all measurements were made at 8600 volts, the approximate line-to-neutral voltage of the cable used during testing. 


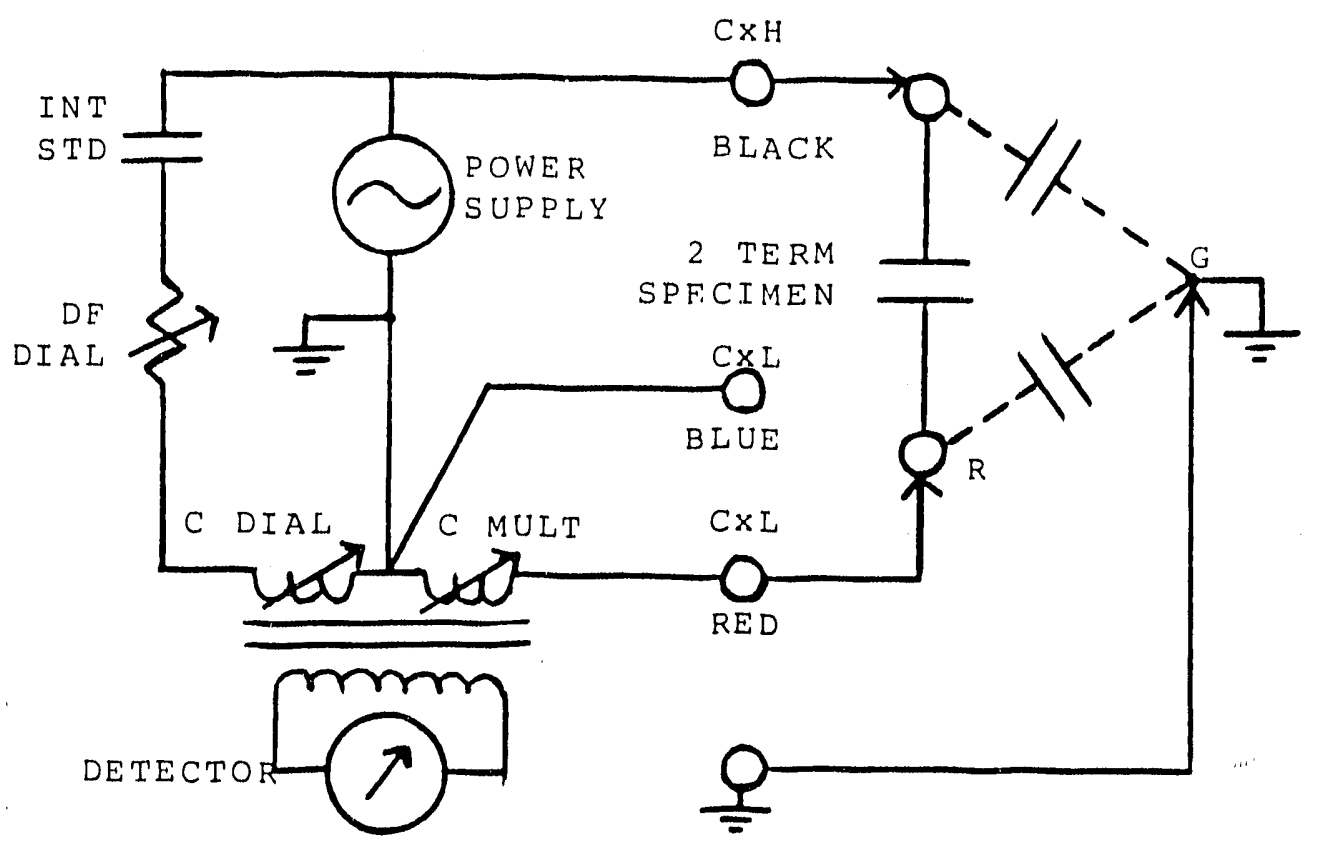

Figure A.12: Biddle Bridge Measurement Circuit (UST-3) 


\section{APPENDIX B \\ EMTP SIMULATION OF THE STEEP-FRONT CIRCUIT II. B. Fan, Visiting Scientist}

Figure B.1 shows the whole circuit for EMTP simulation. This includes the steep-front circuit used for cable test and the divider equivalent circuit. Figures B.2 and B. 3 show the simulated voltage waveforms at node and node 10. Figures B.4 and B.5 show the measured voltage waveforms at node 4 and node 10 , respectively.

Values for specific circuit elements such as resistors, capacitors and transmission cable are known. Values for stray elements such as inductance and capacitance are calculated or chosen to be reasonable. Good agreement between measured (Figures B.4 and B.5) and calculated (Figures B.2 and B.3) values shows that the chosen values must be reasonably valid. The calculated divider rise time (Figure 3) also agrees well with the measured rise time. 


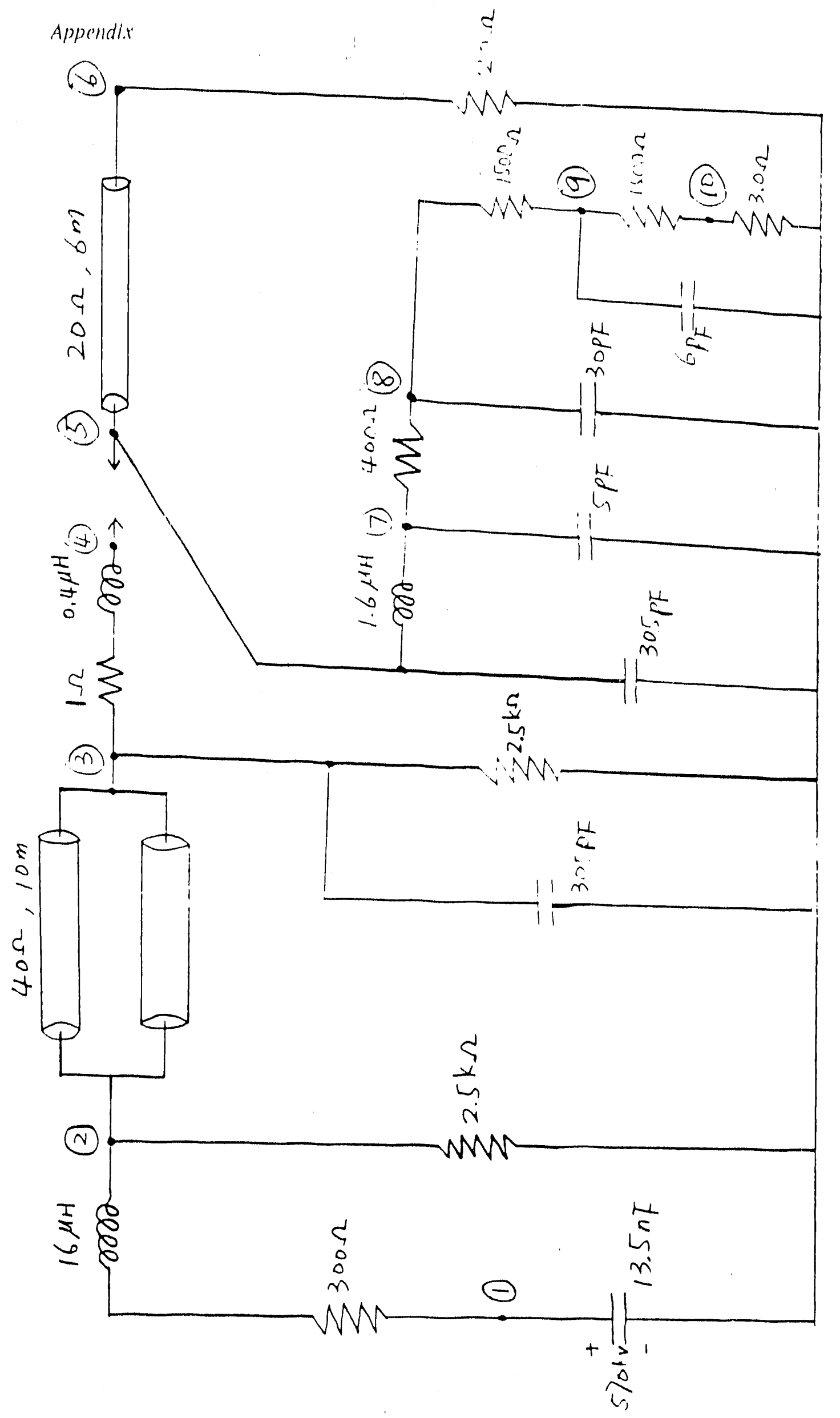




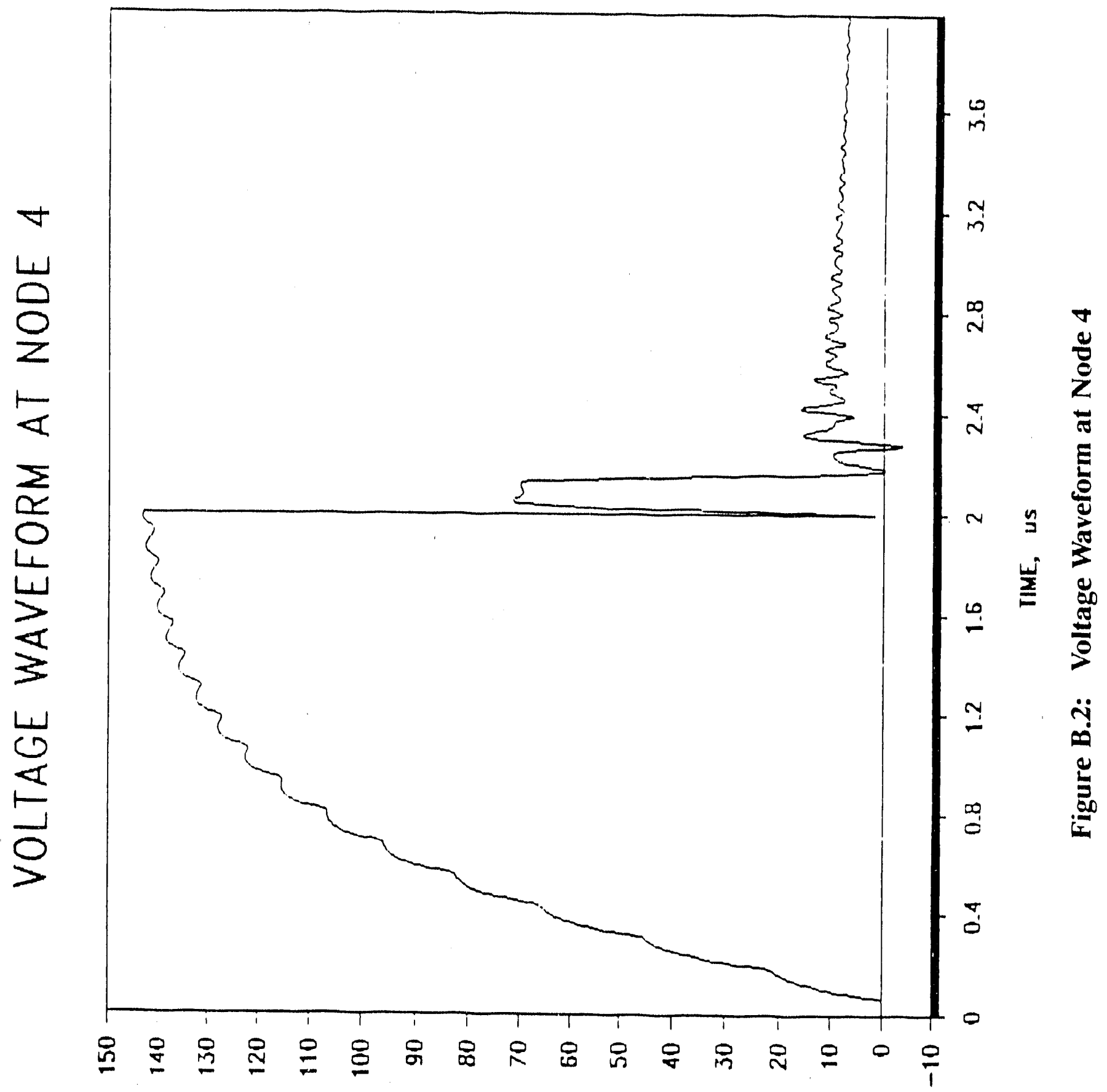

$\wedge x \cdot 30 \forall 170 \wedge$ 


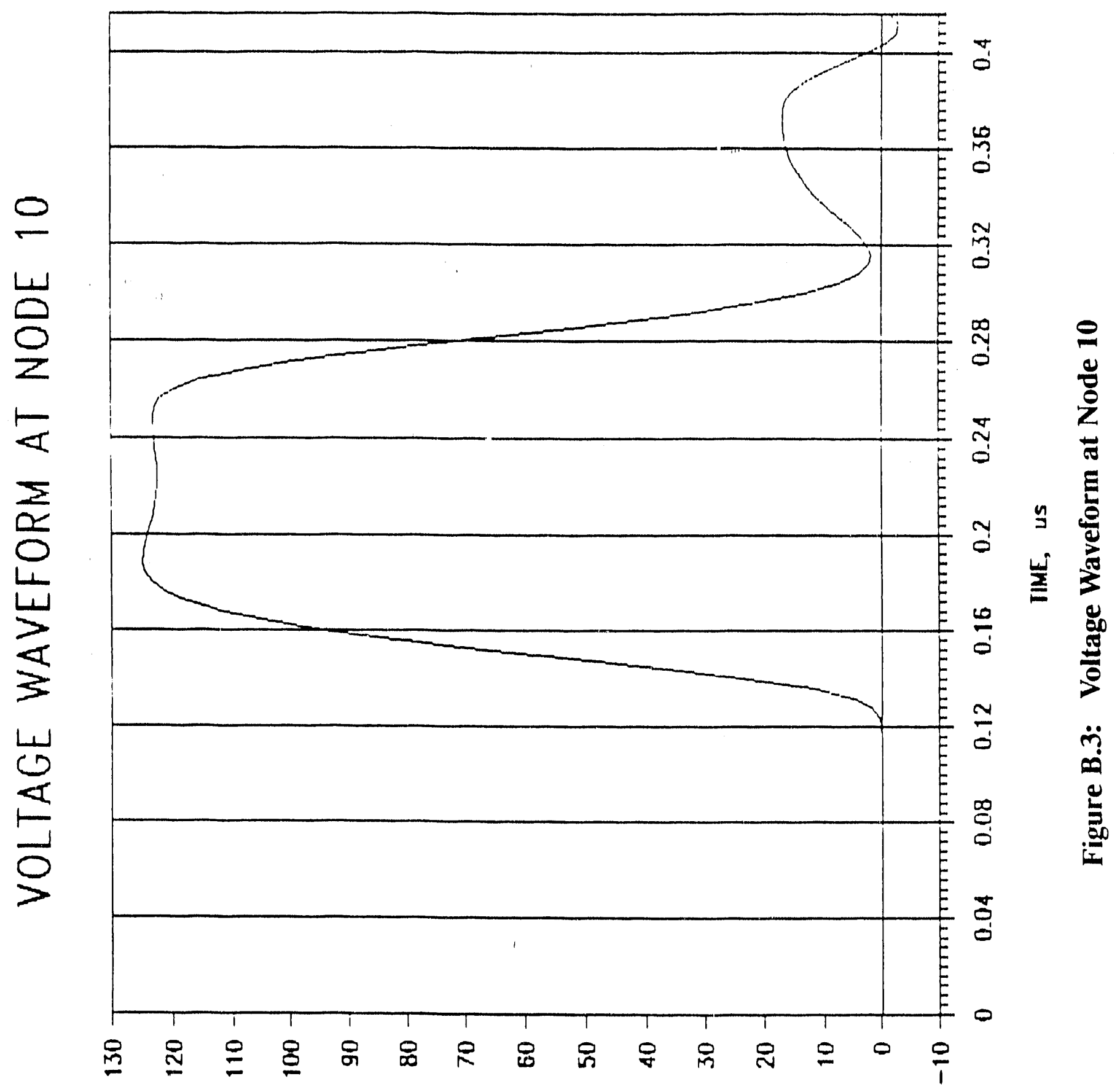

$\wedge$ ヘ $30 \nabla 170 \wedge$ 


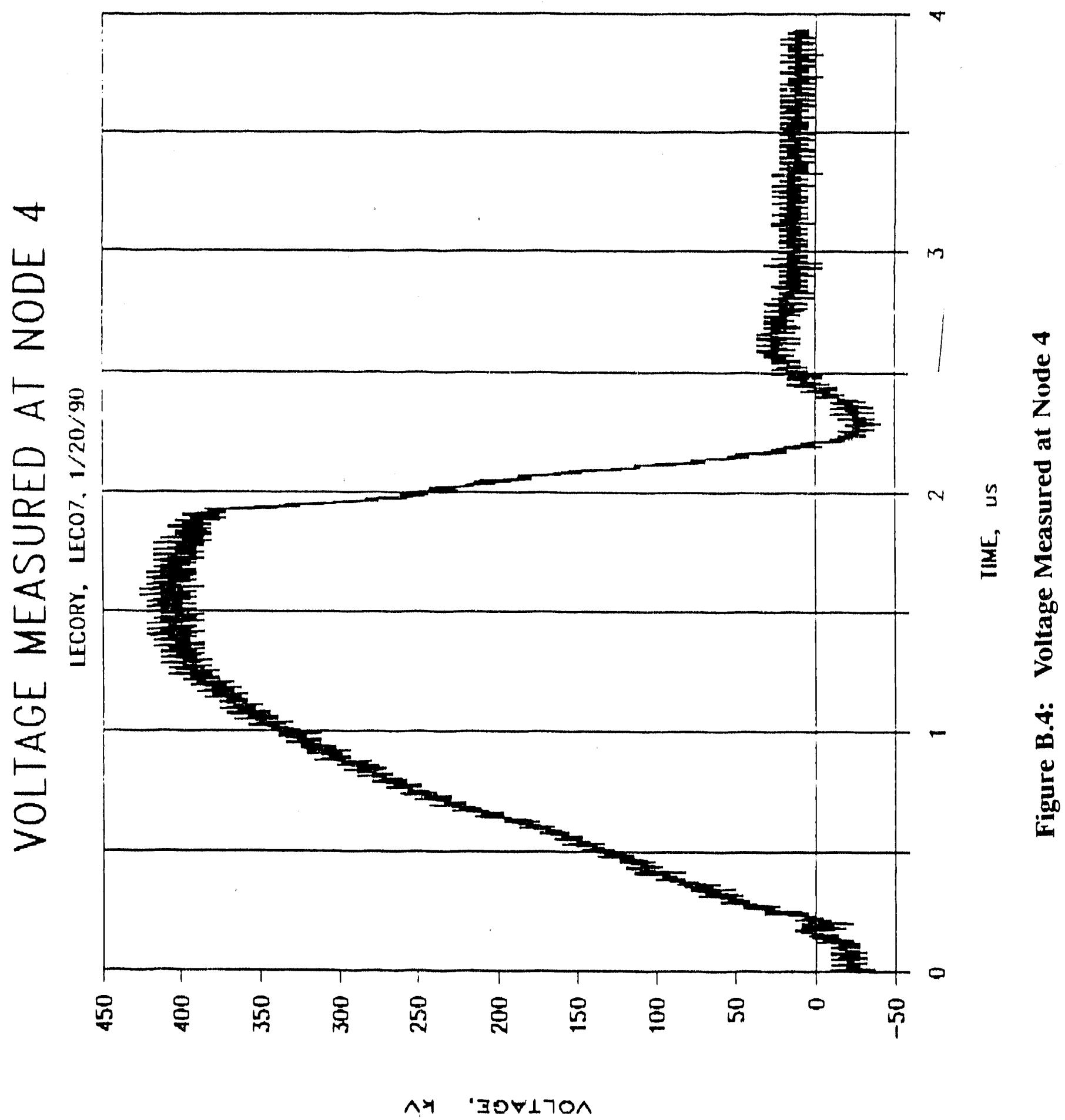




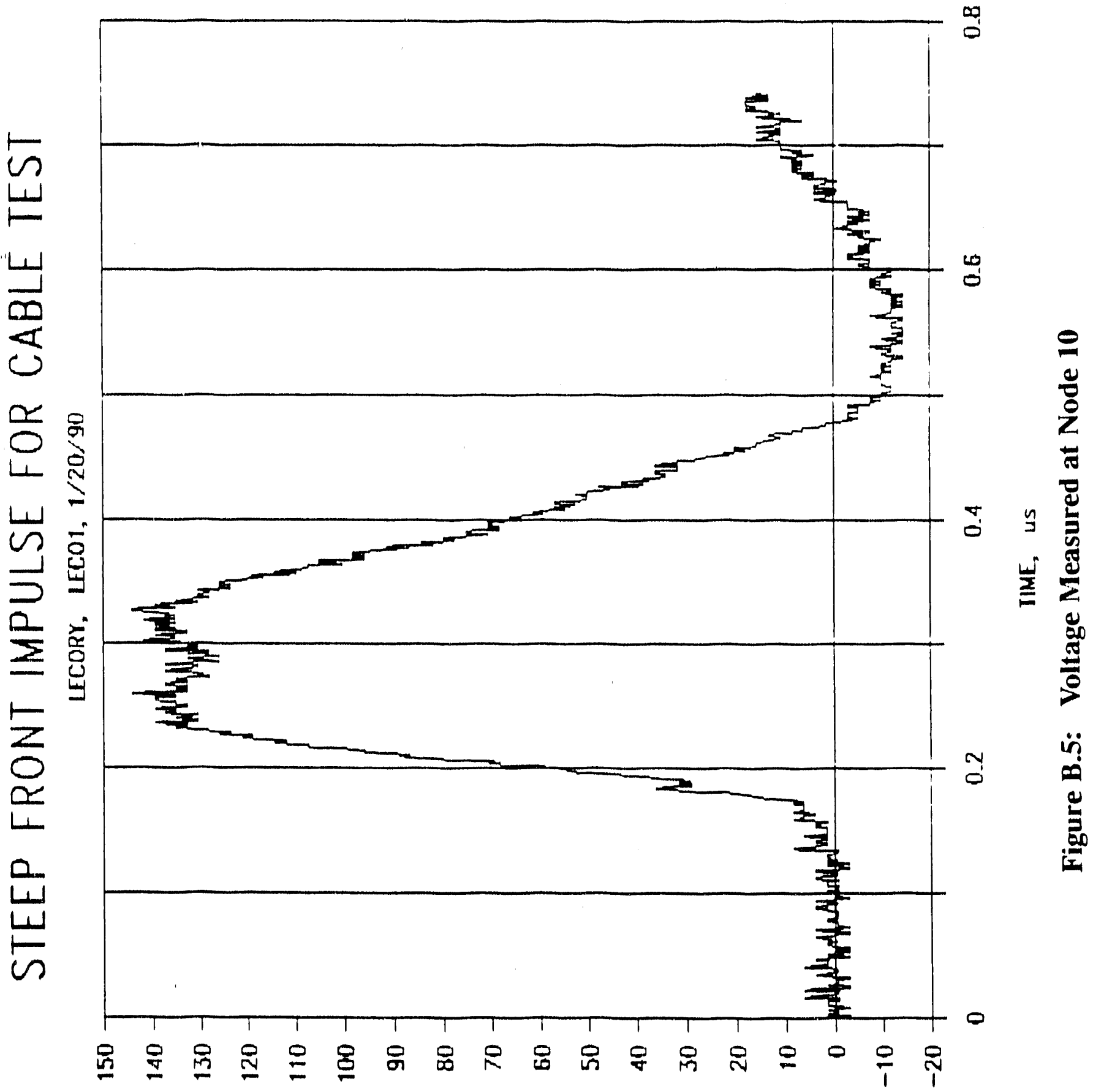

ヘx ' 


\section{INTERNAL DISTRIBUTION}

1-10. P, R, Barnes

11. G. E. Courville

12. P. S. Gillis

13. M. A. Kuliasha

14. B. W. McConnell

15. D. T. Rizy

16. R. B. Shelton
17. J. N. Stone

18. J. P. Stovall

19. ORNL Patent Olfice

20. Central Rescarch Library

21. Document Reference Section

22-24. Laboratory Records

25. Laboratory Records-RC

\section{EXTERNAL DISTRIBUTION}

26. V. D. Albertson, Dept, of Electrical Engineering, University Of Minnesota, 123 Church Street, S.W., Minneapolis, MN 55455.

27. G. Applegren, Main Coordination Center, 1n301 Swift Road, P.O. Box 278, Lombard, Illinois $6(0148$.

28. G. H. Baker, HQ DNA/RAEE, 6801 Telegraph Road, Alexandria, VA 22310-3398.

29. G. D. Birney, Western Area Power Administration, P. O. Box 3402, Golden, CO 80401 .

30. P. D. Blair, Encrgy and Materials Program, Congress of the United States, Office of Technology Assessment, Washington, DC 20510.

31. Ellery Block, SAIC, 6725 Odyssey, Huntsville, AL 35806-3301.

32. L. Bolduc, Hydro Quebec, 1800 Montee Ste Julie, Varennes, QC, Canada, J3X 1S1.

33. E. H. Brchm, Dipl.-Ing., ASEA Brown Boveri AG, Postfach 351, Abt. GK/NP 25, 6800) Mannheim 1, Germany.

34. Larry Bressler, Western Area Power Administration, P. O. Box 3402, Golden, CO 80401.

35. B. G. Buchanan, Computer Science Department, University of Pittsburgh, 206 Mineral Industries Building, Pittsburgh, PA 15260.

36. W. J. Budney, Distribution Systems, Public Service Electric \& Gas Co., 80 Park Plaza, Newark, NJ 07101. 
37. H. S. Cabayan, Lawrence Livermore National Laboratory, P.O. Box 55(14, L-81, Livermore, CA 94550.

38. R. F, Campbell, Transmission \& Electrical Projects, Tennessee Valley Authority, 3N 53A Missionary Ridge Place, Chattanooga, TN 37402-2801.

39. J. Chadwick, 902 Glamis Circle, Signal Mountain, TN 37377.

40. D. J. Christofersen, Manager, Electrical Engineering Division, United Power Association, P. O. Box 80(), Elk River, MN 55330.(0800.

41. P. Chrzanowski, Evaluation \& Planning Program, Lawrence Livermore National Lab, P.O. Box 808, L-81, Livermore, CA 94550.

42. R. F. Chu, Research Engineer, Philadelphia Electric Co., Rescarch Diviston (S10-1), 2301 Market Strect, Philadelphia, PA 19101.

4.3. Lynn Coles, Principal Policy Advisor, SERI, 1617 Cole Boulevard, Golden, CO 80401.

44. O. R. Compton, Richmond Plaza, P. O. Box 26666, Richmond, Virginia 23261.

45. T. B. Cook, 80 Castlewood Dr., Pleasanton, CA 94566.

46. G. H. Coplon, U.S. Department Of Energy, Rm. 8F089, 1000 Independence Avenue, S.W., Washington, DC 20585.

47. C. Cuttica, PJM - Valley Forge Corporate CTr., 955 Jefferson Avenue, Norristown, PA 19403.

48. G. Dahlen, Royal Institute of Technology, Tds, P.O. Box 70043, S-10044, Stockholm, Sweden.

49. S. J. Dale, Manager Transmission Technology Institute, ABB Power T\&D Company Inc., Centennial Campus, 1021 Main Campus Drive, Raleigh, NC.

50. Raymond Dunlop, Director of' Research, New England Power Service Co., 25 Research Drive, Westborough, MA 01582.

51. H. Elbadaly, Underground T\&D Research Manager, Consolidated Edison Company, 4 Irving Place, New York, NY 10003.

52. D. Fagnan, Philadelphia Electric Co., 2301 Market Strect, Philadelphia, PA 19101.

53. W. E. Ferro, Electric Research and Management, Inc., P.O. Box 165, State College, PA 16804. 
54. R. Gates, EMP Program Manager, FEMA, RM 606, 50) C Streel, S.W., Washington, DC 20472.

55. P. R. Gattens, Allegheny Power, 800) Cábin Hill Dr., Greensburg, PA 15601.

56. M. R. Gent, President, North American Electric Reliability Council, 101 College Road East, Princeton, New Jersey 08540-8060.

57. M. Granger, Hydro-Quebec, Planning Systems Division, 855 East Ste-Catherine, 20 leme etage, Montreal, Quebec, Canada, H2L 4PS.

58. J. D. Gregory, Southern Company Services, Inc., P. O. Box 2625, Birmingham, AL $35202-2625$.

59. V. Guten, National Security Agency (M-352), Fort Mead, MD 20755.

60. I. Gyuk, Program Manager, U.S. Department of Energy', 1000 Independence Ave., S.W., Washington, DC 20585.

61. Wayne Hilson, Manager, Transmission and Electrical Systems Department, Tennessec Valley Authority, Missionary Ridge, 3 North 41, 1101 Market Strect, Chattanooga, TN 374()2-2801.

62. Allan Hirsch, Vice President (Environmental Sciencies) and Director (Washington Operations), Midwest Research Institute, 5109 Leesburgh Pike, Suitc 414, Falls Church, VA 22041.

63. Helen M. Ingram, Director, Udall Center for Studies in Public Policy, The University of Arizonia, 803/811 East First Street, Tucson, AZ 85719.

64. J. Kappenman, Minnesota Power, 30 W. Superior St., Duluth, Minnesota 558()2.

65. S. Kashyap, Defense Research Establishment - Ottawa, Electronics Division, 3701 Carling Ave., Ottawa, Ontario K1A0Z4, Canada.

66. J. L. Koepfinger, Director, Systems Studies and Research, Duquesne Light Company, One Oxford Center, 301 Grant Street (19-5), Pittsburgh, PA 15279.

67. B. Korbutiak, Alberta Power, Ltd., 10035 195th St., Edmondton, Alberta T5J 2V6, Canada.

68. J. Kulsetås, Division Manager/Research Director, Norwegian Electric Power Research Institute, Division of High Voltage Technology, N-7(034 Trondheim, Norway.

69. E. Larsen, General Electric, ESDS Bldg. 2, Rm 642, One River Road, Schenectady, NY 12345. 
70. Major Robert Launstein, Defense Nuclear Agency, DNA/RAEE, 6801 Telegraph Rd., Alexandria, VA 22310.

71. R. C. Liimatainen, Committee on Science, Space and Technology, 374 Rayburn House Office Bldg., Rm. B., Washington, DC 20515.

72. J. Lloyd, CEHND-ED-SY, U.S. Army, Engineering Division Huntsville, P.O. Box 1600, Huntsville, AL 35807.

73. C. L. Longmire, Mission Research Corporation, P.O. Drawer 719, Santa Barbara, CA 93102.

74. Calvin D. MacCracken, President, Calmac Manufacturing Corp., 101 West Sheffield Avenue, Englewood, NJ 07631.

75. David Mayhall, Lawrence Livermore National Laboratory, P.O. Box 808, L-156, Livermore, CA 94550.

76. A. P. Meliopoulos, Georgia Tech, School of Electrical Engineering, Atlanta, GA 30332.

77. S. R. Mendoza, Salt River Project, P.O. Box 52025, Phoenix, AZ 85072-2025.

78. N. V. Mesland, Tot Keuring Van Elektrotechnische, Materialen, 6800 ET Arnhem, P.O. Box 9035, The Netherlands.

79. D. L. Nickel, Manager, ABB Power Systems, Inc., 777 Penn Center Blvd., Pittsburgh, PA 15235-5927.

80. S. Nilsson, Program Manager, Electric Power Research Institute, Electrical Systems Division, 3412 Hillview Avenue, P.O. Box 10412, Palo Alto, CA 94303.

81. B. M. Pasternack, American Electric Power Service Corp., 1 Riverside Plaza, P.O. Box 16631, Columbus, OH 43216-6631.

82. J. Z. Ponder, PJM Interconnection, 955 Jefferson Ave., Norristown, PA 19426.

83. J. W. Porter, Electric Power Research Institute, Suite 100, 1019 Nineteenth St. N.W., Washington, DC 20036.

84. M. Rabinowitz, Electric P'wer Research Institute, 3412 Hillview Avenue, P.O. Box 10412, Palo Alio, CA 9430..

85. J. J. Ray, Division of Syst. Planning, BPA, P.O. Box 3621, Portland, OR 97208.

86. T. W. Reddoch, Electrotek Concepts, Inc., 10305 Dutchtown Rd., Suite 103, Knoxville, TN 37932. 
87. J. R. Rempel, Physicist, Defense Intelligence Agency, Washington, DC 20340-6761.

88. Dietrich J. Roesler, U.S. Department of Energy, CE-141, 1000 Independence Avenue SW, Washington, DC 20585.

89. F. Rosa, Division of System Intg., Nuclear Regulatory Commission, MS P1030, Washington, DC 20555.

90. J. E. Scalf, Florida Power \& Light Company, P. O. Box 14000, 700 Universe Blvd., Juno Beach, FL 33408.

91. W. J. Scott, Hq DNA/RAEE, 6801 Telegraph Road, Alexandria, VA 22310-3398.

92. Joe Sefcik, Nuclear Design, Lawrence Livermore National Lab, P.O. Box 808, L-22, Livermore, CA 94550.

93. C. H. Shih, Manager, Electrical Research, American Electric Power Service Corp., 1 Riverside Plaza, Columbus, $\mathrm{OH} 43215$.

94. Jacqueline B. Shrago, Director, Office of Technology Transfer, Vanderbilt University, 405 Kirkland Hall, Nashville, TN 37240.

95. M. L. Sloan, Austin Research Associate, 1101 Capital of Texas Highway S., Building B, Suite 210, Austin, TX 78746.

96. P. Sullivan, Philadelphia Electric Co., 2301 Market Street (S10-1), Philadelphia, PA 19101.

97. E. R. Taylor, ABB Power Systems, Inc. , 777 Penn Center Blvd., Pittsburgh, PA 15235-5927.

98. R. L. Taylor, Director - Power Supply, Florida Power \& Light Co., 9250 W. Flagler, Miami, FL 33102.

99. F. M. Tesche, Consulting Scientist, 6921 Spanky Branch Dr., Dallas, TX 75248.

100. M. V. Thaden, Potomac Electric Power Co., 1900 Pennsylvania Ave., NW, Rm. 311, Washington, DC 20068.

101. J. Tov:le, 3906 Bagley Ave. N., Suitc 100, Seattle, WA. 98103.

102. E. F. Vance, 6885 HWY 1187, Fort Worth, TX 76140.

103. D. R. Volzka, Senior Project Engineer, Wisccnsin Electric Power Company, 333 West Everett Street, Milwaukee, WI 53201.

104. C. L. Wagner, 4933 Simmons Dr., Export, PA 15632. 
105. R. Walling, General Electric Company, Building 2, Rm 507, One River Road, Schenectady, NY 12345.

106. R. C. Webb, Defense Nuclear Agency, RAEE, 6801 Telegraph Road, Alexandria, VA 22310.

107. E. P. Wigner, Consultant, 8 Ober Road, Princeton, NJ 08540.

108. M. W. Wik, Forsvarets Materielverk, Stockholm, S-11588, Sweden.

109. Martin Williams, Professor, Department of Economics, Northern Illinois University, DeKalb, IL 60115.

110. D. Woodford, Suite 400, 1619 Pembina Ave., Winnipeg, Manitoba, R-3T-2G5, Canada.

111. F. S. Young, Director, Electrical Systems Division, Electric Power Research Institute, P.O. Box 10412, Palo Alto, CA 94303.

112. R. W. Zwickl, Space Environment Laboratory, Mail Stop R/E/SE, Boulder, CO 80303.

113. Office of Assistant Manager for Energy, Research and Development, DOE-ORO, P.O. Box 2001.

114-123. OSTI, U.S. Department of Energy, P.O. Box 62, Oak Ridge, TN 37831. 

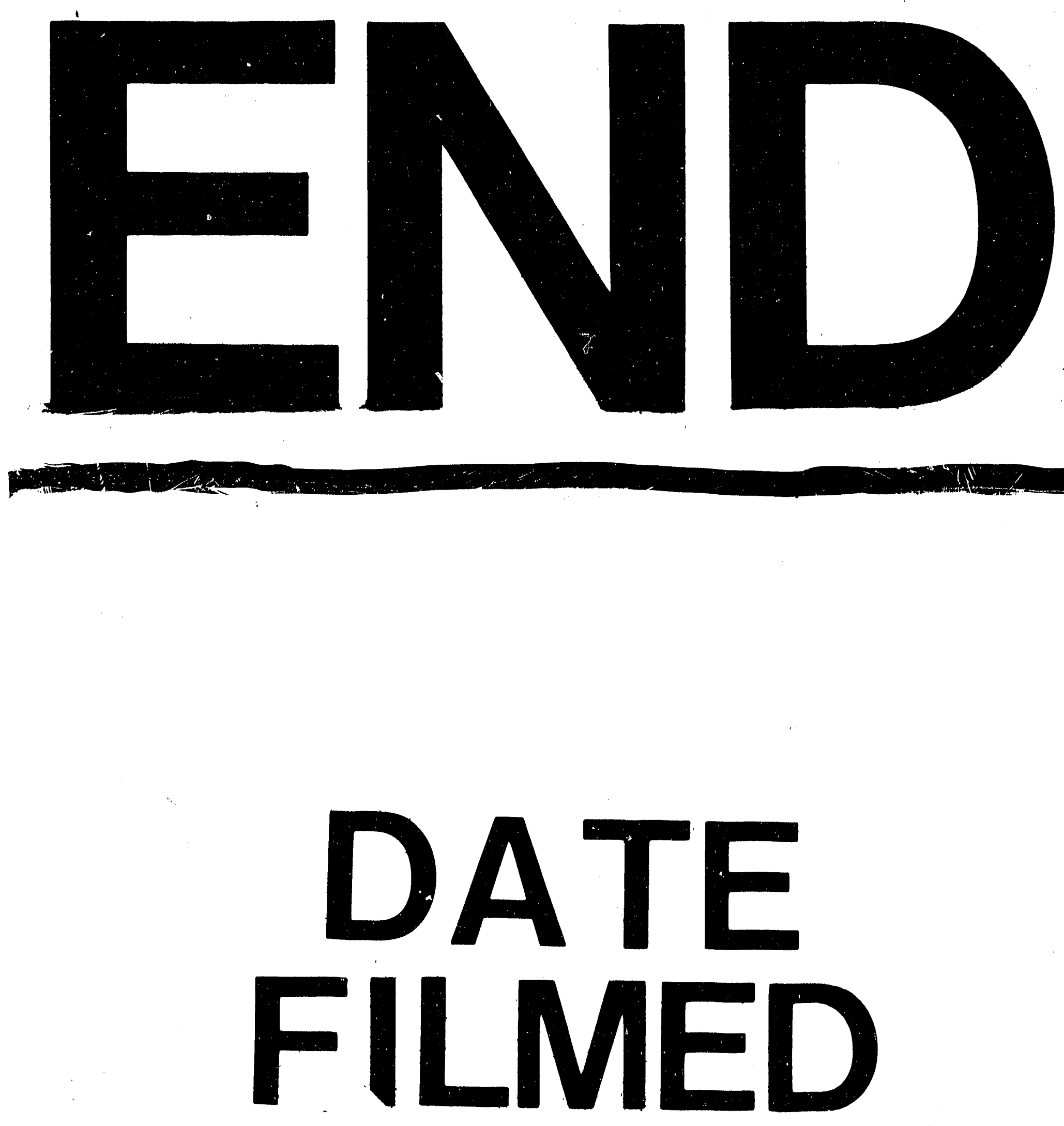

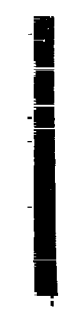

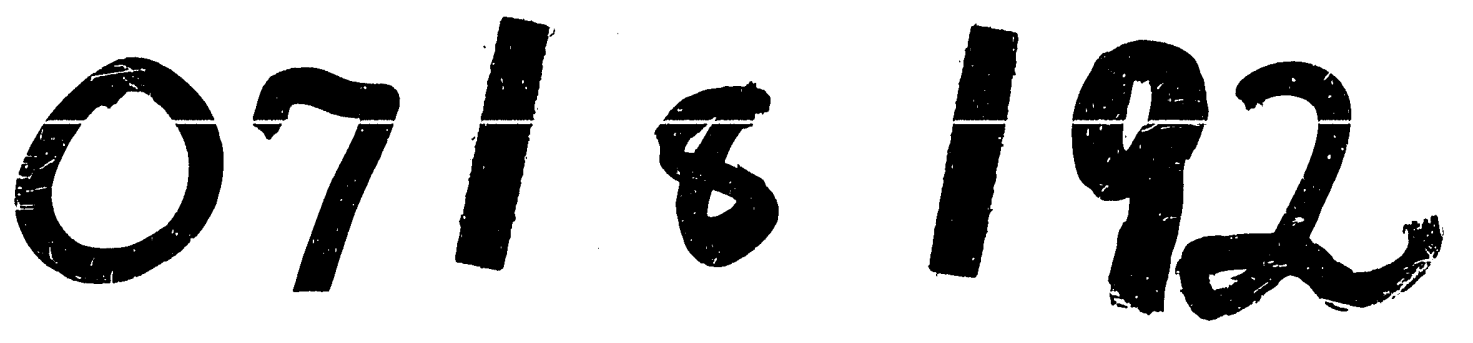


$\mid$ 